
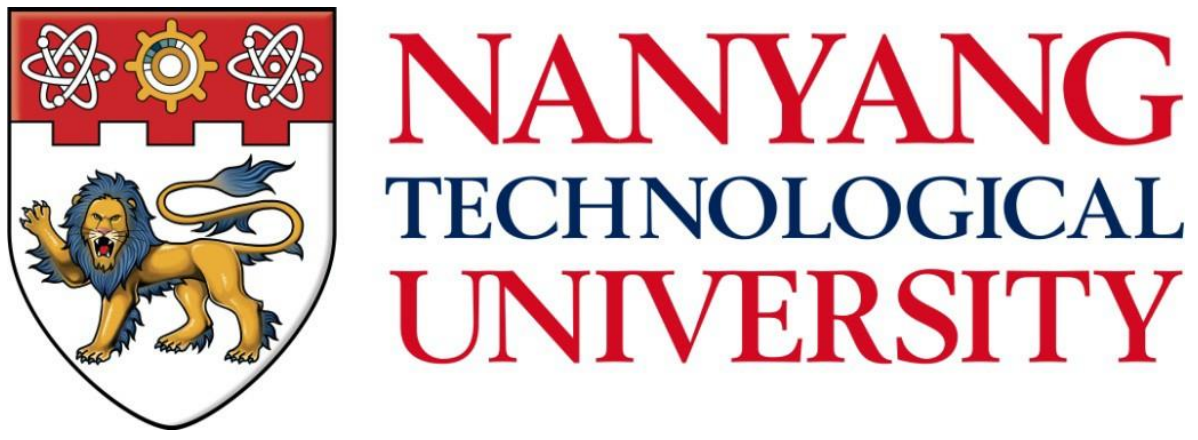

FATE AND TRANSPORT OF PATHOGENS IN FRESHWATER MESOCOSMS: ROLE OF BIOFILMS

NANDINI SHOME

Interdisciplinary Graduate School

Singapore Centre for Environmental

Life Sciences Engineering 


\section{FATE AND TRANSPORT OF PATHOGENS IN FRESHWATER MESOCOSMS: ROLE OF BIOFILMS}

\section{NANDINI SHOME}

\section{Interdisciplinary Graduate School Singapore Centre for Environmental Life Sciences Engineering}

A thesis submitted to the Nanyang Technological University in partial fulfillment of the requirement for the degree of

Doctor of Philosophy 


\section{Acknowledgements}

This dissertation is a compilation of my work at SCELSE, NTU, during which I have had the support of several amazing people and I would like to take this opportunity to thank them. First, I would like to thank my supervisor, Prof Stefan Wuertz for his continued support and patience and I owe my growth as a scientist to him. Thank you for believing in me and giving me the independence to take charge of this project. I am also very grateful for the networking opportunities you have given me over the years. It has been an honor working with you and I look forward to working together again in the future.

I am sincerely grateful to my Thesis Advisory Committee, Prof Sanjay Swarup and Prof Veronica Rajal, for their valuable inputs. I am very appreciative of their recommendations in improving my work. I am also grateful to Prof Scott Rice and Prof Yehuda Cohen for their insightful reviews during my qualifying examination. A special thanks to Prof Hans Curt Flemming for taking time out of his busy schedule and providing valuable suggestions on my research. I am also thankful to Prof Tom Battin, Prof Peter Steinberg and Prof Mark Van Loosdrecht for answering my numerous questions during the early periods of my research.

Next, I would like to thank my field team, Larry L C Wai, Kewei Khiu, Zhong Sheng Chua (Johnson), Wei Jie Ng (Jason), Kaliyamoorthy Eganathan (Nathan). You guys were the best and Larry, without you, I wouldn't have been sane after six rounds of field experiments. Sincere thanks to Dr Martin Tay for designing the amazing DIY monitoring devices for the flumes. Martin, they helped me sleep at peace during the field experiments. Thank you Anisa, Anika, Albert and Ying, for dropping by from time to time and help me in sampling. 
I am also thankful for the continuous support from Dr Ezequiel Marzinelli, Dr Maria Yung, and Ezequiel Santillan during the community analysis and Dr Cecilia M Cruz during qPCR. Special thanks to Dr Minji Kim, from UC Davis, for her valuable advice in data processing. You all helped me learn a lot in areas where I hardly had any previous experience. I would also like to thank Dr Gourvendu Saxena from SCELSE NUS for helping me learn the flume operation, and Abeed Fatima Binti Mohidin Batcha for analysing the DOC samples, Elvagris Segovia Estrada and Kar Ling for analysing the IC samples. I would also like to thank Dr Daniella Moses, Dr Rohan Williams and Krithika Arumugam for their brilliant cooperation that led to a high quality data generation for the metagenomic analysis.

I am also grateful to SCELSE officials, Dr Krager Kai Shyang Koh for his advice regarding safety aspects of the project, Kartini Bte Saharawee, DeborahTjin and Sow Chin for helping me with the financial aspects, Adriel Leong Hay Ying for IT support and Siti Fatimah Binte Tambi, Swee Ki Ng and Tanalachmy d/o Karunanithy for helping me find and hire the field team. A special thanks to Ley Byan Chew and Wahyuna Binte Sulaiman for accommodating my numerous requests for extra laboratory and storage spaces and supplies. I would also like to thank Dr Umid Man Joshi and Dr Augustine Yong for their support at Van Kleef Center, Michelle Sim and Jennifer Lim (PUB) for the permits and Prof Subbu Venkatraman, Prof Joachim Say Chye Loo, Prof Sierin Lim and Prof Enrico Marcili for giving me access to the instruments at Material Science and School of Chemical and Biomedical Engineering, NTU. I would also like to thank National Research Foundation, Singapore and Nanyang Technological University, Singapore for funding this research.

I am grateful to my colleagues at SCELSE, Dr Caroline Chenard, Dr Sujatha Subramoni, Dr Florentine Constancias, Dr Sharon Goh, Dr Thomas Seviour, Dr Su Chuen Chew, Ding Yuanzhao, Yissue Woo, Dan Roizman, Poh Wee Han, Adelicia Yong Ling Li and Adeline 
Yong Mei Hui, who, even though were not directly a part of this project, have helped me time to time with valuable advice, tips and techniques. Finally, I would like to thank my parents and my husband for their tremendous support. Without your constant motivation and encouragement I do not believe I could have completed this research. 


\section{Table of Contents}

Acknowledgements......

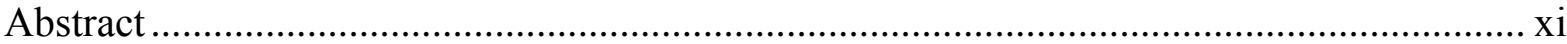

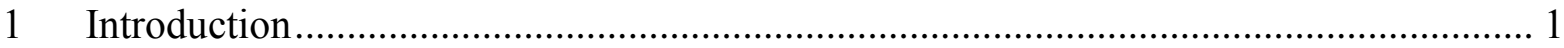

1.1 Fate and transport of pathogens in aquatic systems ........................................ 2

1.1.1 Stages of biofilm formation: Attachment to interfaces ................................. 3

1.1.2 Stages of biofilm formation: Maturation of the biofilm ................................ 6

1.1.3 Stages of biofilm formation: Detachment from biofilm ................................ 7

1.2 Invasion in aquatic biofilm communities ................................................. 10

1.3 Approaches for studying the fate of microorganisms ...................................... 13

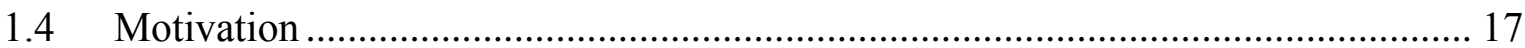

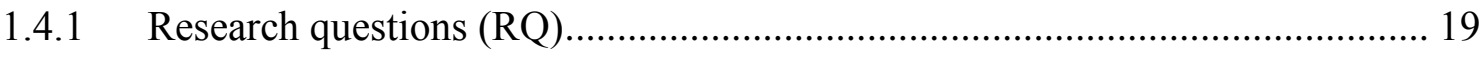

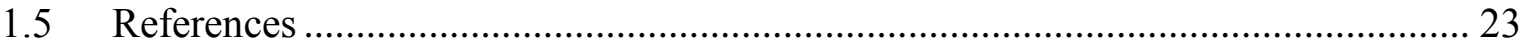

2 Biofilms in mesocosm flumes as source and sink of Pseudomonas aeruginosa, P22 bacteriophage and Enterococcus faecalis: a mass balance approach................................ 36

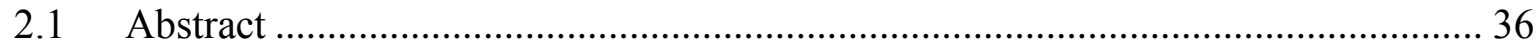

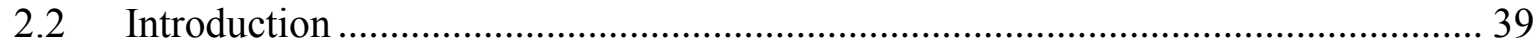

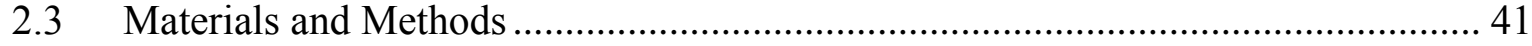

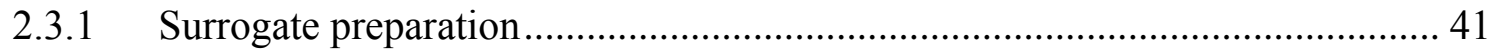

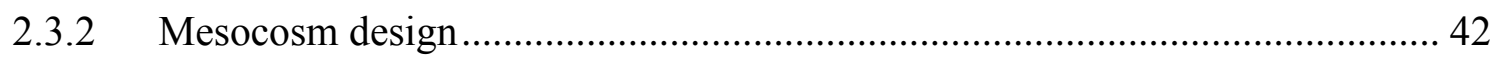

2.3.3 Quantification of P.aeruginosa, E. faecalis, P22 and GA.............................. 44

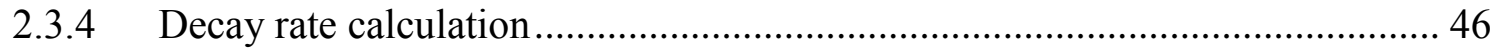

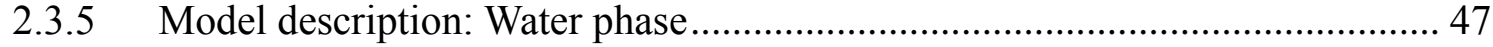

2.3.6 Model description: Biofilm phase .................................................................. 49

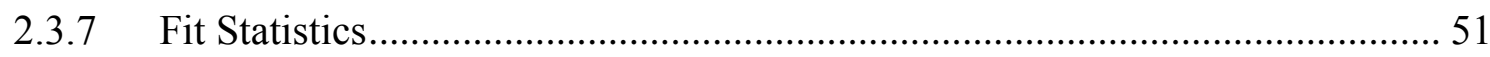

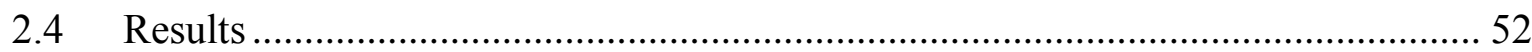


2.4.1 Measured concentrations of surrogates in water and biofilm phase ................ 52

2.4.2 Predictions of Pseudomonas aeruginosa based on mass balance analysis....... 55

2.4.3 Predictions of P22 based on mass balance analysis ...................................... 56

2.4.4 Predictions of Enterococcus faecalis based on mass balance analysis ............ 57

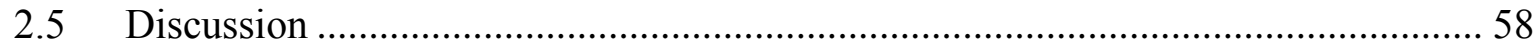

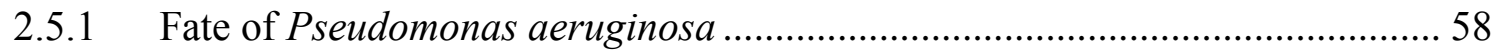

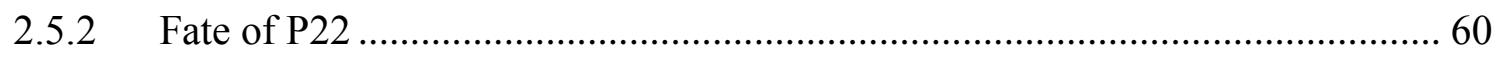

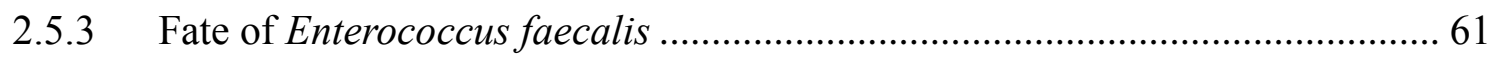

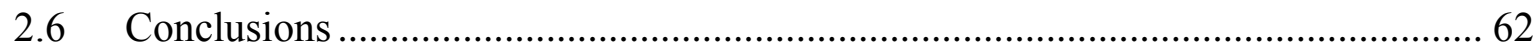

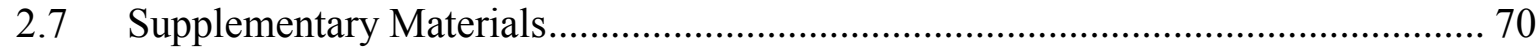

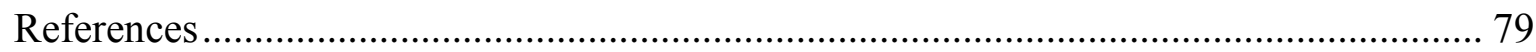

3 Link between flow regime, biofilm properties and pathogen fate in freshwater

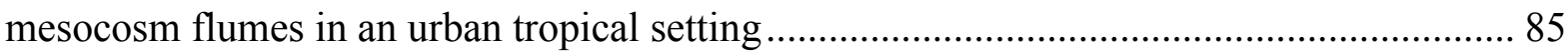

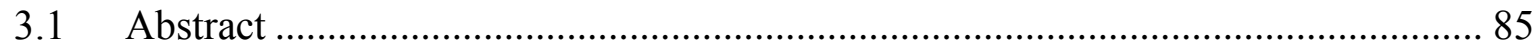

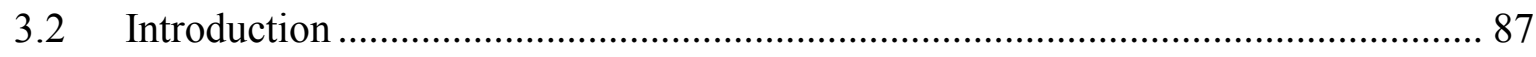

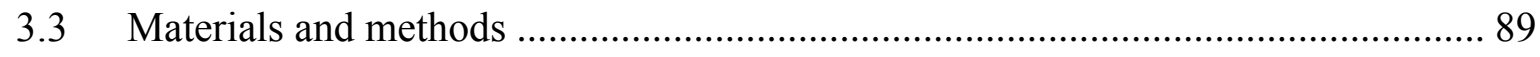

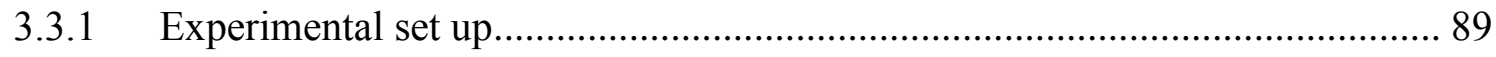

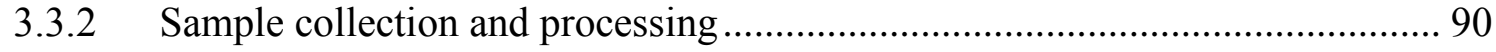

3.3.3 Surrogate mass balance in water and biofilm phases................................... 91

3.3.4 Calculation of decay rate and $\mathrm{T}_{99}$, growth rate and detachment rates............. 92

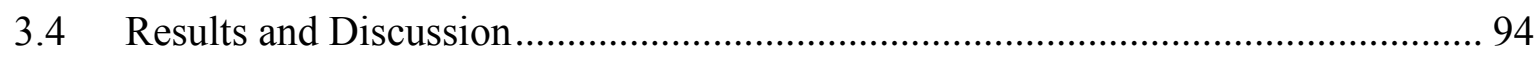

3.4.1 Fate of P. aeruginosa, $\mathrm{P} 22$ and E. faecalis in the aqueous phase at high and low

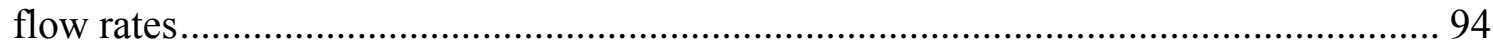

3.4.2 Fate of P. aeruginosa, P22 and E. faecalis viable populations and DNA in biofilms at high and low flow rates................................................................ 96

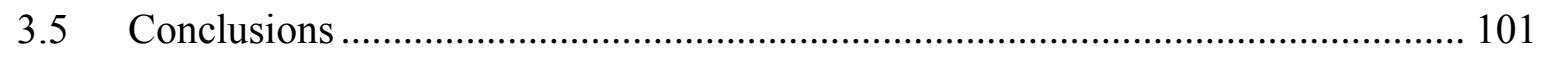

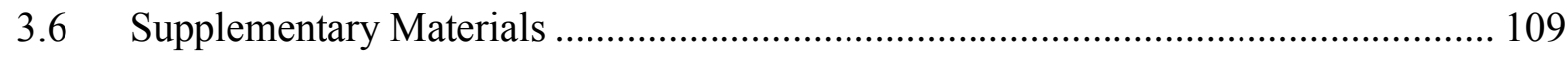


4 Effect of Pseudomonas aeruginosa, Enterococcus faecalis and bacteriophage P22 on freshwater biofilm community assembly in replicate mesocosm flumes under high and low flow conditions

4.1 Abstract

4.2 Introduction

4.3 Materials and Methods

4.3.1 Flume set up and sampling

4.3.2 DNA extraction, library preparation and sequencing

4.3.3 Processing and analysis of metagenomic sequencing datasets

4.3.4 Statistical analysis based on microbial community profile

4.4 Results

4.4.1 Overall microbial community structure of the freshwater biofilms in the flumes 123

4.4.2 Effect of surrogate addition and time on the pre-grown biofilm community . 126

4.4.3 Effect of surrogate addition and time on the functional capability of total

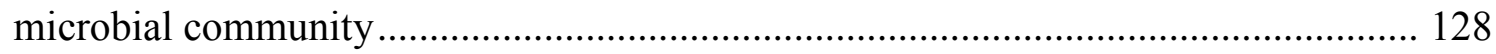

4.4.4 Contribution of environmental and physicochemical factors to community patterns 129

4.5 Discussion 130

4.5.1 Community composition in flume biofilms. 130

4.5.2 Effect of surrogate addition and time on prokaryotic and eukaryotic communities in flume biofilms 131

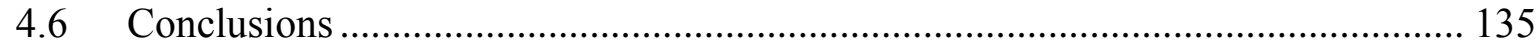

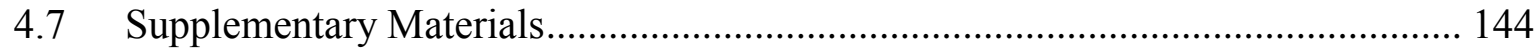

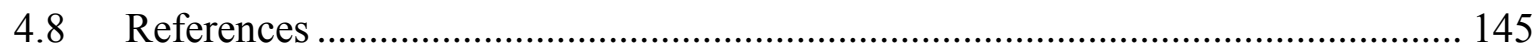

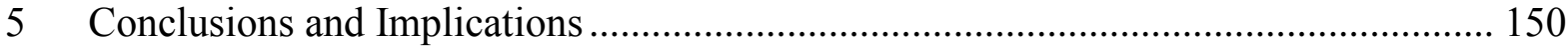




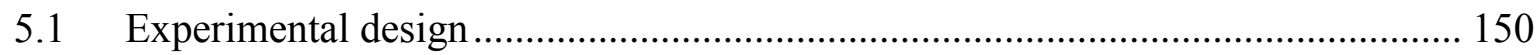

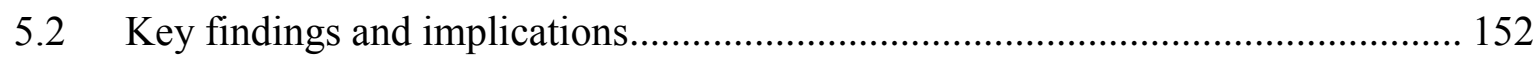

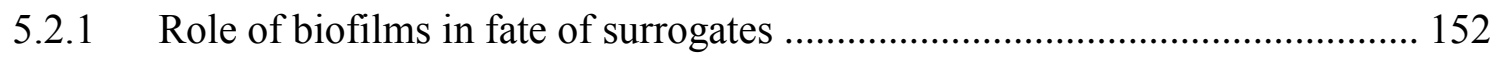

5.2.2 Role of hydrodynamic conditions in fate of surrogates ................................ 154

5.2.3 Impacts of introduction of surrogates on autochthonous biofilm community 155

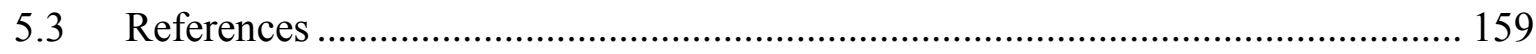




\section{List of figures}

2.1 (A) Schematic diagram of the flume. (B) A set of flumes in operation at Van Kleef Center. .65

2.2 Schematic diagram of experimental plan for studying fate of pathogen surrogates at a low flow rate in duplicate experiments, each time employing four flumes. 65

2.3 Fraction of P.aeruginosa, $\mathrm{P} 22$ and E. faecalis surviving in the aqueous phase as observed in replicate flumes in two independent experiments under low flow conditions (A, B, C). Fraction of surrogates surviving in biofilm phase (D, E, F) .66

2.4 Modeling of P. aeruginosa concentrations in water and biofilm phases. A, B, C and D correspond to the aqueous phase and E, F, G and $\mathrm{H}$ correspond to the biofilm phase.

2.5 Modeling of P22 concentrations in water and biofilm phases. A, B, C and D correspond to the aqueous phase, E, F, G and $\mathrm{H}$ corresponds to the biofilm phase .68

2.6 Modeling of Enterococcus faecalis concentrations in water and biofilm phases. A, B, C and $\mathrm{D}$ correspond to the aqueous phase, E, F, G and $\mathrm{H}$ corresponds to the biofilm phase....69

3.1 Schematic diagram of experimental plan for studying effect of flow rate on fate of surrogates in four different experiments using four mesocosm flumes each time 105

3.2 Measured (closed symbols) and predicted (open symbols) viable populations in aqueous phase at a high flow rate $(\mathrm{Re}=718)$ - (A) P. aeruginosa, (B) P22 and (C) E. faecalis......106 3.3 Measured (closed symbols) and predicted (open symbols) DNA concentrations in aqueous phase at a high flow rate $(\mathrm{Re}=718)-(\mathrm{A})$ P. aeruginosa, (B) P22 and (C) E. faecalis. 106 
3.4 Measured (closed symbols) and predicted (open symbols) biofilm concentrations of cultivable surrogates at a high flow rate $(\mathrm{Re}=718)$ - (A) P. aeruginosa, (B) P22 and (C) E. faecalis 107

3.5 Measured (closed symbols) and predicted (open symbols) biofilm concentrations of surrogate DNA at a high flow rate $(\mathrm{Re}=718)-(\mathrm{A})$ P. aeruginosa, (B) P22 and (C) E. faecalis.

3.6 (A) DOC concentration in water and (B) hydrophobicity of biofilms grown at low and high flow rates 108

4.1 Temporal dynamics of (A) prokaryotic and (B) eukaryotic biofilm communities in the flumes under low and high flow conditions 138

4.2 Temporal changes in community alpha diversity in terms of Hill number (N1) at (A) low flow and (B) high flow.... 140

4.3 Clustering of eukaryotic communities in flumes in the presence and absence of surrogates in the second batch of (A) low and (B) high flow experiments 140

4.4 Change in relative abundance of key eukaryotic OTUs in the second experiment for (A) low flow and (B) high flow conditions

4.5 Clustering of eukaryotic communities at (A) low and (B) high flow on different days since addition of surrogates 


\section{List of tables}

1.1 Water borne pathogens (Adopted from U.S. EPA and WHO)

1.2 Criteria for selecting surrogates

2.1 Specifications for qPCR assays

3.1 Comparison of $\mathrm{T}_{99}$, detachment rate, decay rate and growth rate of P. aeruginosa, $\mathrm{P} 22$ and E. faecalis at low and high flow conditions

4.1 Univariate analysis of alpha diversity based on the first order Hill number (N1) in flumes with and without surrogates in repeat experiments conducted at two different flow rates...147

4.2 Statistical analyses of prokaryotic and eukaryotic communities to determine effect of surrogate addition or time on abundance and composition of the communities at two different

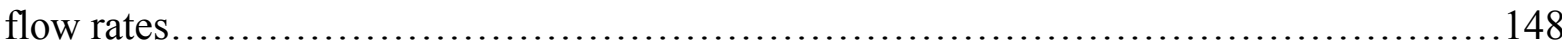

4.3 Pair-wise comparisons (PERMANOVA) of eukaryotic communities in biofilms on different days $(1,3,7,14$ and 21$)$ of the experiments. 


\section{Abstract}

We studied the fate and transport of common waterborne pathogens in freshwater systems using simple hydrodynamic modeling and their effect on mature biofilm communities using metagenomic sequencing. Pathogens were represented by four surrogates: Pseudomonas aeruginosa, Enterococcus faecalis and the bacteriophages P22 and GA. We ran a set of four experiments, at two different flow rates, $6 \mathrm{~L} \mathrm{~min}^{-1}$ (low) and $12 \mathrm{~L} \mathrm{~min}^{-1}$ (high). The flow rates represented conditions in urban canals during dry weather and the annual average. In each experiment, we operated four open channel flumes with partial recirculation (laminar flow range), and two of the flumes were spiked with the surrogates. Spiking was done once and concentrations of viable populations and their nucleic acids in water and biofilm were followed for 21 days. The remaining flumes received no surrogates. Additionally, microbial community assembly was monitored through metagenomic sequencing of the biofilms collected from flumes with and without surrogates.

At low flow settling and decay terms alone could not explain bulk water concentrations in the presence of biofilms. Surrogates attached to biofilms within 24 hours and P. aeruginosa and E. faecalis were also found to grow within biofilms. Bacteriophage P22 was unable to multiply due to the absence of its host, but was retained in the biofilm throughout the experimental period. Bacteriophage GA was not detected in the flumes after spiking. Surrogates were also released into the overlying water column, thereby increasing the number of days required for complete removal of the organisms from the flumes. At low flow, $P$. aeruginosa was initially released continuously from the biofilm. Later, detachment was more random and occurred to a greater extent than expected based on erosion alone, suggesting sloughing via biological dispersal. P22 detachment was by erosion and E. faecalis did not detach. In comparison, at the high flow rate, the role of biofilms as a source and sink 
of surrogates remained the same. However, release of $P$. aeruginosa was through continuous erosion, as compared to random sloughing at the low flow rate. The two-log reduction times of surrogates in water were $24-57 \%$ higher and those in biofilms were $35-500 \%$ lower at high flow than at low flow. Concurrently, the detachment rates in biofilms were almost $80 \%$ higher and decay in biofilms was $22-83 \%$ higher at high flow rate. Growth of P. aeruginosa was either absent or balanced by increased decay at high flow, whereas the growth rate of $E$. faecalis doubled at high flow. Community analysis revealed that the prokaryotic communities were not affected by surrogate addition at any flow rate. Eukaryotic communities showed similar trends. However, in two experiments, when Podocopida and Haplotaxida were present, the abundance of these organisms was related to the presence of surrogates, even though the latter were not pathogenic for any of them. Overall, nascent eukaryotic communities changed due to algal growth, while prokaryotic communities remained the same. In conclusion, freshwater microbial communities were resilient to pathogen exposure and surrogates survived in biofilms through co-existence and not invasion. 


\section{Introduction}

Ours is a "water-planet" and yet, according to the World Health Organization (WHO), lack of access to safe water continues to remain one of the greatest environmental threats. Natural water bodies have the potential to purify themselves and restore water to a quality suitable for healthy consumption (Ostroumov 2004). However, most of them have lost this property due to anthropogenic activities, such as, changing land use patterns involving elimination of marshes and wetlands, modifying or diverting flows, and contamination with wastes (Dokulil et al. 2000, Wei et al. 2009, Wolfe et al. 2001). Between 1990 and 1995, global freshwater usage increased six-fold, which was twice the rate of population growth during the same period (UNEP 2013). Simultaneously, the quantity and diversity of pollutants, including pathogens, entering freshwater systems also remain an increasing trend since 1970s (WHO).

Pathogens are one of the most threatening pollutants which enter freshwater bodies through storm water runoff, sewage leaks, wastewater treatment plant effluent discharge and even recreating public (Drury et al. 2013a, Kim and Wuertz 2015, Wakelin et al. 2008). Over the years, regulating authorities have compiled lists of common water borne pathogens in the context of providing safe drinking water (Table 1). In contrast, data on untreated surface water is lacking in most places. But according to a recent report, currently, 663 million people rely on sub-standard water sources for all necessities including drinking, out of which 159 million are people who use surface waters without further treatment (WHO). Even though in developing countries untreated water is rarely consumed, contaminated surface water leads to outbreaks when used indirectly, such as during recreation. According to a recent report by the U.S. Environmental Protection Agency (EPA), the Centers for Disease Control and Prevention (CDC) and the Council of State and Territorial Epidemiologists on water borne 
outbreaks in the United States, a total of 259 outbreaks, 21,740 cases of estimated illnesses, 36 cases requiring emergency unit admission, 206 cases requiring hospital care and 28 cases of death were recorded from 1971 to 2000 in the U.S. alone (Yoder et al. 2008). Most of these cases were caused by Shigella sp. (Gram negative bacterium), followed by Naeglaria fowleri (amoeba), E. coli O157:H7 (Gram negative), Schistosoma sp. (parasitic flatworm), Norovirus (single stranded RNA virus), Leptospira (Gram negative), Giardia sp. (protozoa) and Cryptosporidium sp. (protozoa) (Wymer 2007). Currently the U.S. guidelines for safe recreational water usage involve monitoring two indicator organisms, enterococci and E.coli, in terms of magnitude, frequency and duration of occurrence. Similar guidelines are adopted by the World Health Organisation (WHO) and the European Union as well. However, frequent occurrences of these outbreaks and illness question the effectiveness of the guidelines and call for modifications based on improved understanding of pathogen behavior in natural systems.

\subsection{Fate and transport of pathogens in aquatic systems}

Conventionally, pathogens released in water-bodies were studied as planktonic cells. However, gradually this assumption was replaced by the realization that pathogens in natural systems are more likely to be present in biofilms (McDougald et al. 2012). Biofilms can be defined as clusters of cells embedded in extrapolymeric substances or EPS, most commonly forming at an air-water or solid-water interface. One of the roles that biofilms may play is to serve as a reservoir of pathogens. For example, fecal indicator organisms have been isolated in low concentrations from river biofilms (Balzer et al., 2010). It has also been reported that aquatic plants from an area where a specific mycobacterial disease was prominent, were aiding in biofilm formation of the causative agent, Mycobacterium ulcerans, and these biofilms were functioning like a reservoir for the same (Marsollier et al. 2004). 
The protective function of biofilms in natural waters is also evident in intertidal systems, where pathogens survive osmotic shock and temperature differences by formation of or integration into flocs and biofilms (Decho 2000). Pathogen retention and subsequent release by biofilms, depending on the concentration of the target microorganism present in the overlying water column, has been seen in engineered systems (flumes) using Cryptosporidium parvum oocytes (Wolyniak et al. 2009). Persistence of the pathogen Campylobacter in nutrient depleted surface waters was also shown to increase almost twofold in the presence of autochthonous bacteria in a biofilm reactor (Buswell et al. 1998). The following sections describe the fate of pathogens in biofilm mode and in presence of autochthonous biofilms in different systems.

\subsubsection{Stages of biofilm formation: Attachment to interfaces}

Once introduced into surface waters, microorganisms, introduced into the aquatic system from point and non-point sources or originating from other biofilms, may remain suspended or settle to the bottom. Suspended microbial populations are most likely to be inactivated quickly, depending on the extent of particle formation, physicochemical conditions such as temperature and solar irradiation, nutrient levels and predation (Hijnen et al. 2006). The settled fraction may adhere depending on the surface properties of the substratum, hydrodynamics of overlying water, physicochemical properties of native biofilms and the cell surface characteristics of the microorganisms, and initiate biofilm formation (Donlan 2002).

Biofilm formation begins when planktonic cells attach to new abiotic interfaces (McDougald et al. 2012). This attachment, referred to as "initial adhesion", is considered to be a weak and reversible interaction (Garrett et al. 2008). Attachment of bacteria to a solid substratum is a function of biological factors like expression of specific polysaccharides and adhesion proteins along with formation of surface appendages like pili and flagella (Hall-Stoodley et 
al. 2004) as well as physical properties like surface roughness, surface charge and hydrophobicity (Donlan 2002).

Among the biological factors crucial for initiating biofilm formation, genes such as those expressing polysaccarides like Pel and Psl in Pseudomonas aeruginosa (Chew et al. 2014) and Pia in Staphylococcus epidermis (Rohde et al. 2010), adhesins like FnBPA and FnBPB in Staphylococcus aureus (O'Neill et al. 2008), and sporulation transcription factor in Bacillus subtilis have been identified. Motility of the microorganism like flagellar or twitching motility is also crucial under certain circumstances in order for the cell to reach a surface and attach (O'Toole and Kolter 1998). Several studies have also highlighted the importance of quorum sensing in initiation of biofilm formation in a variety of microorganisms (Cvitkovitch et al. 2003, Hammer and Bassler 2003, Marketon et al. 2003).

Among the physical parameters identified as influencing biofilm formation, surface roughness generally has a positive impact on adhesion. This is mostly because of two reasons. First, a rough surface results in increased surface area, and second, a rough surface provides microspaces having lesser shear forces acting on them, which serve as ideal spots for initial colonization (Teughels et al. 2006). A positive effect of increased surface roughness has been reported in natural systems like rivers (Baker 1984) and for artificial surfaces like medical implants (Carlen et al. 2001).

Effects of surface properties have been reported in multiple studies using different surfaces of known hydrophobicity and charge, for example, fabricated surfaces such as metal oxide coated glass surfaces ( $\mathrm{Li}$ and Logan 2004), sulfated polystyrene discs ( van Loosdrecht et al. 1990), medical implants (Pascual 2002) and contact lens surfaces (Bruinsma et al. 2001), and natural surfaces like plants (Barthlott and Neinhuis 1997) and sediments ( van Loosdrecht et al. 1990). 
Apart from substratum properties, cell surface properties like cell surface charge and cell hydrophobicity are also important factors governing biofilm formation. Typically, hydrophobic cells show higher adhesion than their less hydrophobic counterparts (van Loosdrecht et al. 1987). Cell surface charge has also been shown to affect attachment (Briandet et al. 1999). Studies on the positively charged bacterium Stenotrophomonas showed that adhesion to negatively charged surfaces like glass and Teflon is much more favored than in negatively charged bacteria like Pseudomonas putida (Jucker et al. 1996).

Different hydrodynamic parameters like velocity gradient, shear stress and others play a major role in transport and deposition as well as resuspension of microorganisms in fluid based systems (O'Melia 1980). In waste water systems, deposition of particles comparable to bacterial cells in size have been repeatedly shown to be a combined effect of diffusion, interception and sedimentation (Bouwer 1987). Higher deposition rates of particles with increasing flow velocity has been reported in flume based systems (Arnon et al. 2007).

However, as microorganisms are not entirely inert particles with constant properties, their transport and deposition is much more complex than can be explained by comparing them with particles or colloids. For example, the hydrodynamics of a system also influences nutrient fluxes within which in turn influence microbial transport and retention of microorganisms on surfaces (Mueller 1996). The genes involved in biofilm formation may often be expressed differently based on existing system conditions (Horswill et al. 2007, Quiñones et al. 2005). Biofilms have also been shown to grow differently both in terms of architecture (Pereira et al. 2002) and community composition (Besemer et al. 2009) under different flow velocities, which supports the notion that the effect of flow is more than just on physical transportation phenomena. 


\subsubsection{Stages of biofilm formation: Maturation of the biofilm}

Upon successful initial attachment, the surface properties of the substratum are further modified with time leading to a stronger irreversible attachment. During this phase the cells multiply rapidly forming micro-colonies and undergo several phenotypic changes (Sauer et al. 2002). With maturation of the biofilm, extensive three-dimensional structures such as mushroom and streamer formations may take place (McDougald et al. 2012, Stoodley et al. 2002) depending on shear forces and nutrient loading. Biofilm maturation is also accompanied by copious EPS production. EPS or extracellular polymeric substances are the "slimy" matrix within which the cells are embedded in a biofilm. It is mainly composed of water (up to 97\%) in which polysaccharides, proteins, eDNA, amyloids, cellulose, lipids, fimbriae, pili and flagellae remain suspended (Flemming et al. 2016).

The matrix gives the biofilm its cohesive properties and strength to form extensive architectural features (Danese et al. 2000, Flemming et al. 2007). The extreme resistance of biofilms to external forces is also conferred by the EPS (Flemming and Wingender 2010, Hall-Stoodley et al. 2004). It helps anchor cells to a surface and facilitate aggregation of bacterial cells, cohesion of biofilms, water retention during draught conditions, tolerance to antimicrobial agents, evasion of predators and invaders, protection of enzymes against oxidative damages, starvation, and exchange of genetic information (Flemming and Wingender 2010). Biofilms are extremely resilient to inactivation by UV (Elasri and Miller 1999), temperature (Thomas et al. 1999), antibiotics (Fux et al. 2005) and predation (Matz and Kjelleberg 2005).

Biofilm formation has been a major concern in the medical field (Donlan and Costerton 2002), chiefly because it is very difficult to completely remove them once pathogens have started forming biofilms. A similar pattern is also seen in engineered systems such as water distribution pipes (Pozos et al. 2004) and natural habitats like aquatic ecosystems. 
EPS production is dependent on both biological characteristics such as growth phase (Smith and Underwood 2000, Vuyst and de Ven 1998) and quorum sensing (Hammer and Bassler 2003, Marketon et al. 2003, Quiñones et al. 2005, Von Bodman et al. 1998) and environmental parameters like salinity, desiccation (Decho 2000), light intensity (Smith and Underwood 2000), cation concentrations (Battin et al. 2004), nutrient availability (Degeest and De Vuyst 1999) oxygen, $\mathrm{pH}$ and temperature (Petry et al. 2000).

\subsubsection{Stages of biofilm formation: Detachment from biofilm}

As the biofilm matures it starts to get overpopulated. This is balanced by the process of biofilm removal. Researchers have identified few ways by which biofilm detachment occurs dispersion, erosion, abrasion, sloughing and predator grazing. Dispersion is the removal of cells from the biofilm that occurs when biofilms "shed" planktonic cells to avoid resource scarcity and expand to new niches (McDougald et al. 2012, Stoodley et al. 2002). Such detachments are regular occurrences in the biofilm and are a highly regulated process. Several factors, both biological and environmental, have been reported to affect dispersion. Resource scarcity, such as fluctuations in nutrient levels, carbon and nitrogen limitations, and oxygen limitations are known to initiate dispersal (Mueller 1996, Rice et al. 2005, Sauer et al. 2004). Physiological cues, such as, D-amino acids have been shown to trigger dispersal in $B$. subtilis, P. aeruginosa and S. aureus biofilms (Kolodkin-Gal et al. 2010). Another widely reported physiological cue is nitric oxide (NO). It has been shown that in low concentrations, NO can regulate genetic pathways responsible for conversion between free floating and surface attached lifestyles of the bacteria (Barraud et al. 2009, Li et al. 2013). NO is also reported to influence cyclic di-GMP signaling, which is yet another well reported factor influencing dispersal. Cyclic di-GMP is thought to be a key element in a signal transduction pathway in bacteria which is responsible for shifts between planktonic and biofilm lifestyles (Jenal and Malone 2006, Thormann et al. 2006). In general, an increased cyclic di-GMP level 
facilitates the biofilm mode while a decreased level leads to dispersal (McDougald et al. 2012).

More drastic detachments occur during erosion, which is the continuous removal of particles from surface of biofilm, and sloughing, which is when large patches of biofilm get removed (Picioreanu et al. 2001). These detachments often occur in response to environmental cues like increased shear stress, starvation and nutrient deficiency or toxic shock. Abrasion happens when biofilms on support media or when granules come into contact, e.g., during backwashing (Gjaltema et al. 1997).

The tendency of a biofilm to slough largely depends on the biofilm's mechanical stability or in other words, strength to withstand and recover from such stresses. The mechanical properties of biofilms are collectively referred to as rheological properties of biofilms and their role in biofilm development and their interrelationship with various environmental parameters are being studied extensively.

Biofilms are thought to be similar to "hydrogels" or extremely hydrated polymer gels whose rheological properties are mainly dependent on the EPS (Hall-Stoodley et al. 2004, Seviour et al. 2009b). Biofilm EPS behaves as a viscoelastic material, which means under steady shear stress biofilms show both "reversible elastic responses and irreversible deformation" depending on the magnitude of the stress/stimulus (Flemming and Wingender 2010). Several researchers have reported typical viscoelastic properties in biofilms grown under different flow regimes in flow cells (Klapper et al. 2002, Stoodley et al. 2002, Towler et al. 2003). However, EPS derived from different types of biofilms, such as flocs and granules in wastewaters or those from environments varying in terms of $\mathrm{pH}$, can have rheological differences (Seviour et al. 2009a). It has further been shown that rheological properties are mainly due to polysaccharides present within the EPS (Seviour et al. 2009b). A recent study 
explained how different types of polysaccharides, Pel and Psl in a P.aeruginosa biofilms, contribute to differences in rheological properties and serve separate functions during biofilm formation (Chew et al. 2014).

However, despite having differences in EPS properties, researchers have reported similar elastic relaxation time (which is the crossover time between solid and fluid behavior) of biofilms from a variety of sources such as clinical implants, human body, photosynthetic mats from creeks as well as single species and multispecies biofilms grown in the laboratory (Shaw et al. 2004). The authors emphasized the significance of having similar relaxation times. They mention that this time is in the same range as the time required by most microorganisms to have a phenotypic response to perturbations in the environment. Hence, most likely rheological properties allow the biofilm to have a buffering period during which it can adapt to changes in its environment. Protection offered by virtue of rheological properties, however, is more than offering buffer time for adaptations. For example, viscosity of biofilms can also play a role in protecting the members from outside invasions like phage penetrations (Hanlon et al. 2001).

However, it is hard to quantify these properties on a time scale as biofilms, being living entities, do not maintain the same physical and biological properties over time. For example, they respond to changes in drag forces or shear acting on them by developing differently in terms of shape and structures. In natural aquatic systems, biofilms develop into streamers or elongated ribbon like structures, depending on the prevailing flow conditions, which impacts the resultant drag on individual components of the biofilms (Stoodley et al. 1999). Mechanical properties of biofilms can also depend on the growth phase of the members as growth phase directly impacts EPS production (Smith and Underwood 2000). Even biofilm communities, as a whole, often diverge in response to various stresses, leading to changes in physical and functional properties (Riemann et al. 2000) 


\subsection{Invasion in aquatic biofilm communities}

Biofilm communities in fresh water systems play crucial roles in maintaining ecosystem health. Natural freshwater systems have been reported to contain mostly Alpha-, Beta-, and Gammaproteobacteria, bacilli, members of the Cytophaga- Flavobacteria- Bacteriodetes group, Cyanobacteria, Sphingobacteria and Actinobacteria (Besemer et al. 2012, Zwart et al. 2002). The most abundant bacteria detected in glacier ice are reported to be Proteobacteria, Actinobacteria, Bacteriodetes, Firmicutes and Cyanobacteria (Wilhelm et al. 2013). In natural aquatic systems, assembly of the biofilm is not a direct reflection of the inoculum present in the overlying water. Earlier studies on successional changes in freshwater biofilms suggested community assembly is not random and certain bacteria contribute more to the assembly than others (Jackson et al. 2001, Lyautey et al. 2005).

In a microcosm study, it was seen than biofilm communities under different flow conditions diverged from an initial community, which was the inoculum present in stream water, and converged as the biofilms matured (Besemer et al. 2007). It was suggested that algae present in the system were influencing the microenvironment in such a way that it was similar in all microcosms, even though the flow regime was different. The observed succession was also not affected by variations in source community.

Bessemer et al.. (2012) studied suspended and biofilm communities in streams and reported that diversity in the overlying water was higher than in the biofilms. They also reported that even though the communities in the overlying water column varied between streams, the biofilm communities were similar. They concluded that species sorting is an important mechanism in biofilm development in aquatic environments (Besemer et al. 2012). The structure and composition of bacterial communities collected from subalpine lakes and tropical reservoirs was compared in a different study using $16 \mathrm{~S}$ rRNA gene sequencing. The authors showed in terms of core and satellite OTUs, that the history of the ecosystems and the 
regional environmental parameters impacted the relative abundances of the individual OTUs (Humbert et al. 2009).

Loares et al. (2013) studied the response of bacterial communities to long term environmental changes. They sampled different inland lakes that were connected to the sea in the past. It was seen that long term salinity change modified the original communities slowly and led to the establishment of several new taxa thus changing the communities entirely (Logares et al. 2013).

Apart from long term environmental changes, random events such as sewage leaks also lead to community changes in freshwater systems (Drury et al. 2013b, Wakelin et al. 2008). In urban areas effluent from waste water treatment plants (WWTP) is a common factor that impacts freshwater microbial community. It has been reported that effluent released in rivers lead to higher nutrient levels, which was accompanied by a decrease in population abundance and diversity of the microbial communities leading to a "biotic homogenization" across the rivers (Drury et al. 2013a). WWTP effluent discharge has also been reported to cause an increase in Cyanobacteria and Thaumarchaeota populations, downstream of a river (Bai et al. 2014). Bacterial and archaeal communities in a stretch of Lake Geneva contaminated with effluent were also found to be significantly different from those found in nearby noncontaminated areas. Most betaproteoproteobacteria clones in the contaminated area were found to be related to dechlorinating bacteria (Dechloromonas). Deltaproteobacteria like sulfate reducing and $\mathrm{Fe}(\mathrm{III})$ reducing (Geobacter) bacteria and methanogenic archaea were also found in the contaminated stretch (Haller et al. 2011).

Sewage leaks also introduce many alien microorganisms into the receiving waterbodies, which can then compete with the native microbial community for resources. In fact, invasion is a common field of research in macroscopic ecosystems and is slowly being addressed in 
microbial ecology as well (Flemming et al. 2016). In a mesocosm study, the colonization potential of different ammonia oxidizing and nitrite oxidizing bacteria was studied. It was observed that of the diverse bacteria present in WWTP effluent, AOB of the Nitrosomonas oligotropha/ureae lineage and NOB of Nitrospira sublineage I could colonize biofilms present in the mesocosms (Mußmann et al. 2013).

In macroecological studies, it has been observed that invasion by alien species often leads to removal of many native species impacting ecosystem health (Ricciardi et al. 1998). For example, in a recent study, native fish populations were found to be susceptible to a pathogen carried by an alien fish species, which was accidentally introduced in to the system (Andreou et al. 2012). Similarly, in a microbial ecology context, invasion by non-native microorganisms might affect the fate of individual members in the community.

A successful colonization by alien species has often been reported to alter the resident community in terms of both composition and functioning. In a microcosm study, it was observed that in the presence of invasive algal species, bacterial taxa capable of degrading algal cellulose increased (Eisenhauer et al. 2013). In a separate study, nitrification activities were reported to be higher in microcosms that had been colonized by added nitrifiers as compared to control microcosms (Mußmann et al. 2013). In a recent study in the North Sea, a phytoplankton bloom was found to affect the resident community significantly. Bacterial richness was reduced after the bloom, certain OTUs such as the SAR92 clade and the Roseobacter RCA cluster were more abundant, and processes such as photosynthesis, protein metabolism and DNA metabolism were affected (Wemheuer et al. 2014).

Success of colonization of natural communities though is widely recognized to be influenced by biodiversity. Eisenhauer et al.. (2013) studied the invasion success of Pseudomonas putida of a resident community of different Pseudomonas fluorescence strains. It was seen that 
invasion success was negatively correlated with the diversity of the resident community and functional dissimilarity. Their study showed that functionally dissimilar bacterial strains use resources available efficiently, leaving less "vacant" niches for invasive species (Eisenhauer et al. 2013).

Finally, despite their resilient nature, biofilm communities undergo decay. In shallow aquatic environments, sunlight is one of the major factors impacting the survival of microorganisms. Sufficient exposure to sunlight has often been used as a low cost disinfection process (Love et al. 2010, Sinton et al. 1999). Other environmental factors, such as suspended particles, salinity and temperature also interfere with decay kinetics of microorganisms (Drummond et al. 2015, Harvey and Ryan 2004, Hijnen et al. 2006, Romero et al. 2011). Hence, even upon successful colonization, pathogens incorporated within a benthic biofilm will not persist for an indefinite time. Hence, it is crucial to understand the risk associated with benthic biofilms if they can act as a reservoir of pathogens in natural systems. The roles of different physicochemical and biological factors affecting pathogen invasion and persistence within such biofilms and the impact on existing benthic biota should be investigated using controlled, representative experimental models that mimic natural aquatic environments.

\subsection{Approaches for studying the fate of microorganisms}

Over the years, several researchers have studied common water borne pathogens to understand their sources and behavior in natural systems. Some authors studied the correlation between water borne disease outbreaks and extreme precipitation in the U.S. and found significant association between the two, which shows that fecal contamination alone is not the source of such outbreaks (Curriero et al. 2001). Studies have shown that zoonotic transmission leads to Cryptosporidium parvuum spread in watersheds and thus cannot be controlled by excluding human activities alone from the watershed (Graczyk et al. 1997). Researchers have also devised novel molecular tools or modified existing methods to detect 
emerging pathogens in a short period of time (Germini et al. 2009, Rasmussen et al. 2003). Direct detection and quantification of pathogens are also required for quantitative microbial risk assessment (QMRA), which helps understand health risks associated with them (Bambic et al. 2011, McBride et al. 2013). Emerging pathogens are also being studied at a genetic level, for example, identification of multidrug resistance in E. coli (Okusu et al. 1996), to better understand their pathogenicity which can then lead to better controls.

However, fate and transport studies, especially those in open or large scale systems, are more often conducted by using surrogates of pathogens. Surrogates can be defined to be particles, chemicals or microorganisms which are used in place of the target pathogens (Gurtler et al. 2010, Lasobras et al. 1999, Rajal et al. 2007, Roberts et al. 1993). Non-pathogenicity of the surrogates often makes them safer to use, especially in open systems. However, apart from safety there are a host of other physicochemical and biological criteria as well (Table 2) that need to be taken into account in order to have a true representative for the pathogen of interest (Sinclair et al. 2012).

Tracers and inert beads are conventionally used in studying pathogen behavior (Arnon et al. 2010, Harvey and Ryan 2004, Shen et al. 2008). Beads and tracers have the advantage of having a well-defined physical and chemical composition, thus reducing uncertainty and variability within the experiment. A drawback of using inert particles is that the fate and transport of the pathogen can be defined in terms of physical processes alone and the effects of biological processes like viability remain unaddressed. To bridge this gap, "live tracers" are increasing being used, for example, bacteriophages (Harvey and Ryan 2004, Kropinski et al. 2009, Masago et al. 2008, Misstear and Gill 2012). Bacteriophages can be produced in large numbers, are pathogenic only to their host bacteria, and often have a very low rate of decay in natural habitats (Kropinski et al. 2009, Love et al. 2010, Masago et al. 2008, Misstear and Gill 2012, Shen et al. 2008). 
In some cases chosen surrogates can also be pathogenic, such as where the individual surrogate of choice represents a group of pathogens of interest (Sinclair et al. 2012). The earliest example of using a surrogate to represent pathogens in water is the use of Escherichia coli as indicator bacterium to detect fecal contamination. In recent times, U.S. EPA guidelines listed Klebsiella terrigena, Cryptosporidium parvum, Poliovirus and Rotavirus as surrogates for coliforms, cysts and virus groups, respectively (Sinclair et al. 2012).

Although surrogates provide an easy and safe way to study pathogens, in some cases, surrogates may misrepresent the actual scenario. For example, Enterococcus faecalis DNA is approved for water quality monitoring by U.S. EPA. Researchers have reported that $E$. faecalis DNA does not decay appreciably in water or sediments, thus questioning the utility of DNA measurements to indicate recent fecal contamination (Bae and Wuertz 2012, Kim and Wuertz 2015).

Irrespective of the decision to study pathogens themselves, or use a surrogate organisms, accurate detection is crucial. Traditionally, cultivation based methods were used for detecting microbes. Such methods, though still widely accepted, suffer from many limitations such as longer time requirement for isolation and detection, higher detection limits and inability to detect non-cultivable microorganisms. Even pathogens that are known to be cultivable, in natural environments, can remain in a "viable but non culturable state (VBNC)" (Toze 1999). Cultivation dependent techniques were also unable to distinguish between different serotypes of the same bacteria, which is often important information in epidemiological studies (Rasmussen et al. 2003). It has also been reported that when compared with microscopic analysis, cultivation based methods often result in underestimation of the microbial load present in the system (Staley and Konopka 1985). However, despite their limitations, cultivation dependent methods provide information on the viability of pathogens, which is important for assessing health risk. 
The limitations of cultivation dependent techniques are overcome by using molecular tools such as qPCR, microarrays and sequencing (Aw and Rose 2012). These methods target the nucleic acids, thus detecting pathogens irrespective of their cultivability. Some of them, like qPCR, are highly specific, being able to differentiate between closely related members or serotypes and require less processing time (Lee et al. 2006, Schriewer et al. 2011).

However, qPCR has the limitation of not being able to distinguish between intracellular and extracellular nucleic acid, which means it cannot differentiate between live or infectious and dead cells. The technique has been modified to account for this limitation. Currently, the PMA-qPCR is used by several researchers to identify live cells (Nocker et al. 2006, Kim and Wuertz 2015). The method involves exposing bacterial cells to a DNA binding agent. The agent binds to extracellular DNA and inhibits its amplification. However, the feasibility of this process is not yet widely validated (Løvdal et al. 2011) and cultivation dependent methods are still employed to gain information on viability.

Fate and transport studies of pathogens have been done using a variety of experimental models, including batch systems (Moore et al. 1981), small scale flow-based systems like columns (Funderburg et al. 1981) and flow cells (Chang et al. 2007), large scale systems like flumes (Besemer et al. 2009, Singer et al. 2006, Wolyniak et al. 2009), and field studies (Battin et al. 2004). Batch studies are mostly used to determine physical parameters like adsorption coefficients, decay rates and so forth. Column studies have been used to determine one-dimensional transport processes, such as attachment and detachment kinetics, while flow cells have almost become the "gold standard" for studying pathogens in biofilms (Crusz et al. 2012). Another approach to studying the fate of pathogens is by mathematical modeling.

Models are useful in gaining insights into pathogen behavior as well as predicting concentrations in large systems where constant monitoring of pathogens would be difficult 
(Tufenkji 2007). Most water quality models are based on advection-dispersion equations derived from mass balance principles. Conventionally, these models treated the pathogens as particles which are removed from the water phase by attachment to sediments (Chapra 2008). Gradually, as it was established that sediments act more as a reservoir than a removal system for pathogens; this notion has been modified to include effects of resuspension from the sediments (Bai and Lung 2005, Fries et al. 2006).

Additionally, sediment-pathogen interactions are not strictly adsorption-desorption processes. While suspended particles can remove pathogens from the water column, they can also change decay kinetics of the pathogen, for example, by changing sunlight exposure (Gao et al. 2011, Kim and Wuertz 2015). Researchers have tried to characterize sediments in terms of particle size, cohesive strength and density. Pathogen detachment, in turn, has been defined in terms of adsorption isotherms and as a function of flow, critical shear stress and other factors. (Bai and Lung 2005, Kim et al. 2010, Reddy et al. 1981). However, these definitions often fail to account for all the uncertainty related to pathogen resuspension, possibly due to the fact that sediment properties in natural ecosystems are not constant. In natural systems, sediments are covered by biofilms which can alter the particle retention properties (Droppo 2009). Pathogens can also form biofilms at interfaces or colonize benthic biofilms. Pathogen retention and release in such a case, can be affected by biological properties of the biofilm members (Liu and Li 2008). Slowly, the role of biofilms is being accounted for in water quality models (Drummond et al. 2015, Pandey et al. 2012). The field, however, still remains in its infancy.

\subsection{Motivation}

Freshwater usage is increasing globally. Yet, microbial water quality monitoring is lacking in most places. Even in developed countries like Singapore, freshwater monitoring includes only blanket parameters such as $\mathrm{pH}$, dissolved oxygen, biochemical oxygen demand, total 
suspended solids, ammonia and sulphide. Recreational water quality control guidelines of Singapore, adopted from the 2003 World Health Organization (WHO) standards (National Environmental Agency, Singapore), consider water bodies having less than or equal to 200 counts of the fecal indicator organism Enterococcus per 100 milliliters of water to be safe for recreational purposes (National Environment Agency, Singapore) while for recreation in fresh waters, a similar Enterococcus count, along with a concentration less than $50 \mu \mathrm{g} / \mathrm{L}$ of chlorophyll-a is required. Even though recreational usage directly impacts public health, these guidelines do not recommend monitoring actual levels of water borne pathogenic bacteria and viruses, nor do they consider the potential pathogen reservoir present in the underlying biofilms.

The primary aim of this research is to understand the fate of pathogens in urban freshwater systems, in the presence of a photosynthetic biofilm, using surrogates of common water borne pathogens. Here, I have studied the fates of four such pathogen surrogates, Pseudomonas aeruginosa, Enterococcus faecalis, P22 bacteriophage and GA bacteriophage. Pseudomonas aeruginosa is an opportunistic pathogen and a known biofilm former. It enters waterbodies through storm water draining and human recreational activities (Mena and Gerba 2009) and has been associated with many cases of recreational water illness (RWIs), where the route of exposure has been direct contact through skin (Yoder et al. 2008). It was chosen to represent common Gram negative opportunistic pathogens present in freshwater systems (Al-Qadiri et al. 2006). The strain used here was isolated from one of the urban canals of Singapore. Enterococcus faecalis is a known microbial water quality indicator and is frequently isolated from natural water bodies. It was selected as a representative of common Gram positive bacterial pathogen present in freshwater systems. P22 bacteriophage is a double stranded (ds) DNA phage with Salmonella typhimurium as host. P22 was selected to 
be a representative of dsDNA phages. Finally, GA, a phage of E. coli, was selected to represent common F-specific coliphages present in fresh water bodies.

To address the fate of pathogens in freshwater, several research questions were asked as explained below.

\subsubsection{Research questions (RQ)}

- Can biofilms in waterways act as a repository of human pathogens?

- Can pathogen fate in freshwater systems in the presence of biofilms be explained by physicochemical mechanisms (settling, decay and detachment) alone?

- In freshwater system, do hydrodynamic conditions affect settling, integration, growth and detachment of pathogens in biofilms?

- Can biofilm kinetic processes be different due to different flow rates and in turn impact the fate of pathogens?

- Does the introduction of pathogens affect the benthic biofilm community in terms of composition and function? If so, is such an effect related to hydrodynamic conditions?

RQ (i) and (ii) are addressed in Chapter 2. I hypothesized that depending on the flow rate present in a system, pathogen surrogates can get incorporated into the underlying biofilm, which will affect their fate and persistence in the system. I operated four flumes at a flow rate representative of that present in Singapore's canals during periods of no rainfall. I showed that biofilms present in these flumes can act as a reservoir of the surrogates long after their initial release. I further showed, with mass balance analysis, that accurate prediction of the fate of the pathogens in the system required a better understanding of biological processes such as growth and decay and cannot be based on physiochemical processes alone.

RQ (iii) and (iv) are addressed in Chapter 3. I hypothesized that the flow rate in the flumes will affect biofilm properties and settling and detachment of surrogates, which together will have an effect on the surrogate fate. Here I studied the fate of the surrogates under two 
different flow rates using four flumes. I repeated the experiments at each flow rate once and compared them in terms of surrogate persistence, biofilm properties as well as water chemistry.

Finally, RQ (v) is addressed in Chapter 4. I hypothesized that the microbial community present in biofilms where surrogates were introduced will be different from that in those biofilms, which did not receive the surrogates. I studied the effect of surrogates on flume biofilms under two different flow rates. Metagenomic community analysis revealed that the community was affected by surrogates when the flow rate was low. The effect was on the abundance of the prokaryotic community and both abundance and composition of the eukaryotic community. I identified the members that are likely to be driving these differences and studied whether functionality of the community was being affected by the differences. 
Table 1: Water borne pathogens (Adopted from U.S. EPA and WHO)

\begin{tabular}{lll}
\hline Pathogen & Type & Disease \\
\hline Acanthamoeba & Protozoan & Eye infection \\
Adenovirus & Virus & Respiratory illness and occasionally gastrointestinal illness \\
Aeromonas hydrophila & Bacterium & Gastrointestinal illness \\
Calcivirus & Virus & Mild self-limiting gastrointestinal illness \\
Campylobacteri jejuni & Bacterium & Mild self-limiting gastrointestinal illness \\
Coxsackieviruses & Virus & Gastrointestinal infection \\
Cryptosporidium parvuum & Protozoan & Gastrointestinal infection \\
Cyanobacteria & Bacterium & Toxin exposure \\
Cyclospora cayetanensis & Protozoan & Diarrhea \\
Dracunculus medinensis & Helminthes & Guinea worm disease \\
Entamoeba histolytica & Protozoan & Gastrointestinal illness \\
Enterovirus & Virus & Mild respiratory illness \\
Escherichia coli (O157) & Bacterium & Gastrointestinal illness and kidney failure \\
Giardia intestinalis & Protozoa & Gastrointestinal illness \\
Helicobacteri pilori & Bacterium & Ulcers and possibly cancers \\
Hepatitis A virus & Virus & Liver disease \\
Legionella pneumophila & Bacterium & Lung disease, possibly cancer \\
Mycobacterium avium & Bacterium & Lung infection \\
Naegleria fowleri & Protozoan & Meningoencephilitis \\
Pseodomonas aeruginosa & Bacterium & Skin/ear infection \\
Salmonella enterica & Bacterium & Mild self-limiting gastrointestinal illness. \\
Schistosomatidae & Helminthes & Swimmer's itch \\
Shigella sonnei & Bacterium & Mild self-limiting gastrointestinal illness and bloody diarrhea \\
Toxoplasma gondii & Protozoan & Toxoplasmosis \\
\hline & &
\end{tabular}

Table 2: Criteria for selecting surrogates 


\begin{tabular}{|c|c|c|c|}
\hline Attributes & & & Example \\
\hline
\end{tabular}




\subsection{References}

Al-Qadiri HM, Al-Holy MA, Lin M, Alami NI, Cavinato AG, Rasco BA (2006). Rapid detection and identification of Pseudomonas aeruginosa and Escherichia coli as pure and mixed cultures in bottled drinking water using Fourier transform infrared spectroscopy and multivariate analysis. Journal of Agricultural and Food Chemistry 54: 5749-5754.

Andreou D, Arkush KD, Guégan J-F, Gozlan RE (2012). Introduced pathogens and native freshwater biodiversity: a case study of Sphaerothecum destruens. PLoS ONE 7: e36998.

Arnon S, Packman AI, Peterson CG, Gray KA (2007). Effects of overlying velocity on periphyton structure and denitrification. Journal of Geophysical Research: Biogeosciences (2005-2012) 112.

Arnon S, Marx LP, Searcy KE, Packman AI (2010). Effects of overlying velocity, particle size, and biofilm growth on stream-subsurface exchange of particles. Hydrological Processes 24: $108-114$.

Aw TG, Rose JB (2012). Detection of pathogens in water: from phylochips to qPCR to pyrosequencing. Current Opinion in Biotechnology 23: 422-430.

Bae S, Wuertz S (2012). Survival of Host-Associated Bacteroidales Cells and Their Relationship with Enterococcus spp., Campylobacter jejuni, Salmonella enterica Serovar Typhimurium, and Adenovirus in Freshwater Microcosms as Measured by Propidium Monoazide-Quantitative PCR. Applied and Environmental Microbiology 78: 922-932.

Bai S, Lung W-S (2005). Modeling sediment impact on the transport of fecal bacteria. Water Research 39: 5232-5240.

Bai Y, Qi W, Liang J, Qu J (2014). Using high-throughput sequencing to assess the impacts of treated and untreated wastewater discharge on prokaryotic communities in an urban river. Applied Microbiology and Biotechnology 98: 1841-1851.

Balzer M, Witt N, Flemming H-C, Wingender J (2010). Faecal indicator bacteria in river biofilms. Water Science and Technology 61: 1105-1111.

Balzer M, Witt N, Flemming H-C, Wingender J (2010). Faecal indicator bacteria in river biofilms. Water Science and Technology 61: 1105-1111.

Baker J (1984). Factors affecting the bacterial colonization of various surfaces in a river. Canadian Journal of Microbiology 30: 511-515. 
Bambic D, McBride G, Miller W, Stott R, Wuertz S (2011). Quantification of pathogens and sources of microbial indicators for QMRA in recreational waters. Water Intelligence Online 10.

Barraud N, Storey MV, Moore ZP, Webb JS, Rice SA, Kjelleberg S (2009). Nitric oxidemediated dispersal in single-and multi-species biofilms of clinically and industrially relevant microorganisms. Microbial Biotechnology 2: 370-378.

Barthlott W, Neinhuis C (1997). Purity of the sacred lotus, or escape from contamination in biological surfaces. Planta 202: 1-8.

Battin T, Wille A, Psenner R, Richter A (2004). Large-scale environmental controls on microbial biofilms in high-alpine streams. Biogeosciences 1: 159-171.

Besemer K, Singer G, Limberger R, Chlup A-K, Hochedlinger G, Hödl I et al. (2007). Biophysical controls on community succession in stream biofilms. Applied and Environmental Microbiology 73: 4966-4974.

Besemer K, Singer G, Hödl I, Battin TJ (2009). Bacterial community composition of stream biofilms in spatially variable-flow environments. Applied and Environmental Microbiology 75: 7189-7195.

Besemer K, Peter H, Logue JB, Langenheder S, Lindström ES, Tranvik LJ et al. (2012). Unraveling assembly of stream biofilm communities. The ISME Journal 6: 1459-1468.

Bouwer EJ (1987). Theoretical investigation of particle deposition in biofilm systems. Water Research 21: 1489-1498.

Briandet R, Meylheuc T, Maher C, Bellon-Fontaine MN (1999). Listeria monocytogenes Scott A: Cell surface charge, hydrophobicity, and electron donor and acceptor characteristics under different environmental growth conditions. Applied and Environmental Microbiology 65: 5328-5333.

Bruinsma GM, van der Mei HC, Busscher HJ (2001). Bacterial adhesion to surface hydrophilic and hydrophobic contact lenses. Biomaterials 22: 3217-3224.

Buswell CM, Herlihy YM, Lawrence LM, McGuiggan JT, Marsh PD, Keevil CW et al. (1998). Extended survival and persistence of Campylobacter spp. in water and aquatic biofilms and their detection by immunofluorescent-antibody and-rRNA staining. Applied and Environmental Microbiology 64: 733-741.

Carlen A, Nikdel K, Wennerberg A, Holmberg K, Olsson J (2001). Surface characteristics and in vitro biofilm formation on glass ionomer and composite resin. Biomaterials 22: 481-487. 
Chang W-S, van de Mortel M, Nielsen L, de Guzman GN, Li X, Halverson LJ (2007). Alginate production by Pseudomonas putida creates a hydrated microenvironment and contributes to biofilm architecture and stress tolerance under water-limiting conditions. Journal of Bacteriology 189: 8290-8299.

Chapra SC (2008). Surface water-quality modeling. Waveland press.

Chew SC, Kundukad B, Seviour T, van der Maarel JR, Yang L, Rice SA et al. (2014). Dynamic remodeling of microbial biofilms by functionally distinct exopolysaccharides. MBio 5: e01536-01514.

Crusz SA, Popat R, Rybtke MT, Cámara M, Givskov M, Tolker-Nielsen T et al. (2012). Bursting the bubble on bacterial biofilms: a flow cell methodology. Biofouling 28: 835-842.

Curriero FC, Patz JA, Rose JB, Lele S (2001). The association between extreme precipitation and waterborne disease outbreaks in the United States, 1948-1994. American Journal of Public Health 91: 1194-1199.

Cvitkovitch DG, Li Y-H, Ellen RP (2003). Quorum sensing and biofilm formation in Streptococcal infections. The Journal of Clinical Investigation 112: 1626-1632.

Danese PN, Pratt LA, Kolter R (2000). Exopolysaccharide production is required for development of Escherichia coli K-12 biofilm architecture. Journal of Bacteriology 182: 3593-3596.

Decho AW (2000). Microbial biofilms in intertidal systems: an overview. Continental Shelf Research 20: 1257-1273.

Degeest B, De Vuyst L (1999). Indication that the nitrogen source influences both amount and size of exopolysaccharides produced by Streptococcus thermophilus LY03 and modelling of the bacterial growth and exopolysaccharide production in a complex medium. Applied and Environmental Microbiology 65: 2863-2870.

Dokulil M, Chen W, Cai Q (2000). Anthropogenic impacts to large lakes in China: the Tai Hu example. Aquatic Ecosystem Health \& Management 3: 81-94.

Donlan RM (2002). Biofilms: microbial life on surfaces. Emerging Infectious Diseases 8: 881-890.

Donlan RM, Costerton JW (2002). Biofilms: Survival mechanisms of clinically relevant microorganisms. Clinical Microbiology Reviews 15: 167-193. 
Droppo IG (2009). Biofilm structure and bed stability of five contrasting freshwater sediments. Marine and Freshwater Research 60: 690-699.

Drummond JD, Davies-Colley RJ, Stott R, Sukias JP, Nagels JW, Sharp A et al. (2015). Microbial transport, retention, and inactivation in streams: A combined experimental and stochastic modeling approach. Environmental Science \& Technology 49: 7825-7833.

Drury B, Rosi-Marshall E, Kelly JJ (2013a). Wastewater treatment effluent reduces the abundance and diversity of benthic bacterial communities in urban and suburban rivers. Applied and Environmental Microbiology 79: 1897-1905.

Drury B, Scott J, Rosi-Marshall EJ, Kelly JJ (2013b). Triclosan exposure increases triclosan resistance and influences taxonomic composition of benthic bacterial communities. Environmental Science \& Technology 47: 8923-8930.

Eisenhauer N, Schulz W, Scheu S, Jousset A (2013). Niche dimensionality links biodiversity and invasibility of microbial communities. Functional Ecology 27: 282-288.

Elasri MO, Miller RV (1999). Study of the response of a biofilm bacterial community to UV Radiation. Applied and Environmental Microbiology 65: 2025-2031.

Flemming H-C, Neu TR, Wozniak DJ (2007). The EPS matrix: the "house of biofilm cells". Journal of Bacteriology 189: 7945-7947.

Flemming H-C, Wingender J (2010). The biofilm matrix. Nature Reviews Microbiology 8: 623-633.

Flemming H-C, Wingender J, Szewzyk U, Steinberg P, Rice SA, Kjelleberg S (2016). Biofilms: an emergent form of bacterial life. Nature Reviews Microbiology 14: 563-575.

Fries JS, Characklis GW, Noble RT (2006). Attachment of fecal indicator bacteria to particles in the Neuse River Estuary, NC. Journal of Environmental Engineering 132: 1338-1345.

Funderburg SW, Moore BE, Sagik BP, Sorber CA (1981). Viral transport through soil columns under conditions of saturated flow. Water Research 15: 703-711.

Fux CA, Costerton JW, Stewart PS, Stoodley P (2005). Survival strategies of infectious biofilms. Trends in Microbiology 13: 34-40.

Gao G, Falconer RA, Lin B (2011). Numerical modelling of sediment-bacteria interaction processes in surface waters. Water Research 45: 1951-1960. 
Garrett TR, Bhakoo M, Zhang Z (2008). Bacterial adhesion and biofilms on surfaces. Progress in Natural Science 18: 1049-1056.

Germini A, Masola A, Carnevali P, Marchelli R (2009). Simultaneous detection of Escherichia coli O175: H7, Salmonella spp., and Listeria monocytogenes by multiplex PCR. Food Control 20: 733-738.

Gjaltema, A., M. C. M. Van Loosdrecht, and J. J. Heijnen. Abrasion of suspended biofilm pellets in airlift reactors: effect of particle size. Biotechnology and Bioengineering 55.1 (1997): 206-215.

Graczyk T, Fayer R, Cranfield M (1997). Zoonotic transmission of Cryptosporidium parvum: Implications for water-borne cryptosporidiosis. Parasitology Today 13: 348-351.

Gurtler JB, Rivera RB, Zhang HQ, Geveke DJ (2010). Selection of surrogate bacteria in place of E. coli O157: $\mathrm{H} 7$ and Salmonella Typhimurium for pulsed electric field treatment of orange juice. International Journal of Food Microbiology 139: 1-8.

Hall-Stoodley L, Costerton JW, Stoodley P (2004). Bacterial biofilms: from the natural environment to infectious diseases. Nature Reviews Microbiology 2: 95-108.

Haller L, Tonolla M, Zopfi J, Peduzzi R, Wildi W, Pote J (2011). Composition of bacterial and archaeal communities in freshwater sediments with different contamination levels (Lake Geneva, Switzerland). Water Research 45: 1213-1228.

Hammer BK, Bassler BL (2003). Quorum sensing controls biofilm formation in Vibrio cholerae. Molecular Microbiology 50: 101-104.

Hanlon GW, Denyer SP, Olliff CJ, Ibrahim LJ (2001). Reduction in exopolysaccharide viscosity as an aid to bacteriophage penetration through Pseudomonas aeruginosa biofilms. Applied and Environmental Microbiology 67: 2746-2753.

Harvey RW, Ryan JN (2004). Use of PRD1 bacteriophage in groundwater viral transport, inactivation, and attachment studies. FEMS Microbiology Ecology 49: 3-16.

Hijnen W, Beerendonk E, Medema GJ (2006). Inactivation credit of UV radiation for viruses, bacteria and protozoan (oo) cysts in water: a review. Water Research 40: 3-22.

Horswill AR, Stoodley P, Stewart PS, Parsek MR (2007). The effect of the chemical, biological, and physical environment on quorum sensing in structured microbial communities. Analytical and Bioanalytical Chemistry 387: 371-380. 
Humbert JF, Dorigo U, Cecchi P, Le Berre B, Debroas D, Bouvy M (2009). Comparison of the structure and composition of bacterial communities from temperate and tropical freshwater ecosystems. Environmental Microbiology 11: 2339-2350.

Jackson CR, Churchill PF, Roden EE (2001). Successional changes in bacterial assemblage structure during epilithic biofilm development. Ecology 82: 555-566.

Jenal U, Malone J (2006). Mechanisms of cyclic-di-GMP signaling in bacteria. Annual Reviews of Genetics 40: 385-407.

Jucker BA, Harms H, Zehnder AJ (1996). Adhesion of the positively charged bacterium Stenotrophomonas (Xanthomonas) maltophilia 70401 to glass and Teflon. Journal of Bacteriology 178: 5472-5479.

Kim J-W, Pachepsky YA, Shelton DR, Coppock C (2010). Effect of streambed bacteria release on E. coli concentrations: Monitoring and modeling with the modified SWAT. Ecological Modelling 221: 1592-1604.

Kim M, Wuertz S (2015). Survival and persistence of host-associated Bacteroidales cells and DNA in comparison with Escherichia coli and Enterococcus in freshwater sediments as quantified by PMA-qPCR and qPCR. Water Research 87: 182-192.

Klapper I, Rupp CJ, Cargo R, Purvedorj B, Stoodley P (2002). Viscoelastic fluid description of bacterial biofilm material properties. Biotechnology and Bioengineering 80: 289-296.

Kolodkin-Gal I, Romero D, Cao S, Clardy J, Kolter R, Losick R (2010). D-amino acids trigger biofilm disassembly. Science 328: 627-629.

Kropinski AM, Mazzocco A, Waddell TE, Lingohr E, Johnson RP (2009). Enumeration of bacteriophages by double agar overlay plaque assay. Bacteriophages: Methods and Protocols, Volume 1: Isolation, Characterization, and Interactions: 69-76.

Lasobras J, Dellunde J, Jofre J, Lucena F (1999). Occurrence and levels of phages proposed as surrogate indicators of enteric viruses in different types of sludges. Journal of Applied Microbiology 86: 723-723.

Lee C, Kim J, Shin SG, Hwang S (2006). Absolute and relative QPCR quantification of plasmid copy number in Escherichia coli. Journal of biotechnology 123: 273-280.

Li B, Logan BE (2004). Bacterial adhesion to glass and metal-oxide surfaces. Colloids and Surfaces B: Biointerfaces 36: 81-90. 
Li Y, Heine S, Entian M, Sauer K, Frankenberg-Dinkel N (2013). NO-induced biofilm dispersion in Pseudomonas aeruginosa is mediated by an MHYT domain-coupled phosphodiesterase. Journal of bacteriology 195: 3531-3542.

Liu Y, Li J (2008). Role of Pseudomonas aeruginosa biofilm in the initial adhesion, growth and detachment of Escherichia coli in porous media. Environmental Science \& Technology 42: 443-449.

Logares R, Lindstrom ES, Langenheder S, Logue JB, Paterson H, Laybourn-Parry J et al. (2013). Biogeography of bacterial communities exposed to progressive long-term environmental change. The ISME Journal 7: 937-948.

Løvdal, T., Hovda, M. B., Björkblom, B., \& Møller, S. G. (2011). Propidium monoazide combined with real-time quantitative PCR underestimates heat-killed Listeria innocua. Journal of Microbiological Methods 85.2: 164-169.

Love DC, Silverman A, Nelson KL (2010). Human virus and bacteriophage inactivation in clear water by simulated sunlight compared to bacteriophage inactivation at a southern California beach. Environmental Science \& Technology 44: 6965-6970.

Lyautey E, Jackson CR, Cayrou J, Rols J-L, Garabétian F (2005). Bacterial community succession in natural river biofilm assemblages. Microbial Ecology 50: 589-601.

Marketon MM, Glenn SA, Eberhard A, González JE (2003). Quorum sensing controls exopolysaccharide production in Sinorhizobium meliloti. Journal of Bacteriology 185: 325331.

Marsollier L, Stinear T, Aubry J, Saint André JP, Robert R, Legras P et al. (2004). Aquatic plants stimulate the growth of and biofilm formation by Mycobacterium ulcerans in axenic culture and harbor these bacteria in the environment. Applied and Environmental Microbiology 70: 1097-1103.

Masago Y, Shibata T, Rose JB (2008). Bacteriophage P22 and Staphylococcus aureus attenuation on nonporous fomites as determined by plate assay and quantitative PCR. Applied and Environmental Microbiology 74: 5838-5840.

Matz C, Kjelleberg S (2005). Off the hook - how bacteria survive protozoan grazing. Trends in Microbiology 13: 302-307.

McBride GB, Stott R, Miller W, Bambic D, Wuertz S (2013). Discharge-based QMRA for estimation of public health risks from exposure to stormwater-borne pathogens in recreational waters in the United States. Water Research 47: 5282-5297. 
McDougald D, Rice SA, Barraud N, Steinberg PD, Kjelleberg S (2012). Should we stay or should we go: mechanisms and ecological consequences for biofilm dispersal. Nature Reviews Microbiology 10: 39-50.

Mena KD, Gerba CP (2009). Risk assessment of Pseudomonas aeruginosa in water. Reviews of Environmental Contamination and Toxicology Vol 201. Springer. pp 71-115.

Misstear DB, Gill LW (2012). The inactivation of phages MS2, ФX174 and PR772 using UV and solar photocatalysis. Journal of Photochemistry and Photobiology B: Biology 107: 1-8.

Moore BE, Sagik B, Sorber CA (1981). Viral transport to ground water at a wastewater land application site. Journal (Water Pollution Control Federation): 1492-1502.

Mueller RF (1996). Bacterial transport and colonization in low nutrient environments. Water Research 30: 2681-2690.

Mußmann M, Ribot M, von Schiller D, Merbt SN, Augspurger C, Karwautz C et al. (2013). Colonization of freshwater biofilms by nitrifying bacteria from activated sludge. FEMS Microbiology Ecology 85: 104-115.

National Environmental Agency, Singapore http:/www.nea.gov.sg/anti-pollution-radiationprotection/water-pollution-control/recreational-water-quality

Nocker, Andreas, Ching-Ying Cheung, and Anne K. Camper (2006). Comparison of propidium monoazide with ethidium monoazide for differentiation of live vs. dead bacteria by selective removal of DNA from dead cells. Journal of Microbiological Methods 67.2: 310320 .

O'Melia CR (1980). ES Features: Aquasols: the behavior of small particles in aquatic systems. Environmental Science \& Technology 14: 1052-1060.

O'Neill E, Pozzi C, Houston P, Humphreys H, Robinson DA, Loughman A et al. (2008). A novel Staphylococcus aureus biofilm phenotype mediated by the fibronectin-binding proteins, FnBPA and FnBPB. Journal of Bacteriology 190: 3835-3850.

O'Toole GA, Kolter R (1998). Flagellar and twitching motility are necessary for Pseudomonas aeruginosa biofilm development. Molecular Microbiology 30: 295-304.

Okusu H, Ma D, Nikaido H (1996). AcrAB efflux pump plays a major role in the antibiotic resistance phenotype of Escherichia coli multiple-antibiotic-resistance (Mar) mutants. Journal of Bacteriology 178: 306-308.

Ostroumov, S. A (2004). On the biotic self-purification of aquatic ecosystems: elements of the theory. Doklady Biological Sciences 396: 206-211 
Pandey PK, Soupir ML, Rehmann CR (2012). A model for predicting resuspension of Escherichia coli from streambed sediments. Water Research 46: 115-126.

Pascual A (2002). Pathogenesis of catheter-related infections: Lessons for new designs. Clinical Microbiology and Infection 8: 256-264.

Pereira MO, Kuehn M, Wuertz S, Neu T, Melo LF (2002). Effect of flow regime on the architecture of a Pseudomonas fluorescens biofilm. Biotechnology and Bioengineering 78: 164-171.

Petry S, Furlan S, Crepeau M-J, Cerning J, Desmazeaud M (2000). Factors affecting exocellular polysaccharide production by Lactobacillus delbrueckii subsp. bulgaricus grown in a chemically defined medium. Applied and Environmental Microbiology 66: 3427-3431.

Picioreanu C, Van Loosdrecht MC, Heijnen JJ (2001). Two-dimensional model of biofilm detachment caused by internal stress from liquid flow. Biotechnology \& Bioengineering 72: 205-218.

Pozos N, Scow K, Wuertz S, Darby J (2004). UV disinfection in a model distribution system:: biofilm growth and microbial community. Water Research 38: 3083-3091.

Quiñones B, Dulla G, Lindow SE (2005). Quorum sensing regulates exopolysaccharide production, motility, and virulence in Pseudomonas syringae. Molecular Plant-Microbe Interactions 18: 682-693.

Rajal VB, McSwain BS, Thompson DE, Leutenegger CM, Kildare BJ, Wuertz S (2007). Validation of hollow fiber ultrafiltration and real-time PCR using bacteriophage PP7 as surrogate for the quantification of viruses from water samples. Water Research 41: 14111422 .

Rasmussen TB, Uttenthal Å, De Stricker K, Belak S, Storgaard T (2003). Development of a novel quantitative real-time RT-PCR assay for the simultaneous detection of all serotypes of foot-and-mouth disease virus. Archives of Virology 148: 2005-2021.

Reddy K, Khaleel R, Overcash M (1981). Behavior and transport of microbial pathogens and indicator organisms in soils treated with organic wastes. Journal of Environmental Quality 10: $255-266$.

Ricciardi A, Neves RJ, Rasmussen JB (1998). Impending extinctions of North American freshwater mussels (Unionoida) following the zebra mussel (Dreissena polymorpha) invasion. Journal of Animal Ecology 67: 613-619. 
Rice S, Koh K, Queck S, Labbate M, Lam K, Kjelleberg S (2005). Biofilm formation and sloughing in Serratia marcescens are controlled by quorum sensing and nutrient cues. Journal of Bacteriology 187: 3477-3485.

Riemann, Lasse, Grieg F. Steward, and Farooq Azam (2000). Dynamics of bacterial community composition and activity during a mesocosm diatom bloom. Applied and Environmental Microbiology 66.2: 578-587.

Roberts D, Guegler K, Winter J (1993). Antibody as a surrogate receptor in the screening of a phage display library. Gene 128: 67-69.

Rohde H, Frankenberger S, Zähringer U, Mack D (2010). Structure, function and contribution of polysaccharide intercellular adhesin (PIA) to Staphylococcus epidermidis biofilm formation and pathogenesis of biomaterial-associated infections. European Journal of Cell Biology 89: 103-111.

Romero OC, Straub AP, Kohn T, Nguyen TH (2011). Role of temperature and Suwannee river natural organic matter on inactivation kinetics of Rotavirus and Bacteriophage MS2 by solar irradiation. Environmental Science \& Technology 45: 10385-10393.

Sauer K, Camper AK, Ehrlich GD, Costerton JW, Davies DG (2002). Pseudomonas aeruginosa displays multiple phenotypes during development as a biofilm. Journal of Bacteriology 184: 1140-1154.

Sauer K, Cullen M, Rickard A, Zeef L, Davies D, Gilbert P (2004). Characterization of nutrient-induced dispersion in Pseudomonas aeruginosa PAO1 biofilm. Journal of Bacteriology 186: 7312-7326.

Schriewer A, Wehlmann A, Wuertz S (2011). Improving qPCR efficiency in environmental samples by selective removal of humic acids with DAX-8. Journal of Microbiological Methods 85: 16-21.

Seviour T, Pijuan M, Nicholson T, Keller J, Yuan Z (2009a). Gel-forming exopolysaccharides explain basic differences between structures of aerobic sludge granules and floccular sludges. Water Research 43: 4469-4478.

Seviour T, Pijuan M, Nicholson T, Keller J, Yuan Z (2009b). Understanding the properties of aerobic sludge granules as hydrogels. Biotechnology and Bioengineering 102: 1483-1493.

Shaw T, Winston M, Rupp CJ, Klapper I, Stoodley P (2004). Commonality of elastic relaxation times in biofilms. Physical Review Letters 93: 098102. 
Shen C, Phanikumar MS, Fong TT, Aslam I, McElmurry SP, Molloy SL et al. (2008). Evaluating bacteriophage P22 as a tracer in a complex surface water system: the Grand River, Michigan. Environmental Science \& Technology 42: 2426-2431.

Sinclair RG, Rose JB, Hashsham SA, Gerba CP, Haas CN (2012). Criteria for selection of surrogates used to study the fate and control of pathogens in the environment. Applied and Environmental Microbiology 78: 1969-1977.

Singer G, Besemer K, Hödl I, Chlup A, Hochedlinger G, Stadler P et al. (2006). Microcosm design and evaluation to study stream microbial biofilms. Limnology and Oceanography: Methods 4: 436-447.

Sinton LW, Finlay RK, Lynch PA (1999). Sunlight inactivation of fecal bacteriophages and bacteria in sewage-polluted seawater. Applied and Environmental Microbiology 65: 36053613.

Smith DJ, Underwood GJC (2000). The production of extracellular carbohydrates by estuarine benthic diatoms: the effects of growth phase and light and dark treatment. Journal of Phycology 36: 321-333.

Staley JT, Konopka A (1985). Measurement of in situ activities of nonphotosynthetic microorganisms in aquatic and terrestrial habitats. Annual Reviews in Microbiology 39: 321346.

Stoodley P, Lewandowski Z, Boyle JD, Lappin-Scott HM (1999). Structural deformation of bacterial biofilms caused by short-term fluctuations in fluid shear: An in situ investigation of biofilm rheology. Biotechnology and Bioengineering 65: 83-92.

Stoodley P, Cargo R, Rupp CJ, Wilson S, Klapper I (2002). Biofilm material properties as related to shear-induced deformation and detachment phenomena. Journal of Industrial Microbiology and Biotechnology 29: 361-367.

Teughels W, Van Assche N, Sliepen I, Quirynen M (2006). Effect of material characteristics and/or surface topography on biofilm development. Clinical Oral Implants Research 17: 6881 .

Thomas C, Hill DJ, Mabey M (1999). Evaluation of the effect of temperature and nutrients on the survival of Campylobacter spp. in water microcosms. Journal of Applied Microbiology 86: $1024-1032$.

Thormann KM, Duttler S, Saville RM, Hyodo M, Shukla S, Hayakawa Y et al. (2006). Control of formation and cellular detachment from Shewanella oneidensis MR-1 biofilms by cyclic di-GMP. Journal of Bacteriology 188: 2681-2691. 
Towler BW, Rupp CJ, Cunningham AB, Stoodley P (2003). Viscoelastic properties of a mixed culture biofilm from rheometer creep analysis. Biofouling 19: 279-285.

Toze S (1999). PCR and the detection of microbial pathogens in water and wastewater. Water Research 33: 3545-3556.

Tufenkji N (2007). Modeling microbial transport in porous media: Traditional approaches and recent developments. Advances in Water Resources 30: 1455-1469.

UNEP (2013). Global Environment Outlook 2000, vol. 1. Routledge.

van Loosdrecht MC, Lyklema J, Norde W, Schraa G, Zehnder AJ (1987). The role of bacterial cell wall hydrophobicity in adhesion. Applied and Environmental Microbiology 53: 18931897.

van Loosdrecht MM, Norde W, Lyklema J, Zehnder AB (1990). Hydrophobic and electrostatic parameters in bacterial adhesion. Aquatic Sciences 52: 103-114.

Von Bodman SB, Majerczak DR, Coplin DL (1998). A negative regulator mediates quorumsensing control of exopolysaccharide production in Pantoea stewartii subsp. stewartii. Proceedings of the National Academy of Sciences 95: 7687-7692.

Vuyst D, de Ven V (1998). Production by and isolation of exopolysaccharides from Streptococcus thermophilus grown in a milk medium and evidence for their growthassociated biosynthesis. Journal of Applied Microbiology 84: 1059-1068.

Wakelin SA, Colloff MJ, Kookana RS (2008). Effect of wastewater treatment plant effluent on microbial function and community structure in the sediment of a freshwater stream with variable seasonal flow. Applied and Environmental Microbiology 74: 2659-2668.

Wei G, Yang Z, Cui B, Li B, Chen H, Bai J et al. (2009). Impact of dam construction on water quality and water self-purification capacity of the Lancang River, China. Water Resources Management 23: 1763-1780.

Wemheuer B, Güllert S, Billerbeck S, Giebel H-A, Voget S, Simon M et al. (2014). Impact of a phytoplankton bloom on the diversity of the active bacterial community in the southern North Sea as revealed by metatranscriptomic approaches. FEMS Microbiology Ecology 87: 378-389.

WHO. WHO http://www.who.int/heli/risks/water/water/en/.

Wilhelm L, Singer GA, Fasching C, Battin TJ, Besemer K (2013). Microbial biodiversity in glacier-fed streams. The ISME Journal 7: 1651-1660. 
Wolfe AP, Baron JS, Cornett RJ (2001). Anthropogenic nitrogen deposition induces rapid ecological changes in alpine lakes of the Colorado Front Range (USA). Journal of Paleolimnology 25: 1-7.

Wolyniak E, Hargreaves B, Jellison K (2009). Retention and release of Cryptosporidium parvum oocysts by experimental biofilms composed of a natural stream microbial community. Applied and Environmental Microbiology 75: 4624-4626.

Wymer LJ (2007). Statistical framework for recreational water quality criteria and monitoring, vol. 65. John Wiley \& Sons.

Yoder JS, Hlavsa MC, Craun GF, Hill V, Roberts V, Yu PA et al. (2008). Surveillance for waterborne disease and outbreaks associated with recreational water use and other aquatic facility-associated health events-United States, 2005-2006. MMWR Surveillience Summary 57: 1-29.

Zwart G, Crump BC, Kamst-van Agterveld MP, Hagen F, Han S-K (2002). Typical freshwater bacteria: an analysis of available 16S rRNA gene sequences from plankton of lakes and rivers. Aquatic Microbial Ecology 28: 141-155. 


\section{Biofilms in mesocosm flumes as source and sink of Pseudomonas aeruginosa, P22 bacteriophage and Enterococcus faecalis: a mass balance approach}

\subsection{Abstract}

Pathogen release in freshwater habitats is a serious environmental threat. Human exposure from both direct and indirect consumption of contaminated water has led to a rising number of outbreaks coupled with substantial economic losses in recreational areas. A proper understanding of pathogen fate in natural environments can reduce such occurrences. Yet, most fate and transport studies do not account for properties of the natural systems, such as presence of biofilms at air-water or solid-water interfaces. We studied the fate of four pathogen surrogates - Pseudomonas aeruginosa, Enterococcus faecalis, and bacteriophages P22 and GA - using four open channel flumes with partial recirculation (laminar range) in repeat experiments. Two mesocosm flumes were spiked once with the surrogates and concentrations of both viable populations and nucleic acids monitored in the bulk water and biofilm for $21 \mathrm{~d}$. The remaining flumes were used as controls. We analysed the role of biofilms in the fate of surrogates using a hydrodynamic model based on the mass conservation principle. Within $24 \mathrm{~h}$ surrogates settled in the biofilm in all amended flumes. In addition, Pseudomonas and Enterococcus strains were found to grow within biofilms. Hence settling and decay terms alone could not predict pathogen concentrations in the presence of biofilms. P. aeruginosa also existed as viable but noncultivable cells. .Bacteriophage P22 did not grow due to lack of a proper host, but was retained in the biofilm like the bacterial strains, thus making the biofilm a reservoir long after the initial spike had been cleared from the water phase. Over time biofilms released the surrogates back into the water, thereby increasing the length of time required for their complete removal from the flumes from one to 
two days to up to a week or longer depending on the surrogate. Of the three surrogates, $P$. aeruginosa, at first, was released continuously from the biofilm due to detachment. Later, the release was more random and involved much higher concentrations than would be expected due to physical detachment mechanisms, suggesting a biological phenomenon such as dispersal. P22 was continuously released due to erosion and no dispersal was observed. Release of E. faecalis from biofilm could not be determined due to very low concentrations present. Finally, our analysis suggested that decay and growth rates of surrogates in a biofilm are different from those of planktonic cells and parameters like TSS and grazing can influence them. Understanding the forces that allow pathogens to persist in biofilms may lead to improved prediction of risk of exposure in natural systems, thus opening doors for better management strategies. 
Nomenclature:

$\mathrm{Re}=$ Reynolds number

$\mathrm{r}_{\mathrm{h}}=$ Hydraulic radius

$\mathrm{u}_{\mathrm{m}}=$ mean bulk fluid velocity

$v=$ coefficient of kinematic velocity

$\mathrm{A}_{\mathrm{c}}=$ cross sectional area of the system

$\mathrm{P}_{\mathrm{c}}=$ wetted perimeter of the system

$i$ : Surrogate of species $i$

$k_{i}$ : Net specific decay rate constant of surrogate $i$, considers net specific decay and growth in the system $\left(\mathrm{d}^{-1}\right)$

$v_{r}$ : Detachment velocity of surrogate from biofilm $\left(\mathrm{cm} \mathrm{d}^{-1}\right)$

$v_{s}$ : Settling velocity of surrogate on biofilm $\left(\mathrm{cm} \mathrm{d}^{-1}\right)$

$V$ : Flume volume (L)

$A_{b}$ : Area of biofilm in contact with the water, assuming that the biofilm is continuum non-porous $\left(\mathrm{cm}^{2}\right)$

$\rho$ : Specific linear volume of biofilm $\left(\mathrm{cm}^{-1}\right)$

$H$ : Height of water column $(\mathrm{cm})$

$Q_{s p}$ : Flow rate at which spike of surrogate is added in to flume $\left(\mathrm{Ld}^{-1}\right)$

$Q_{\text {in }}:$ Flow rate in inlet pipe $\left(\mathrm{Ld}^{-1}\right)$
$Q_{b}$ : Flow rate of surrogates entering water from the biofilm $\left(\mathrm{Ld}^{-1}\right)$

$Q_{s}:$ Flow rate at which surrogates are settling on biofilm $\left(\mathrm{Ld}^{-1}\right)$

$Q_{\text {out }}:$ Flow rate in outlet pipe $\left(\mathrm{Ld}^{-1}\right)$

$C_{i}^{w}$ : Concentration of surrogate $i$ in water (cfu/pfu/gc L ${ }^{-1}$ ), at time $t$

$C_{i}^{s p}$ : Concentration of surrogate $i$ in spike (cfu/pfu/gc L ${ }^{-1}$ ), at time t.

$C_{i}^{i n}$ : Concentration of surrogate $i$ in inlet pipe (cfu/pfu/gc L $\left.{ }^{-1}\right)$, at time $t$

$C_{i}^{\text {out }}$ : Concentration of surrogate $i$ at outlet pipe (cfu/pfu/gc L ${ }^{-1}$ ), at time $t$

$C_{i}^{b}$ : Concentration of surrogate $i$ on the surface of the biofilm ( $\mathrm{cfu} / \mathrm{pfu} / \mathrm{gc} \mathrm{cm}^{-2}$ ), at time $t$

$C_{i, 0}^{w}$ : Concentration of surrogate $i$ in the water $\left(\mathrm{cfu} / \mathrm{pfu} / \mathrm{gc} \mathrm{L}^{-1}\right)$ at initial time $(t: 0)$ :

$F_{p}$ : Fraction of surrogate attaching to the biofilms, either due to superficial interactions or to settling of suspended particles with adsorbed surrogates

$P$ : Fraction of surrogates detaching from the biofilm

$t:$ Time $(\mathrm{d})$

$\mathrm{n}=$ number of measurements 


\subsection{Introduction}

In the past few decades, global freshwater usage increased at an unprecedented rate (WHO). Simultaneously, the quantity and diversity of pollutants entering freshwater bodies also increased (UNEP 2013). Among these pollutants, pathogens are an emerging threat. Pathogens are often released into aquatic environments through rare events such as sewage leaks or seasonal events like heavy rainfall (McBride et al. 2013) or by shedding from the recreating public (Craun et al. 2005). In the United States alone, in 2012, among 3762 coastal recreation beaches, $40 \%$ had one or more advisory or closure notices due to an excess of applicable bacteria levels (Kim and Wuertz 2015). In tropical urban cities like Singapore, human pathogens including Norovirus GI and GII (Aw et al. 2009), Astrovirus, Enterovirus, Adenovirus and Hepatitis A virus (Aw and Gin 2011) have been detected in urban waters in the recent past.

Pathogen contamination of water affects the quality of life of the public and results in major economic losses. A recent study reported that in the US, water-borne pathogens have led to more than 40,000 hospitalization cases per year resulting in $\$ 970$ million losses each year (Ralston et al. 2011). The scenario is worse in developing places where untreated freshwater is often consumed directly. Yet, very few countries have strict guidelines to account for pathogen contamination. Even when guidelines are present, they do not include monitoring actual levels of waterborne pathogenic bacteria and viruses, or consider the potential pathogen reservoir present in biofilms.

Biofilms are defined as clusters of cells embedded in extracellular polymeric substances or EPS, most commonly forming at an air-water or solid-water interface. When pathogens are released in to the environment where interfaces are present, like water bodies, they interact with the existing biofilms. The biofilm mode is considered to be the preferred mode of life for microorganisms in natural ecosystems (Costerton et al. 1995) as biofilms offer several 
benefits to the microorganisms in terms of survival. For example, it has been shown using flow cells and animal models that pathogenic microorganisms in biofilms survive longer than planktonic cells when subjected to antibiotics (Stewart and William Costerton 2001), dehydration (Chang et al. 2007), UV irradiation (Elasri and Miller 1999) and the host immune system (Leid et al. 2005). But even though biofilms and their role in the survival of pathogens are well studied in medical settings, the role of freshwater biofilms in survival of waterborne pathogens is unclear.

In fate and transport models, pathogens have been treated as planktonic cells and the substratum has been considered as an inert surface which can function as a source and sink of pathogens depending on surface chemistry and surface properties (Benham et al. 2006). But as biofilms are not inert surfaces and their properties vary depending on several environmental conditions, their role in pathogen persistence is more than simple adsorption. Stochastic modeling has been used to show that stream beds and submerged macrophytes act as long term reservoirs of some pathogens (Drummond et al. 2015). In recirculating flumes, microspheres tended to be deposited more in beds colonized with biofilm compared to a sand-coated bed (Arnon et al. 2010). Increased survival time of pathogens in the presence of biofilm has also been reported in biphasic microcosms (Buswell et al. 1998). In contrast, indigenous microorganisms may inhibit growth of invading pathogens in certain environments (van Veen et al. 1997).

It can be hypothesized that if waterborne pathogens can get integrated or grow within benthic biofilms, they can also continue to be released long after their initial introduction into the aquatic system through continuous passive erosion or "seeding dispersal" (McDougald et al. 2012). Additionally, pathogens may be released in greater amounts during events of sloughing resulting from a sudden high shear or burrowing activities of grazers, if present. These releases will pose a threat to the recreating public. In this study, we addressed two 
research questions: i) Can biofilms in waterways act as repository of human pathogens and ii) can physicochemical processes (settling, decay and detachment) alone account for the fate of pathogens in fresh water systems? By studying pathogen survival in the presence of a mature photosynthetic biofilm, we mimicked actual conditions present in natural water bodies, allowing for a better understanding of the long term persistence of these pathogens.

\subsection{Materials and Methods}

\subsubsection{Surrogate preparation}

The fate of four different microorganisms, Pseudomonas aeruginosa (SS1), Enterococcus faecalis (ATCC 47077), and the bacteriophages P22 (ATCC 97541) and GA (SW1) were studied. The Pseudomonas aeruginosa strain was isolated from sediments of an urban canal in Singapore, using culture based methods. Briefly, the sediments were serially diluted in physiological saline $(0.85 \%, \mathrm{NaCl}, \mathrm{w} / \mathrm{v})$ and then plated on King's $\mathrm{B}$ agar (KBA) medium. The plates were incubated at $30{ }^{\circ} \mathrm{C}$ for $48 \mathrm{~h}$ and the colonies were sequenced (16S) to verify the phylogenetic identity. Subsequently, the isolated strain was cultured in M9 minimal medium (48 mM Na $2 \mathrm{HPO}_{4} ; 22 \mathrm{mM} \mathrm{KH} \mathrm{KHO}_{4} ; 9 \mathrm{mM} \mathrm{NaCl} ; 19 \mathrm{mM} \mathrm{NH} 4 \mathrm{Cl} ; 2 \mathrm{mM}$ $\mathrm{MgSO}_{4} \cdot \mathrm{H}_{2} \mathrm{O} ; 0.1 \mathrm{mM} \mathrm{CaCl}$ and $0.04 \%$ (w/v) glucose) supplemented with $0.2 \%$ (w/v) casamino acids. These surrogates were selected to represent specific groups of water borne pathogens, like Gram positive and Gram negative bacteria, double stranded DNA viruses and single stranded RNA viruses.

P. aeruginosa and E. faecalis were grown overnight at $37^{\circ} \mathrm{C}$, in nutrient broth and brain heart infusion broth, respectively. After incubation, the bacteria were washed and resuspended in 1X PBS. Culturing the bacteriophages was a two-step process. First, overnight cultures of the host bacteria were prepared. The host strain for P22 was Salmonella enterica serovar typhimurium (ATCC 19585), and that of GA was Escherichia coli (ATCC 23631). Both strains were grown overnight in LB broth at $37^{\circ} \mathrm{C}$. Once the cultures had reached log phase of 
growth, $100 \mu \mathrm{L}$ of the host bacteria and $500 \mu \mathrm{L}$ of the phage were added to $5 \mathrm{~mL}$ of sterile LB broth and incubated at $37^{\circ} \mathrm{C}$ for 12 to $18 \mathrm{~h}$. At the end of the incubation, the culture was centrifuged at $10,000 \mathrm{~g}$ for $8 \mathrm{~min}$ and the supernatant was filtered through a $0.2-\mu \mathrm{m}$ syringe filter to remove the host bacteria.

\subsubsection{Mesocosm design}

Four open channel flumes with partial recirculation were used in duplicate studies (Fig 2.1A and B). The flow rate inside the flume was controlled with the recirculation flow rate. For this study, the flow rate was selected so as to correspond to the dry weather flow conditions in Singapore's urban canals (Saxena 2014). This flow rate is in the laminar range and corresponds to a Reynolds number of 359 (laminar range for open channel flow is <1000). The Reynolds number was calculated as described in previous works (Singer et al. 2006, Venugopalan et al. 2005). Briefly, the Reynolds number is defined as the ratio of inert forces to frictional forces in a flow and for rectangular channels can be calculated as per the following equation.

$R e=\frac{r_{h} \cdot u_{m}}{v}$ Equation 2.1

and,

$r_{h}=\frac{A_{c}}{P_{c}}$

Equation 2.2

Where Re the dimensionless the Reynolds number, $r_{h}$ is the hydraulic radius, $\mu \mathrm{m}$ is the mean bulk fluid velocity, $v$ is the coefficient of kinematic velocity $A_{c}$ is the cross sectional area of the system and $P_{c}$ is the wetted perimeter of the system. The flumes were set up in an outdoor research facility (Van Kleef Center) next to an urban canal (Sungei Ulu Pandan) in Singapore. The location was selected to ensure that experimental conditions, including diurnal cycles, temperature and relative humidity, were similar to those in the canals. 
The reactors were fabricated using $1.8 \mathrm{~cm}$ thick acrylic glass sheets. Each reactor was 235.1 cm long (internal length: $220 \mathrm{~cm}$ ), $18.6 \mathrm{~cm}$ wide (internal width: $10 \mathrm{~cm}$ ) and $16.8 \mathrm{~cm}$ high (internal height: $15 \mathrm{~cm}$, water height $10 \mathrm{~cm}$ ). Ten centimeters of reactor space along the length on the extreme ends of the reactors was isolated from rest of the reactor using $0.5 \mathrm{~cm}$ thick partitions with $5 \mathrm{~mm}$ perforations on the top $(10 \mathrm{~cm})$ and $2 \mathrm{~mm}$ perforations at the bottom $(5 \mathrm{~cm})$, to smoothen the flow of recirculating water. The set-up was kept on an elevated platform which was shared by two reactors. Polyvenyl chloride (PVC) sheets were raised between the reactor mixing tanks to prevent cross contamination due to splattering. Reactors were covered with fine mesh to prevent any contamination from debris deposition (dried leaves, etc.) and outdoor animals (birds).

Each reactor was fitted with its own recirculation and replacement circuit. The recirculation circuit included water outflow, sink, connecting PVC pipes $(32 \mathrm{~mm})$, centrifugal pump (Eheim 5000, 41.5-83.3 $\mathrm{Lmin}^{-1}$ ) and gate valves. The replacement circuit included replacement water tanks (PVC150L), silicon tubes $(5 \mathrm{~mm})$, peristaltic pump (MasterFlex L/S® Easy-Load® II), connector PVC piping and two-stop pump tubing (silicone platinumcured) tubes: MasterFlex L/S® 16). To keep the same flow across inlet and outlet of fresh water, a single peristaltic pump was used for incoming as well as outgoing water. Two flumes, one with and another without added surrogates used water from one feed tank.

Prior to each experiment, the flumes were primed by operating them with fresh canal water for three weeks. The microbial inoculum present in canal water settled in the flume and facilitated growth of a mature benthic photosynthetic biofilm that closely resembled biofilms found in the shallow depths of freshwater systems (Fig S.2.1). We excluded sediments from our system to have a low nutrient surface, which represented naturally occurring interfaces. After priming, two flumes were spiked with $50 \mathrm{ml}$ of each bacterial strain (in PBS) and bacteriophage (in LB broth). Phages were kept suspended in media because, unlike bacteria, 
they could not be removed by centrifugation alone and more rigorous removal processes might have lead to losses. Additionally, the volume of medium added was insignificant compared to the total volume of the flumes, thus ensuring that there was no significant increase in nutrient concentration. The surrogates were added to the mixing tank of each flume. The average concentrations of the bacterial strains and phages were $10^{9} \mathrm{cfu} \mathrm{mL}^{-1}$ and $10^{11} \mathrm{pfu} \mathrm{mL}^{-1}$ respectively. The remaining two flumes were used as procedural controls and received equal volumes of sterile $1 \mathrm{X}$ PBS and LB media (Fig 2.2). The changes in concentration of viable cells/particles and nucleic acids of the added surrogates in the bulk water and biofilm were monitored for the next $20 \mathrm{~d}$. Water and biofilm samples were collected on alternate days using sterile syringes. Samples were collected from the middle section of the flume (100 cm length wise) to obtain an area receiving smooth flow. Samples were then collected in triplicates across the length. Water samples were collected first, without disturbing the underlying biofilm. After collecting samples for surrogate quantification, water quality parameters such as $\mathrm{pH}$, temperature, dissolved oxygen (DO) and conductivity in feed water as well as within the flumes were determined using a standard handheld instrument (YSI Professional Plus, United States) Dissolved organic carbon levels were measured using a total organic carbon (TOC) analyzer (TOC-L series, Shimadzu).

\subsubsection{Quantification of P.aeruginosa, E. faecalis, P22 and GA}

The $P$. aeruginosa viable population was estimated using the membrane filter technique (Legnani et al. 1999). Briefly, a volume of water was filtered through a $0.2-\mu \mathrm{m}$ sterile nitrocelluloase filter. The filter was then placed on Cetrimide agar and incubated at $37^{\circ} \mathrm{C}$. Viable E. faecalis cells were determined similarly using MEI agar as medium, which was then incubated at $42^{\circ} \mathrm{C}$ for $24 \mathrm{~h}$. Viable bacteriophages were enumerated using the double agar layer (DAL) method (Kropinski et al. 2009). Briefly, $500 \mu 1$ of sample (or appropriate dilutions) and $100 \mu \mathrm{L}$ of respective host were added to $5 \mathrm{~mL}$ of semisolid $\mathrm{LB}$ agar and mixed 
using a vortex. The media was then poured over a solidified LB agar plate and allowed to rest until the top semisolid layer solidified. The plates were then incubated at $37{ }^{\circ} \mathrm{C}$ overnight and number of plaque forming units was counted.

For measuring nucleic acid concentrations, $500-1000 \mu \mathrm{L}$ of water sample was extracted using Purelink viral DNA/RNA Minikit following manufacturers' instructions. Cell lysis was achieved through bead beating using a combination of glass, ceramic and silica beads (FastPrep Lysing matrix E, FastPrep homogenizer, MP BioMedicals). Biofilms were homogenized with $1 \mathrm{X}$ sterile phosphate buffered saline. $500 \mu \mathrm{L}$ of homogenate was then used for DNA extraction. For GA phage, a further step of cDNA preparation was required. cDNA was generated using Superscript III first strand synthesis system (Invitrogen ${ }^{\mathrm{TM}}$ ) following the manufacturer's protocol.

Taqman qPCR assays for P. aeruginosa (Volkmann et al. 2007), E. faecalis (Santo Domingo et al. 2003), P22 (Masago et al. 2008) and GA (Ogorzaly and Gantzer 2006) were adopted from previous studies (Table 2.1). These assays were selected after verifying that they do not cross react with other surrogates or non-spiked canal water and biofilm. Reactions were performed in a StepOne Real Time PCR System (Applied Biosystems, Foster City, CA, USA). Each $25 \mu \mathrm{L}$ qPCR reaction volume contained $12.5 \mu \mathrm{L}$ of Taqman Universal Mastermix II, with UNG (Applied Biosystems, Foster City, CA, USA), $5 \mu \mathrm{L}$ of nucleic acid extract, and appropriate concentrations of primers and probes and DNAse-RNAse -free water to complete the reaction volume.

Negative controls were prepared in a similar way replacing nucleic acids with DNAse RNAse free water. Thermal cycling conditions were 2 min at $50{ }^{\circ} \mathrm{C}$ followed by 10 min at $95{ }^{\circ} \mathrm{C}$, followed by 40 cycles of $15 \mathrm{~s}$ at $95{ }^{\circ} \mathrm{C}$ and $1 \mathrm{~min}$ at $60{ }^{\circ} \mathrm{C}$. A serial dilution approach was employed for each sample to remove potential PCR inhibitors that might be present in the 
sample (Schriewer et al. 2011). Sample limits of detection $\left(\mathrm{S}_{\mathrm{LOD}} \mathrm{s}\right)$ were calculated as previously described (Table 2.1). Briefly, $\mathrm{S}_{\mathrm{LOD}} \mathrm{S}$ for water and biofilm phases were calculated as

$$
S_{L O D, \text { water }}=\frac{A_{L O D} \times V_{N . A . E} \times I}{V_{T e m p} \times E_{N . A . E} \times V_{\text {Sample }}}
$$

and

$$
S_{L O D, \text { Biofilm }}=\frac{A_{L O D} \times V_{N . A . E} \times I}{V_{T e m p} \times E_{N . A . E} \times A_{\text {Sample }}},
$$

where, $A_{L O D}$ is the assay limit of quantification, $V_{\text {N.A.E }}$ is volume of sample used for nucleic acid extraction, $I$ is the dilution necessary to produce a positive PCR result and is expressed as the inverse of the dilution factor, $V_{\text {Temp }}$ is volume of nucleic acid template added to the PCR reaction, $E_{\text {N.A.E }}$ is nucleic acid extraction efficiency, and $V_{\text {sample }}$ and $A_{\text {sample }}$ are original sample volume and area for water and biofilm, respectively (Rajal et al. 2007).

\subsubsection{Decay rate calculation}

Decay rates of the target surrogates were determined in a separate microcosm experiment using six 1000-mL glass bottles, each fitted with four glass tubes and sealed using rubber stoppers. The tubes were used for aeration and sample collection. The open ends of two tubes were fitted with a $0.2-\mu \mathrm{m}$ syringe filter to ensure passage of sterile ambient air. The microcosms were set up at the Van Kleef Center, Singapore. They were placed on a table top in the outdoor shed to ensure similar ambient conditions as the flume experiments. Aeration was provided to increase levels of dissolved oxygen in the water to levels found in flumes where photosynthesizing algae were present on the bed.

Five of the microcosms were spiked with overnight cultures of $P$. aeruginosa, E. faecalis, $\mathrm{P} 22$ and GA. The final concentration of the individual surrogates in each flask was roughly $10^{7}$ units $\mathrm{mL}^{-1}$. The remaining bottle was spiked with an equal volume of sterile medium and 
considered to be the procedural control. After spiking, samples were collected every alternate day for 2 weeks. Both viable counts of surrogates and nucleic acid concentrations were determined as described in previous sections.

The decay rate of $P$. aeruginosa was calculated by a first order exponential decay model containing a lag period before the beginning of logarithmic decay: $N=N_{0} \times e^{-k\left(t-t_{0}\right)}$, where $t_{0}$ is the time at the end of lag period, $t$ is any time after lag period, $N$ is the number of gene copies of cells at time $t, N_{0}$ is the initial concentration, and $k$ is the decay rate constant. Decay rates of E. faecalis and P22 were calculated using a first order exponential decay model $N=N_{0} \times e^{-k t}$. Non-linear regression analysis and curve fitting were done using SigmaPlot $^{\mathrm{TM}} 12$ (Systat Software Inc, San Jose, CA).

\subsubsection{Model description: Water phase}

A simple mass balance model was developed to predict the fate of surrogates in bulk water. The purpose of the model was to understand the extent to which different processes affected the fate of the surrogates and whether growth of surrogates had occurred. Flumes were treated as a well-mixed control volume with one inflow and one outflow. The system received surrogate load from three sources, as follows:

- A pulse input from the spiking event at the start of the experiment

- A continuous input from native populations, if present, entering the system through the inflow

- A continuous input from the underlying biofilm reaching the bulk water through resuspension (detachment).

Mass Balance equation for water phase can be written as:

$$
V \frac{d C_{i}^{w}}{d t}=Q_{s p} C_{i}^{s p}+Q_{\text {in }} C_{i}^{i n}+Q_{b} \rho C_{i}^{b}-Q_{\text {out }} C_{i}^{o u t}-Q_{s} C_{i}^{w}-k_{i} C_{i}^{w} V \quad \text { Equation } 2.5
$$


Experimentally it was observed that the system was well mixed, i.e.

$C_{i}^{\text {out }}=C_{i}^{w}$

Equation 2.6

Additionally, since area of biofilm and settling and resuspension velocity of particle associated surrogate $i$ and fraction of surrogate attached to particles is known,

$Q_{b}=v_{r} A_{b} P$

Equation 2.7

and,

$Q_{s}=v_{s} A_{b} F_{p}$

Equation 2.8

Hence, equation 5 can be written as,

$V \frac{d C_{i}^{w}}{d t}=Q_{s p} C_{i}^{s p}+Q_{\text {in }} C_{i}^{i n}+v_{r} A_{b} P \rho C_{i}^{b}-\left(Q_{o u t}+v_{s} A_{b} F_{p}+k_{i} V\right) C_{i}^{w} \quad$ Equation 2.9

Or,

$\frac{d C_{i}^{w}}{d t}+\lambda^{w} C_{i}^{w}=\frac{Q_{s p} C_{i}^{s p}+Q_{i n} C_{i}^{i n}+v_{r} A_{b} P \rho C_{i}^{b}}{V}$

Equation 2.10

where,

$\lambda^{w}=\frac{Q_{o u t}+v_{s} A_{b} F_{p}+k_{i} V}{V}=\frac{Q_{o u t}}{V}+\frac{v_{s} F_{p}}{H}+k_{i}$

Equation 2.11

assuming that the biofilm developed covering the base of the flume so $V=A_{b} H ; C_{i}^{b}$ and $C_{i}^{i n}$ are experimentally determined.

In equation 10 , the flow mass rate of surrogates added through spiking $\left(Q_{s p} C_{i}^{s p}\right)$ can be modeled as a pulse load. This can be defined as $m \delta(t)$ (Chapra 2008), where $m$ is the mass of surrogates added during spiking and $\delta(t)\left(\right.$ in $\left.^{-1}\right)$ is the Dirac function (or impulse function) defined as $\delta(t)=1$ for $t=0, \delta(t)=0$ for $t \neq 0$ and $\int_{-\infty}^{\infty} \delta(t) d t=$ 1. Then, 
$\frac{d C_{i}^{w}}{d t}+\lambda^{w} C_{i}^{w}=\frac{m \delta(t)+Q_{i n} C_{i}^{i n}+v_{r} A_{b} \rho P C_{i}^{b}}{V}$

$Q_{i n} C_{i}^{i n}$ was experimentally determined every day and $v_{r} A_{b} P \rho C_{i}^{b}$ was introduced in the water only after the initial event of spiking, and was measured daily. Hence, $\left(\frac{Q_{i n} C_{i}^{i n}+v_{r} A_{b} P C_{i}^{b}}{V}\right)$ which captures additional introduction of surrogates into the water, is a known value obtained through measurement.

Equation 12 is a non-homogeneous, linear, first order, ordinary differential equation, and can thus be solved for temporal change in concentration due to spiking and additional surrogates introduced through biofilm detachment and feed. Temporal change in spiked concentration can be solved as

$$
\begin{aligned}
& C_{i}^{w}=\left(\frac{m}{V}-\frac{Q_{i n} C_{i}^{i n}+v_{r} A_{b} \rho P C_{i}^{b}}{V \lambda^{w}}\right) e^{-\lambda^{w} t}+\left(\frac{Q_{i n} C_{i}^{i n}+v_{r} A_{b} \rho P C_{i}^{b}}{V \lambda^{w}}\right) \\
& C_{i}^{w}=C_{i, 0}^{w} e^{-\lambda^{w} t}+\left(\frac{Q_{i n} C_{i}^{i n}+v_{r} A_{b} \rho P C_{i}^{b}}{V \lambda^{w}}\right)\left(1-e^{-\lambda^{w} t}\right)
\end{aligned}
$$

Equation 2.14

Model parameters and their sources are given in Supplementary Table S.2.1. Basic assumptions made in the calculations are listed in Box 1. Resuspension (detachment) velocity was calculated as previously described (Kim and Wuertz 2015).

\subsubsection{Model description: Biofilm phase}

A similar mass balance model was also developed for the surrogate concentrations in the biofilm. The biofilm receives the surrogates from the overlying water column through settling. A portion of the settled load is lost from the biofilm at the same time through detachment. The surrogates also undergo decay or growth within the biofilm. Hence, at any given time, the concentration of surrogates in the water can be written as,

$$
A_{b} \frac{d C_{i}^{b}}{d t}=Q_{s} C_{i}^{w}-Q_{b} \rho C_{i}^{b}-k_{i} C_{i}^{b} A_{b}
$$

Substituting $Q_{b}=v_{r} A_{b} P$ and, $Q_{s}=v_{s} A_{b} F_{p}$, Equation 2.15 can be written as, 
$A_{b} \frac{d c_{i}^{b}}{d t}=v_{s} A_{b} F_{p} C_{i}^{w}-v_{r} A_{b} \rho P C_{i}^{b}-k_{i} C_{i}^{b} A_{b}$

Equation 2.16

Or,

$\frac{d c_{i}^{b}}{d t}+\lambda^{b} C_{i}^{b}=v_{s} F_{p} C_{i}^{w}$

Equation 2.17

Where $\lambda^{b}=v_{r} \rho P+k_{i}$ and $C_{i}^{w}=C_{i, 0}^{w} e^{-\lambda^{w} t}+\left(\frac{Q_{i n} C_{i}^{i n}+v_{r} A_{b} \rho P C_{i}^{b}}{V \lambda^{w}}\right)\left(1-e^{-\lambda^{w} t}\right)$, where, $C_{i, 0}^{w}$ is experimentally determined.

Equation 2.17 can be solved as,

$C_{i}^{b}=\left(C_{i, 0}^{b}-\frac{v_{S} F_{P} C_{i}^{w}}{\lambda^{b}}\right) e^{-\lambda^{b} t}+\frac{v_{S} F_{P} C_{i}^{w}}{\lambda^{b}}$

Equation 2.18

Or,

$C_{i}^{b}=C_{i, 0}^{b} e^{-\lambda^{b} t}+\frac{v_{S} F_{P} C_{i}^{w}}{\lambda^{b}}\left(1-e^{-\lambda^{b} t}\right)$

Equation 2.19 


\section{Box 2.1 Assumptions for the model}

1. System is well mixed

2. Decay rates in batch culture are similar to decay rates in flumes. The decay rate is the net decay rate accounting for a combination of both decay and growth in the system. The decay in the system is result of a combination of photo-oxidative decay and predator grazing. The decay rate has been assumed to be the same in water and in the benthic algal biofilm.

3. Fraction of surrogates attached to particles, $\mathrm{Fp}=0.7$, is considered to be attached to fine particles (Bai and Lung 2005)

4. Settling velocity, $\mathrm{V}_{\mathrm{s}}=0.01 \mathrm{~cm} / \mathrm{min}$ (typical settling velocity of green algae (Gonenc and Wolflin 2004). It is assumed that surrogates settle only after getting associated with suspended particles.

5. Suspended solids concentration in water column $=200 \mathrm{mg} / \mathrm{L}$ or $0.2 \mathrm{mg} / \mathrm{mL}$ ( Kim and Wuertz 2015)

6. Porosity of algal biofilm $=0.5$ (Battin et al. 2003)

7. The term "detachment" is calculated based on physical process of particle removal from the bed through resuspension. In this study, the term is referred to as a lumped factor, accounting for both dispersion and resuspension.

8. $\mathrm{V}_{\mathrm{r}}=0.002 \mathrm{md}^{-1}$ (Calculated based on Kim and Wuertz, 2015)

\subsubsection{Fit Statistics}

Residual error between the data points and model predictions were calculated using average percent relative error and root mean error.

Average Error $=\frac{\sum_{i}^{n}\left(\frac{\left|\widehat{c}_{i}\left(t_{i}\right)-C_{i}\left(t_{i}\right)\right|}{\widehat{c}_{i}\left(t_{i}\right)}\right.}{n} \times 100 \%$ Equation 2.18 
Root Mean Squared Error $=\sqrt{\frac{\sum_{i}^{n}\left(\left(\widehat{C}_{l}(t)_{i}-C_{i}(t)_{i}\right)^{2}\right.}{n-1}}$

Equation 2.19

Mass balance models and model errors were prepared using Microsoft Excel 2010.

\subsection{Results}

\subsubsection{Measured concentrations of surrogates in water and biofilm phase}

The decay rates of P. aeruginosa, P22 and E. faecalis as estimated from the batch study were $0.96,0.58$ and $2.4 \mathrm{~d}^{-1}$ for the viable population and $0.83,0$ and $0.86 \mathrm{~d}^{-1}$ for DNA, respectively (Table S.2.1). The rate constants give an initial idea about the behavior of surrogates in the flumes. P. aeruginosa and P22 were found to have comparable decay rates for viable populations, whereas $P$. aeruginosa and E. faecalis DNA decayed at similar rates. E. faecalis had the highest decay rate for both viable cells and DNA. P22 DNA was not found to be decaying under the experimental conditions. For all surrogates, DNA decay was lower than decay of respective cultivable populations.

In the flume studies, concentrations of P. aeruginosa, P22 and E. faecalis in the water phase decreased with time. GA was not detected in any sample due to a sampling error leading to insufficient target (RNA) for quantification. The two replicate experiments showed good agreement (Fig 2.3A- F).

Most of the viable cells of $P$. aeruginosa added $\left(\approx 10^{7} \mathrm{cfu} \mathrm{mL}^{-1}\right)$ were removed steadily from the water phase by the end of week 1 (Fig 2.3. A). Later, the bacteria were detected in the water phase randomly, for example, on day 14 and day 20 in one of the flumes in concentrations of $10 \mathrm{cfu} \mathrm{mL}^{-1}$ and $40 \mathrm{cfu} \mathrm{mL}^{-1}$. In contrast, the DNA (added as cells in initial concentrations of $\approx 10^{7} \mathrm{gc} \mathrm{mL}^{-1}$ ) was detected for 10-12 days. DNA was removed at a rate similar to that of cells until day 2 , after which the removal was slower and the concentration remained almost constant $\left(\approx 10^{2}-10^{3} \mathrm{gc} \mathrm{mL}^{-1}\right)$ until the middle of week 2 . After that, the 
DNA was detected once more, at a high concentration $\left(10^{5} \mathrm{gc} \mathrm{mL}^{-1}\right)$, on day 12 in one of the flumes.

Concentration profiles of $\mathrm{P} 22$ phage resembled those of $P$. aeruginosa. The removal rates of viable paticles and DNA remained similar initially (until day 4), after which removal of DNA continued at a slower rate (Fig 2.3B). The removal rate of the phage was slower in comparison to that of $P$. aeruginosa, which may be due to their different decay kinetics. After day 10, P22 DNA concentrations remained almost constant $\left(10^{4} \mathrm{gc} \mathrm{mL}^{-1}\right)$, whereas the infectious particles were no longer detected.

E. faecalis cells were detected at low concentrations $\left(\approx 10^{1} \mathrm{cfu} / 100 \mathrm{~mL}\right)$ during the entire experiment (3.C). However, DNA concentrations could not be detected after day 5, except once on day $10\left(10^{2} \mathrm{gc} \mathrm{mL}^{-1}\right)$. The continuous detection of viable cells is due to the lower detection limit of viable cells compared to DNA (Table 2.1). In the membrane filtration assay, used for detecting viable cells, a much larger sample volume was analyzed thus leading to a more sensitive, but time consuming detection of E. faecalis.

There were no P. aeruginosa or P22 detected in the canal water used as feed. However, the feed was found to contain an autochthonous E. faecalis population $\left(10^{0}-10^{2} \mathrm{cfu}\right.$ or $\left.\mathrm{gc}^{-1}\right)$. The presence of E. faecalis in the feed water made it difficult to differentiate between spiked and authochthonous populations.

A small fraction of the surrogates added (approximately $<10 \%$ at the time of spiking) was detected in the biofilms from day 1 . Both viable cells and nucleic acids of P. aeruginosa were detected during the entire experiment (Fig 2.3.D), even when P. aeruginosa were removed from the water phase. The concentrations in the biofilm remained almost constant once the spike was washed out from the system $\left(10^{3}-10^{4}\right.$ cfu or $\left.\mathrm{gc} \mathrm{mL}^{-1}\right)$, suggesting very little loss. 
There was occasional increase in concentrations which may be due to growth within the biofilms.

In the case of $\mathrm{P} 22$, the proportion of phages that had settled on the bed $\left(10^{0}-10^{1} \mathrm{pfu} \mathrm{mL}^{-1}\right)$ remained viable for two weeks (Fig 2.3.E). P22 DNA was detected for the entire duration of the experiment. Similar to $P$. aeruginosa, the concentration of P22 also remained quite constant. However, the ratio of DNA to infectious phage was much higher than the ratios of DNA and live cells of specific bacteria. This indicates that even though net removal rate of P22 was low, the phage rapidly lost infectivity in the biofilm. No hosts for P22 were detected in the water or biofilm and hence growth of this phage was unlikely.

The E. faecalis viable population in biofilms had decreased markedly from $10^{5} \mathrm{cfu}^{-1}$ to $10^{0} \mathrm{cfu} \mathrm{mL}^{-1}$ by day 6 (Fig 2.3.F). No viable cell was detected between days 6 and 10. During this period no E. faecalis cells were detected in the feed either. For the remainder of the study the E. faecalis viable cell concentration remained almost constant $\left(10^{0}-10^{1} \mathrm{cfu} \mathrm{mL}^{-1}\right)$. However, for all positive detections in the biofilm, there was a simultaneous detection in feed water $\left(10^{0}-10^{1} \mathrm{cfu} \mathrm{mL}^{-1}\right)$. E. faecalis DNA concentration decreased over time, but the rate of decrease was slower than that of the viable cells. DNA was detected once between days 6 and 10. However, it was no longer detected after day 12. These patterns suggest that the $E$. faecalis in biofilms may have recently settled on the bed from the feed and were not derived from the original inoculum. This would also explain why both DNA and viable cells were detected at the beginning, when two sources (added and autochthonous) were present, but only viable cells were being detected later (by the assay with higher sensitivity) when only the autochthonous population was present. No spatial pattern was found in concentration of surrogates in biofilm and variation (SE) between samples collected across the length of the flume was negligible. 


\subsubsection{Predictions of Pseudomonas aeruginosa based on mass balance analysis}

The fate of the $P$. aeruginosa cells in bulk water was a function of decay, settling, dilution and detachment (Fig 2.4.A, B). Similar trends were observed for DNA (Fig 2.4.C and D). If detachment is neglected, the model underestimated the concentrations of cells and DNA over time (Table S.2.2). By end of week 1, without detachment from biofilm, predicted values would be $97 \%$ lower than actual concentrations of viable cells and $99 \%$ lower for DNA, which means the surrogate would be predicted to have been removed 1-2 days before the last observed detection. Detachment was more prominent as the source of the surrogate once the primary source (spike) had been removed from the bulk water.

After day 6, the fraction of spiked surrogates that remains in the water became negligible. According to the model, after day 6, concentrations of cells and DNA in the water were expected to be low for the remainder of the experiment based on continuous detachment from the biofilm. However, such predictions matched with observation for additional one or two days. For the remainder, the release was occasional and in high concentrations. The occasionally high concentrations of cells and DNA that were detected during week 2 and 3 could not be explained by detachment via erosion alone. In the absence of any other source of the surrogate, it is therefore likely that these cells and DNA were released due to random events of sloughing from the biofilm. Hence, initially erosion was continuously introducing P. aeruginosa surrogate into the overlying bulk water and later detachment became a random event, suggesting that the surrogate population had become fully integrated within the biofilm, and detachment was dominated by sloughing, which indicated a weakening of internal forces in the biofilm, possibly in the context of biologically determined dispersal.

Additionally, varying $\mathrm{v}_{\mathrm{r}} P$, or the product of resuspension velocity and fraction detached (between 0.1 to 0.01 and 1) improved the predicted values in the model. These adjustments indicate that bed erodibility is affected due to biofilm growth leading to an increased 
resuspension velocity as well as less surrogates getting suspended. These variations were observed across flumes, between surrogates and often did not follow a specific temporal pattern suggesting biofilm heterogeneity to be a deciding factor in such variations. Erodibility is reduced as the EPS produced by the biofilm traps the underlying particles, thus reducing their ability to get suspended (Decho 2000).

The biofilms were a much more dynamic system (Fig. $2.4 \mathrm{E}$ to H). In most cases, the model was able to simulate the rate of loss of $P$. aeruginosa cells and DNA from the biofilm (Fig. 2.4 E). In flume 1, the model underestimated the concentration of viable cells after day 12 . A similar underestimation was seen for DNA (Fig. 2.4 G). Such differences can be explained by changes in decay kinetics of the organisms. An overgrowth of algae in the system can reduce sunlight exposure, leading to reduced decay in the viable cell population or possibly growth. Such corrections were not accounted for by our model, resulting in the observed discrepancies. In flume 2, an underestimation of DNA concentrations was observed, which was also reflected in the viable cell concentration profile (Fig. $2.4 \mathrm{~F}$ and $\mathrm{H}$ ). Similar differences between observed and predicted DNA concentrations were also observed in both flumes in the repeat experiment (Fig S.2.2). However, because corresponding cell counts were not available for repeat experiment, it was not possible to differentiate between the occurrence of VBNC cells and growth.

\subsubsection{Predictions of P22 based on mass balance analysis}

The concentrations of both viable phages and DNA in water were mostly explained by dilution, settling and detachment (Fig 2.5 A-D). Without detachment, DNA concentrations in water should not have been detectable after 12-14 d based on mass balance calculations. In the actual scenario, the DNA was detected for the entire experimental period of $21 \mathrm{~d}$. The effect of detachment on viable phage concentration was negligible due to very low concentrations of viable phages present in the biofilm phase. The DNA concentration profiles 
indicate that the phage DNA was however being released from the biofilm into the water column (Table S.2.2). Due to this continuous release from the biofilm, after day 12, a constant concentration of P22 DNA was detected in the water.

In a few instances, the observed value was much higher than predicted, which could have resulted from burrowing activities in the biofilm or inherent heterogeneity of the biofilm.

Because P22 did not grow and also had a very low decay rate in the system, it acted as a conservative tracer; for this reason the biofilm model predicted both viable cell and DNA concentrations with good accuracy (Fig. $2.5 \mathrm{E}$ to H). Similar to the water phase, detachment had negligible effect on the viable concentration in biofilm. Similar trends were observed in the repeat experiments (Fig S.2.3)

\subsubsection{Predictions of Enterococcus faecalis based on mass balance analysis}

Viable $E$. faecalis cells in water were a function of dilution, settling, decay and concentration of autochthonous populations in the feed (Fig. 2.6 A and B). Detachment from the biofilm was found to be insignificant. This was because of two reasons: 1) the surrogate concentration in the biofilm was very low and 2) decay kinetics were fast. Without secondary addition of the autochthonous population, the added spike would have been washed out of the system by day 2 . After day 2, this secondary addition of E. faecalis explains its continuing detection throughout the experiment. DNA concentrations showed similar trends (Fig. 2.6 C and D).

In the case of biofilms the model captured the general trends of surrogate levels. During week 3, the model underestimated the cell concentrations in both the flumes as was observed for $E$. faecalis. Such underestimations of cell counts, without simultaneous increase in DNA concentrations, suggest decreased decay possibly due to shade provided by algal growth. Additionally, on days 6 to 8 in flume 1 (both cell and DNA) and days 4 to 14 in flume 2 (for 
cells), the model overestimated the abundances of cells (Fig. 2.6 E and F). These deviations could not be accounted for by changing any of the physical processes, suggesting that surrogate concentrations in biofilms were dependent on variability in biological processes inherent in source and sink terms like predation and growth, that were not specifically included in our model. As expected, predictions were more accurate for the water phase than for biofilms, as revealed by the root mean square error, average error and adjusted $\mathrm{R}^{2}$ values for corresponding models (Supplementary Table S.2.3). Trends remained the same in the repeat experiments (Fig. S.2.4)

\subsection{Discussion}

The main objectives of the study was to understand factors influencing the temporal variations in cell numbers and total DNA levels of P. aeruginosa, E. faecalis, P22 and GA in a flume mesocosm under controlled conditions in the presence of biofilms, and to understand the role of biofilm as repository to these microorganisms. We show that biofilms can be a reservoir of $P$. aeruginosa, $\mathrm{P} 22$ and $E$. faecalis and the observed patterns can be explained in terms of losses from the system via flow discharge, settling, detachment and decay. Taken together, these trends indicate that source and sink terms like growth, decay, detachment and predation play important roles in influencing the fate of surrogates. The decay kinetics were determined in a separate batch experiment without biofilms. The batch study was designed in such a way that the derived decay rate represents net photo-oxidative decay and bacterial growth in the system.

\subsubsection{Fate of Pseudomonas aeruginosa}

In the flume study, concentrations of $P$. aeruginosa in the bulk water were explained by washout from the system (the flume had only partial recycling of water), settling and decay as commonly observed in natural aquatic ecosystems (Brookes et al. 2004). 
A fraction of the initial inoculum of $P$. aeruginosa ( $<10 \%$ for viable cells, $<30 \%$ for DNA) entered the biofilm phase. Here, $P$. aeruginosa was able to survive and either grow or enter into a VBNC state. P. aeruginosa is a known biofilm former (Stoodley et al. 2002). The species possesses specific mechanisms that favor growth as biofilm, such as evading predation (Matz and Kjelleberg 2005), modifying biofilm architecture (Battin et al. 2007) and cell signaling (Purevdorj et al. 2002) and cells often enter the VBNC state under nutrient poor or stressed conditions (Khan et al. 2007).

In biofilms, the concentration of $P$. aeruginosa cells and DNA varied abruptly. The model was able to account for a decreasing trend overall but was unable to predict specific peaks and valleys of concentrations. It has been previously shown that growth rates of bacteria even within similar microenvironments can be very different (Fux et al. 2005). Growth of $P$. aeruginosa is triggered by various environmental factors such as nutrient concentration, $\mathrm{pH}$, presence of other ions, and so forth (Horswill et al. 2007, Sauer et al. 2004), which were highly variable within our system on a daily basis. Growth kinetics of $P$. aeruginosa has also been shown to be different in planktonic, single species and multispecies biofilms, suggesting, community diversity can alter the fate of this surrogate (Lee et al. 2014). Another source of variability would be physical versus biological mechanisms of detachment, which may be influenced by the environment (Boulêtreau et al. 2006), but were not accounted separately in our model.

Once the primary source of the surrogate had washed out from the flumes, the biofilm became a source of the surrogate due to intermittent release of cells and DNA in to the overlying water column. $P$. aeruginosa has been found in river water and shown to be similar in genetic diversity to clinical isolates, suggesting river water as a potential reservoir for the microorganism (Pirnay et al. 2005). Similarly, viable P. aeruginosa cells were found at higher concentrations in tropical riverbed sediments compared to those in the overlying water, 
suggesting that sediments can protect the bacteria (Mwanamoki et al. 2014). The strain SS1, used in our flume studies was isolated from sediments in Singapore's waterways.

Release from the biofilm was not always governed by detachment via erosion or resuspension, especially during later phases of the experiment. Several researchers have established that transfer of $P$. aeruginosa from biofilms to the overlying matrix is influenced by many factors including nutrient availability (Sauer et al. 2004), chemistry of the overlying matrix (Banin et al. 2006) and phenotype (Sauer et al. 2002), in addition to shear forces. Studies have also shown that in natural aquatic systems, growth of biofilms can lead to sediment stabilization and prevents release due to the copious amounts of EPS produced (Decho 2000). This would explain the lack of continuous release of cells from the biofilm over time.

\subsubsection{Fate of P22}

A very small fraction $(<3 \%)$ of spiked P22 DNA reached the biofilm on day 1 , and in the bulk water both viable particles and DNA concentrations could be explained initially by dilution alone. In a natural system, this behavior would indicate a higher possibility of long distance/widespread transfer (Tufenkji 2007). Gradually, decay and settling became important terms as well for predicting viable particle concentrations in the flume. Long distance transport, with decay and settling being key processes affecting P22 survival, had been observed in large river systems (Shen et al. 2008). In those systems, the decay rate of viable P22 particles was marginally lower than determined by our batch experiment $\left(0.58 \mathrm{~d}^{-1}\right)$. The marginally higher value in our study was due to a lower TSS content in our flumes compared to the river study of Shen and colleagues.

P22 DNA was released continuously from the biofilm unlike $P$. aeruginosa, which was released randomly. In fresh water systems, if pathogenic viruses with similar behavior were introduced, such continuous release would lead to longer recovery times for the system (time 
to purge pathogen from the system). In both water and biofilm, we detected P22 DNA longer than the viable populations. Slower decay of DNA compared to loss of viability of bacteriophages is a common phenomenon in the environment, though loss of viability has not been established to be the same as complete degradation of the virus (Masago et al. 2008, Wommack et al. 1996). Thus, for pathogenic strains, the presence of DNA would still be considered a threat.

In the biofilms, the concentration of viable particles was much less than what would be expected due to settling from the bulk water. Another factor could have been rapid decay in the biofilm phase. Loss of viability of bacteriophages has been associated with many biofilm properties, such as, particulate matter present, bacteriovorous activity of protists and oxygen concentration (Wommack et al. 1996). Viral viability can be reduced with decreasing oxygen concentrations in the environment (Weinbauer and Höfle 1998). It is possible that the phages were buried deeper within the biofilm in anoxic layers, as a result of which viability was reduced.

In contrast, measured P22 DNA concentrations in biofilms were similar to estimates based on the fraction of DNA removed by settling from the overlying water. Even though P22 DNA did not decay, in the biofilm, the concentrations decreased over time and mass balance analysis showed secondary losses, possibly involving grazing by different protozoa and metazoa present in the system. Grazing has been established as a common phenomenon in freshwater ecosystems (Arndt et al. 2003, McDougald et al. 2012) and viral infectivity is greatly reduced in the presence of sunlight and flagellates in such environments (Bouvy et al. 2011, Suttle and Chen 1992).

\subsubsection{Fate of Enterococcus faecalis}

Fate of E. faecalis in the water phase was dependent on physical processes as for the other surrogates. In the absence of any substantial secondary inoculation from biofilm, the 
autochthonous populations present in the feed mainly determined concentrations in the water. Previous models have also identified photo-decay and settling as important factors for the fate of fecal indicator bacteria (FIB) in surface waters (Cho et al. 2010). Our data showed that Enterococcus cells and DNA were removed by physical processes, similar to P. aeruginosa. E. faecalis concentrations in the biofilm were much lower than those of $P$. aeruginosa. But in natural freshwater environments, E. faecalis is often found in high concentrations in sediments, and certain algae, like Cladophora, are known to facilitate survival of enterococci (Byappanahalli et al. 2003). This contradiction can be due to two reasons; first, in the present study, the flumes were shallow, exposing the substratum to higher radiation levels than in the mentioned study, and second, such interactions may be species specific. Increased decay of Enterococcus in the presence of sunlight has been reported previously (Bae and Wuertz 2012, Sinton et al. 1999).

Although detachment was insignificant in our flumes due to low concentrations of E. faecalis in the biofilm, mass balance analysis showed that there was growth in the settled fraction. Growth of fecal indicator microorganisms like E. faecalis has been observed in sediments especially in the tropical and subtropical environment (de Brauwere et al., 2014) Growth in our flumes suggested that in natural environments, E. faecalis can grow in the biofilm and with sufficient shear force, will get reintroduced to the overlying water. Such a ubiquitous presence of $E$. faecalis questions its effectiveness as a fecal indicator in tropical waters, especially when pollution source identification is required.

\subsection{Conclusions}

- In this study, we showed that $P$. aeruginosa was growing in the biofilm and was being released to the overlying water sporadically, whereas P22 phage was being released continuously. This suggests that even in shallow depths with ample sunlight, biofilms 
can function as a secondary source of inoculum long after the initial release of pathogens in an aquatic system.

- P22 concentrations were mainly a function of loss via outflow and settling and the phage decayed slowly. This indicates that P22 can act as a conservative tracer.

- Autochthonous Enterococcus faecalis were found at moderate concentrations in the feed water drawn from the canal. Due to its ubiquitous presence, E. faecalis may not be an ideal choice for monitoring microbial water quality in Singapore's waterways.

Our study quantitatively showed how the interplay of hydrodynamics, growth and decay parameters affects concentrations of surrogates of pathogens in a freshwater system. This research is expected to lead to a better understanding of the fate of pathogens in natural waters, especially in biofilms, and thus help in the development of better management practices for recreational waters. 


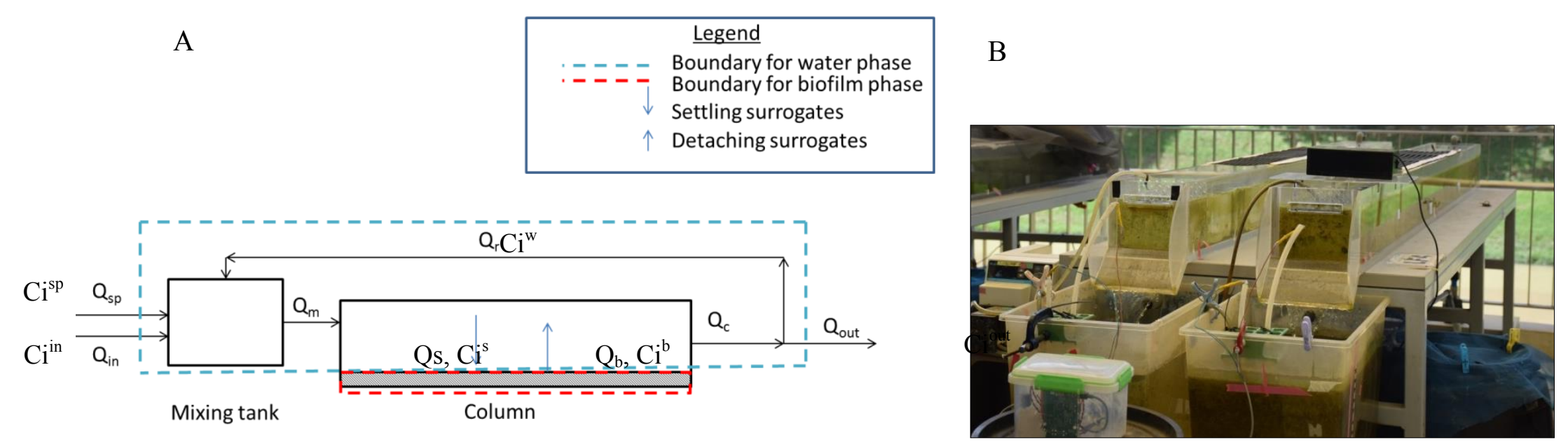

Figure 2.1 (A) Schematic diagram of the flume. $\mathrm{Q}_{\mathrm{in}}=$ inlet flow rate $\left(0.02 \mathrm{Lmin}^{-1}\right), \mathrm{Q}_{\text {out }}=$ outlet flow rate $\left(0.02 \mathrm{~L} \mathrm{~min}^{-1}\right), \mathrm{Q}_{\mathrm{r}}=$ recirculation flow rate $\left(6 \mathrm{~L} \mathrm{~min}^{-1}\right)$, volume of mixing tank $(25 \mathrm{~L})$, volume of water phase $(20 \mathrm{~L})$, surface area of biofilm phase $\left(2200 \mathrm{~cm}^{2}\right)$; (B) A set of flumes in operation at Van Kleef Center.

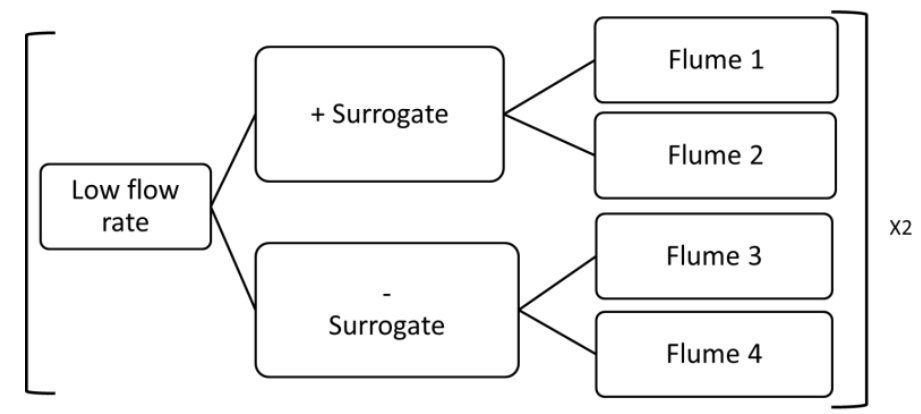

Figure 2.2. Schematic diagram of experimental plan for studying fate of pathogen surrogates at a low flow rate in duplicate experiments, each time employing four flumes 

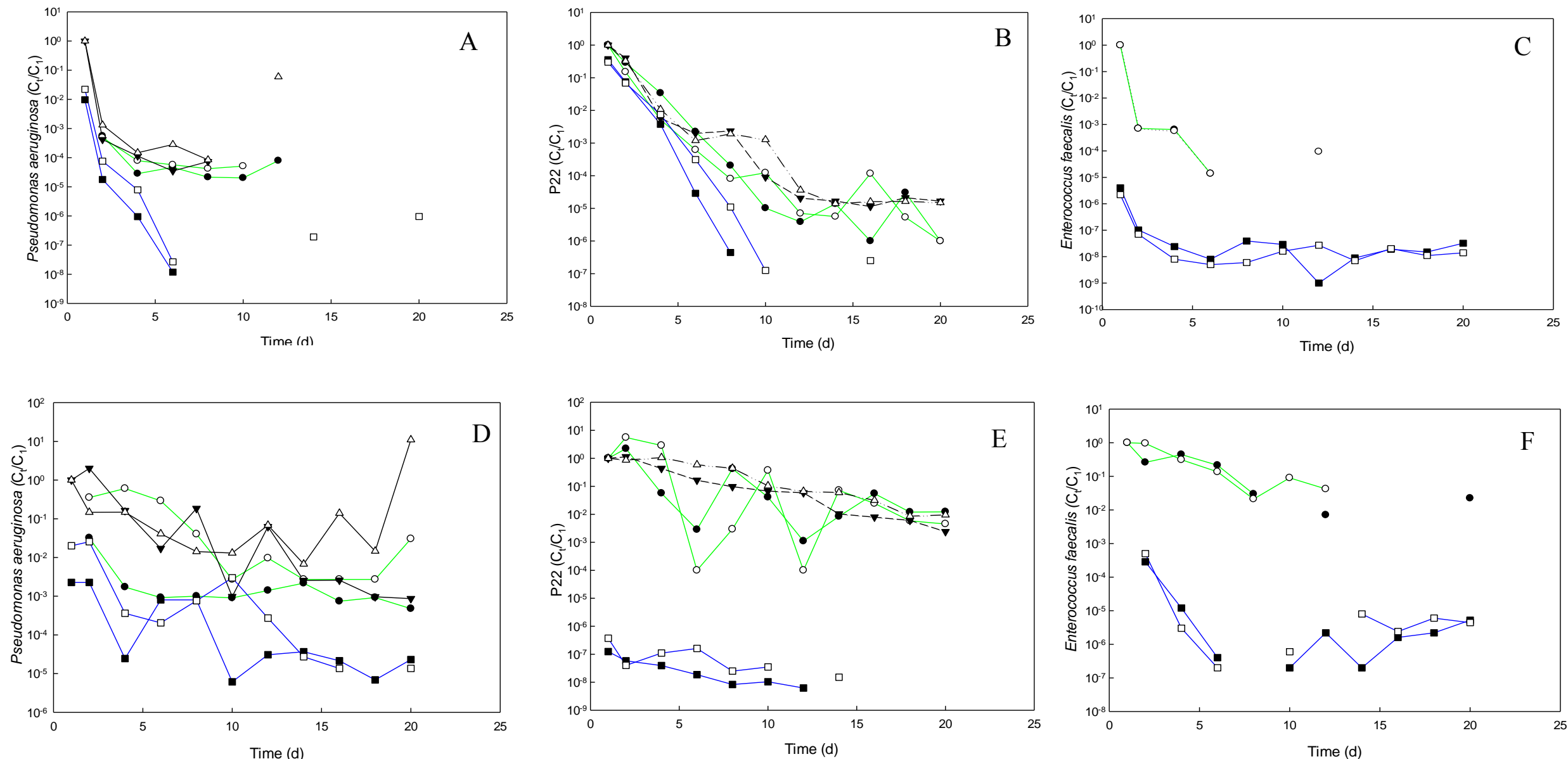

Figure 2.3. Fraction of P.aeruginosa, $\mathrm{P} 22$ and E. faecalis surviving in the aqueous phase as observed in replicate flumes in two independent experiments under low flow conditions (A, B, C). Fraction of surrogates surviving in biofilm phase (D, E, F) as observed in replicate flumes in two independent experiments under low flow conditions. Circles represent gene copies from the first experiment, triangles represent gene copies from the second experiment and squares represent viable counts. Open and closed symbols in identical colors indicate replicate flumes. 

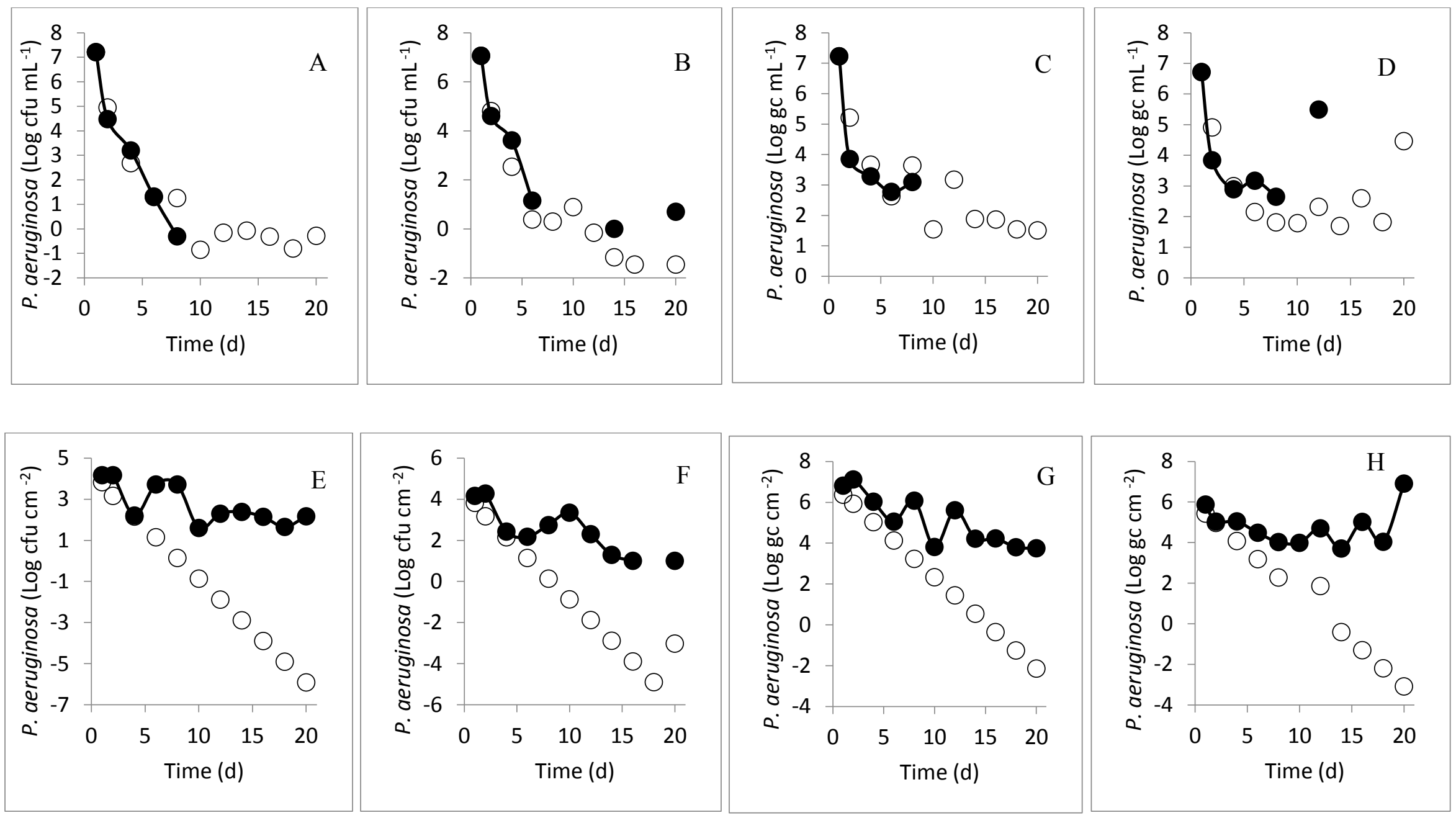

Figure 2.4 Modeling of P. aeruginosa concentrations in water and biofilm phases. A, B, C and D correspond to the aqueous phase and E, F, G and $\mathrm{H}$ correspond to the biofilm phase. Closed symbols indicate actual measurements whereas open markers indicate model predictions. A, B, E and F show viable concentrations C, D, G and H show DNA concentrations. A, C, E, G represent trends in flume 1, B, D, F, H represent replicate flume 2. The experiment was repeated once. 

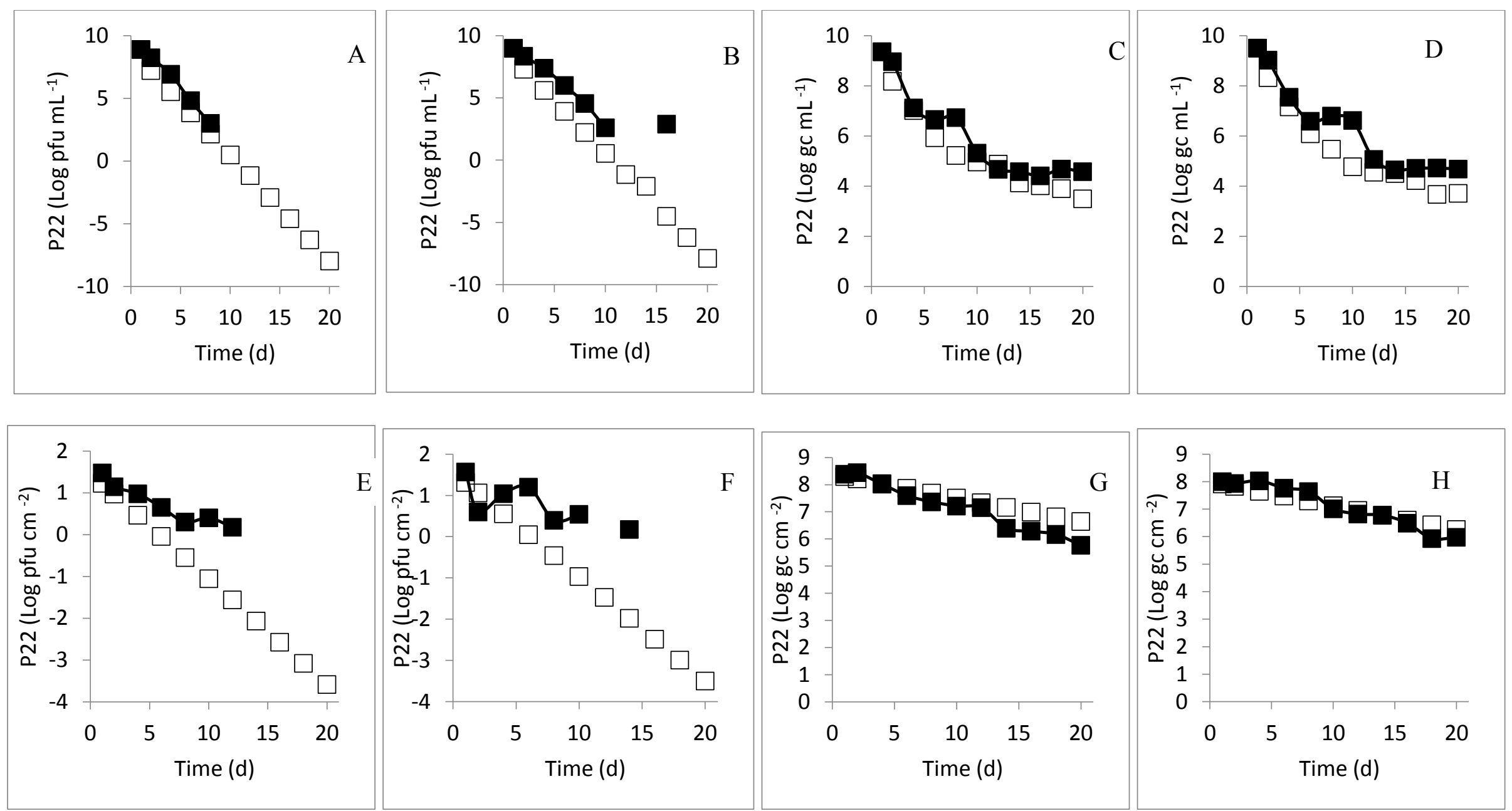

Figure 2.5 Modeling of P22 concentrations in water and biofilm phases. A, B, C and D correspond to the aqueous phase, E, F, G and $\mathrm{H}$ corresponds to the biofilm phase. Closed symbols indicate actual measurements whereas open markers indicate model predictions. A, B, E and F show viable concentrations C, D, G and H show DNA concentrations. A, C, E, G represent trends in flume 1, B, D, F, H represent replicate flume 2. The experiment was repeated once. 

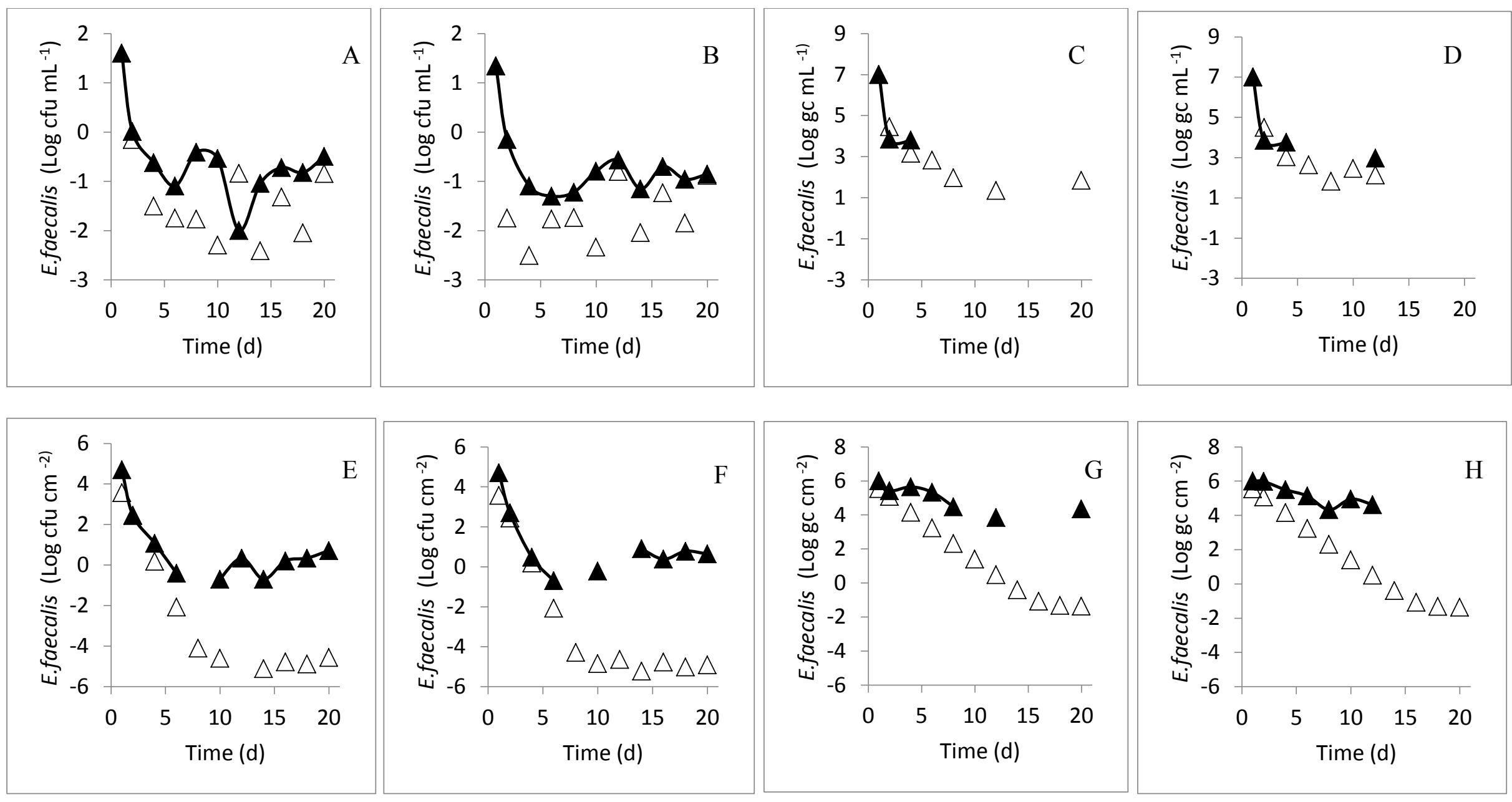

Figure 2.6 Modeling of Enterococcus faecalis concentrations in water and biofilm phases. A, B, C and D correspond to the aqueous phase, E, F, $\mathrm{G}$ and $\mathrm{H}$ corresponds to the biofilm phase. Closed symbols indicate actual measurements whereas open markers indicate model predictions. A, $\mathrm{B}, \mathrm{E}$ and $\mathrm{F}$ show viable concentrations $\mathrm{C}, \mathrm{D}, \mathrm{G}$ and $\mathrm{H}$ show DNA concentrations. A, C, E, G represent trends in flume 1, B, D, F, H represent replicate flume 2 . The experiment was repeated once. 
Table 2.1: Specifications for $q P C R$ assays

\begin{tabular}{|c|c|c|c|c|c|c|}
\hline Surrogate & Amplicon & $\begin{array}{l}\text { Primer } \\
\text { Forward }\end{array}$ & $\begin{array}{l}\text { Primer } \\
\text { Reverse }\end{array}$ & Probe & $\begin{array}{l}\text { Sample limit of } \\
\text { detection }\left(S_{L O D}\right)\end{array}$ & Reference \\
\hline P. aeruginosa & $23 \mathrm{~s}$ rDNA & $\begin{array}{l}\text { TCCAAGTTT } \\
\text { AAGGTGGT } \\
\text { AGGCTG }\end{array}$ & $\begin{array}{l}\text { ACCACTTCG } \\
\text { TCATCTAAA } \\
\text { AGACGAC }\end{array}$ & $\begin{array}{l}\text { FAM-5'- } \\
\text { AGGTAAATCCGGGGTTT } \\
\text { CAAGGCC-3'-TAMRA }\end{array}$ & $86 \mathrm{gc} \mathrm{mL}^{-1}$ & $\begin{array}{l}\text { Volkmann et al., } \\
2007\end{array}$ \\
\hline E. faecalis & 16s rDNA & $\begin{array}{l}\text { CGCTTCTTT } \\
\text { CCTCCCGA } \\
\text { GT }\end{array}$ & $\begin{array}{l}\text { GCCATGCGG } \\
\text { CATAAACTG }\end{array}$ & $\begin{array}{l}\text { [6FAM]- } \\
\text { CAATTGGAAAGAGGAG } \\
\text { TGGCGGACG-[TAMRA] }\end{array}$ & $110 \mathrm{gc} \mathrm{mL}^{-1}$ & $\begin{array}{l}\text { Santo Domingo } \\
\text { et al., } 2003\end{array}$ \\
\hline $\mathbf{P 2 2}$ & $\begin{array}{l}\text { Viral } \\
\text { packing } \\
\text { genes }\end{array}$ & $\begin{array}{l}\text { CTTAACAA } \\
\text { GCTCTGAC } \\
\text { TGCTCATCA }\end{array}$ & $\begin{array}{l}\text { CCATCGCCT } \\
\text { GTGACTGGA } \\
\mathrm{T}\end{array}$ & $\begin{array}{l}\text { [FAM]- } \\
\text { TCGCAACGATGCAGAAC } \\
\text { GACTCG-[TAMRA] }\end{array}$ & $80 \mathrm{gc} \mathrm{mL}^{-1}$ & $\begin{array}{l}\text { Masago et al., } \\
2008\end{array}$ \\
\hline GA & $\begin{array}{l}\text { Viral } \\
\text { replicase } \\
\text { genes }\end{array}$ & $\begin{array}{l}\text { TGCAAACC } \\
\text { TAACTCGG } \\
\text { AATGG } \\
\end{array}$ & $\begin{array}{l}\text { AGGAGAGA } \\
\text { ACGCAGGCC } \\
\text { TCTA }\end{array}$ & $\begin{array}{l}{[\text { FAM }]-} \\
\text { TCCCTCTATTTCCTC- } \\
\text { [MGBNFQ] }\end{array}$ & $498 \mathrm{gc} \mathrm{mL}^{-1}$ & $\begin{array}{l}\text { Ogorzaly and } \\
\text { Gantzer } 2006\end{array}$ \\
\hline
\end{tabular}




\begin{tabular}{|c|c|c|}
\hline Parameter & Value & Source \\
\hline $\mathbf{Q}_{\text {in }}$ & $20 \mathrm{mLmin}^{-1}$ & System defined \\
\hline $\mathbf{Q}_{\text {out }}$ & $20 \mathrm{mLmin}^{-1}$ & System defined \\
\hline $\mathbf{A}_{\mathbf{s}}$ & $2200 \mathrm{~cm}^{2}$ & System defined \\
\hline \multirow[t]{2}{*}{ k (P. aeruginosa $)$} & $0.96 \mathrm{~d}^{-1}(0.19)^{*}[$ cell $]$ & Experimentally determined \\
\hline & $0.83 \mathrm{~d}^{-1}(0.08)[\mathrm{DNA}]$ & \\
\hline \multirow[t]{2}{*}{$\mathbf{k}($ E. faecalis $)$} & $2.35 \mathrm{~d}^{-1}(0.33)$ [cell] & Experimentally determined \\
\hline & $0.86 \mathrm{~d}^{-1}(0.04)[\mathrm{DNA}]$ & \\
\hline \multirow[t]{2}{*}{ k (P22) } & $0.58 \mathrm{~d}^{-1}(0.08)$ [cell] & Experimentally determined \\
\hline & $0 \mathrm{~d}^{-1}[\mathrm{DNA}]$ & \\
\hline $\mathbf{V}$ & $45 \mathrm{~L}$ & System defined \\
\hline $\mathbf{H}$ & $10 \mathrm{~cm}$ & System defined \\
\hline $\mathbf{v}_{\mathbf{r}}$ & $0.002 \mathrm{~m} \mathrm{~d}^{-1}$ & $\begin{array}{l}\text { Calculated (Kim and Wuertz } \\
\text { 2015) }\end{array}$ \\
\hline
\end{tabular}

*: Values within parenthesis represent standard error 
Table S2.2 Ratio of estimated to measured concentrations of surrogates in aqueous phase according to different models derived by sequentially selecting one or more physical processes (Di, S, De and Rs) as key drivers of surrogate fate

\begin{tabular}{|c|c|c|c|c|c|c|c|}
\hline \multirow{2}{*}{ Surrogate } & \multirow{2}{*}{ Target } & \multirow{2}{*}{$\begin{array}{c}\text { Time } \\
\text { (d) }\end{array}$} & \multicolumn{5}{|c|}{ Ratio of estimated to measured concentration } \\
\hline & & & $\mathbf{D i}^{1}$ & $\overline{\mathbf{D i}+\mathbf{S}^{2}}$ & $\mathbf{D i}+\mathbf{S}+\mathrm{De}^{3}$ & $\mathbf{D i}+\mathrm{De}+\mathrm{S}+\mathbf{R s}^{4}$ & $\mathbf{D i}+\mathbf{S}+\mathbf{R s}$ \\
\hline Pseudomonas & Viable & 2 & 151.99 & 20.24 & 2.97 & 2.97 & 20.24 \\
\hline \multirow[t]{7}{*}{ aeruginosa } & & 4 & 792.37 & 14.06 & 0.30 & 0.31 & 14.07 \\
\hline & & 6 & 17624.75 & 41.64 & 0.13 & 1.04 & 42.55 \\
\hline & & 8 & 196013.55 & 61.68 & 0.03 & 1.85 & 98.17 \\
\hline & Nucleic & 2 & 664.32 & 88.48 & 16.82 & 17.44 & 89.90 \\
\hline & acid & 4 & 680.10 & 12.08 & 0.44 & 0.68 & 17.30 \\
\hline & & 6 & 614.68 & 1.50 & 0.03 & 0.79 & 18.48 \\
\hline & & 8 & 81.14 & 0.05 & 0.01 & 3.52 & 8.11 \\
\hline Enterococcus & Viable & 2 & 12.42 & 1.58 & 0.14 & & \\
\hline \multirow[t]{12}{*}{ faecalis } & & 4 & 19.35 & 0.76 & 0.53 & & \\
\hline & & 6 & 30.14 & 1.61 & 1.59 & & \\
\hline & & 8 & 4.59 & 0.33 & 0.33 & & \\
\hline & & 10 & 5.58 & 0.44 & 0.44 & & \\
\hline & & 12 & 156.96 & 12.70 & 12.70 & & \\
\hline & & 14 & 17.29 & 1.41 & 1.41 & & \\
\hline & & 16 & 8.17 & 0.67 & 0.67 & & \\
\hline & & 18 & 10.34 & 0.85 & 0.85 & & \\
\hline & & 20 & 4.85 & 0.40 & 0.40 & & \\
\hline & Nucleic & 2 & 664.32 & 88.48 & 16.82 & 89.90 & \\
\hline & acid & 4 & 680.10 & 12.08 & 0.44 & 17.30 & \\
\hline & & 6 & 614.68 & 1.50 & 0.03 & 18.48 & \\
\hline
\end{tabular}




\begin{tabular}{|c|c|c|c|c|c|c|c|}
\hline \multirow{2}{*}{ Surrogate } & \multirow{2}{*}{ Target } & \multirow{2}{*}{$\begin{array}{c}\text { Time } \\
\text { (d) }\end{array}$} & \multicolumn{4}{|c|}{ Ratio of estimated to measured concentration } & \multirow[b]{2}{*}{$\mathbf{D i}+\mathbf{S}+\mathbf{R s}$} \\
\hline & & & $\mathbf{D i}^{1}$ & $\mathbf{D i}+\mathbf{S}^{2}$ & $\mathbf{D i}+\mathbf{S}+\mathbf{D e}^{3}$ & $\mathrm{Di}+\mathrm{De}+\mathrm{S}+\mathrm{Rs}^{4}$ & \\
\hline & & 8 & 81.14 & 0.05 & 0.01 & 8.11 & \\
\hline \multirow[t]{15}{*}{$\mathbf{P 2 2}$} & Viable & 2 & 1.21 & 0.29 & 0.09 & & \\
\hline & & 4 & 3.09 & 0.17 & 0.02 & & \\
\hline & & 6 & 20.63 & 0.27 & 0.01 & & \\
\hline & & 8 & 163.91 & 0.52 & 0.00 & & \\
\hline & & 10 & 3987.74 & 2.98 & 0.01 & & \\
\hline & Nucleic & 2 & 0.69 & 0.16 & 0.16 & & 0.17 \\
\hline & acid & 4 & 13.48 & 0.76 & 0.76 & & 1.00 \\
\hline & & 6 & 10.81 & 0.14 & 0.14 & & 0.86 \\
\hline & & 8 & 2.53 & 0.01 & 0.01 & & 0.61 \\
\hline & & 10 & 18.39 & 0.01 & 0.01 & & 1.58 \\
\hline & & 12 & 22.58 & 0.00 & 0.00 & & 0.70 \\
\hline & & 14 & 7.72 & 0.00 & 0.00 & & 0.85 \\
\hline & & 16 & 3.15 & 0.00 & 0.00 & & 1.25 \\
\hline & & 18 & 0.47 & 0.00 & 0.00 & & 0.67 \\
\hline & & 20 & 0.17 & 0.00 & 0.00 & & 0.85 \\
\hline
\end{tabular}

${ }^{\mathrm{T}} \mathrm{Di}=$ removal via outflow from the flume, ${ }^{2} \mathrm{~S}=$ removal by settling from water, ${ }^{3} \mathrm{De}=$ net photooxidative decay and growth of surrogates in flume water, ${ }^{4} \mathrm{Rs}=$ detachment from biofilm 
Table S.2.3 Fit statistics for model

\begin{tabular}{|c|c|c|c|c|c|c|c|}
\hline Surrogate & Target & Phase & Data set & $\mathrm{n}$ & RMSE & Av. Error \% & Adj. $R^{2}$ \\
\hline \multirow[t]{6}{*}{ P. aeruginosa } & DNA & Water & Exp1, Flume1 & 5 & 0.69 & 9.76 & 0.86 \\
\hline & & & Exp1, Flume2 & 5 & 0.67 & 11.64 & 0.91 \\
\hline & & & Exp2, Flume1 & 7 & 0.56 & 11.60 & 0.89 \\
\hline & & & Exp2, Flume2 & 6 & 0.63 & 7.42 & 0.83 \\
\hline & Cell & & Exp2, Flume1 & 4 & 0.40 & 7.39 & 0.97 \\
\hline & & & Exp2, Flume2 & 6 & 0.67 & 13.27 & 0.93 \\
\hline \multirow[t]{6}{*}{ P22 } & DNA & & Exp1, Flume1 & 11 & 0.72 & 14.13 & 0.91 \\
\hline & & & Exp1, Flume2 & 11 & 0.58 & 11.62 & 0.90 \\
\hline & & & Exp2, Flume1 & 11 & 0.28 & 2.73 & 0.98 \\
\hline & & & Exp2, Flume2 & 11 & 0.26 & 2.77 & 0.98 \\
\hline & Cell & & Exp2, Flume1 & 5 & 0.45 & 4.12 & 0.96 \\
\hline & & & Exp2, Flume2 & 6 & 0.55 & 8.48 & 0.96 \\
\hline \multirow[t]{4}{*}{ E. faecalis } & DNA & & Exp1, Flume1 & 3 & 0.53 & 3.06 & 0.86 \\
\hline & & & Exp1, Flume2 & 3 & 0.48 & 6.53 & 0.89 \\
\hline & Cell & & Exp2, Flume1 & 11 & 0.44 & 42.21 & 0.73 \\
\hline & & & Exp2, Flume2 & 11 & 0.33 & 22.90 & 0.79 \\
\hline \multirow[t]{6}{*}{ P. aeruginosa } & DNA & Biofilm & Exp1, Flume1 & 11 & 0.82 & 19.93 & 0.50 \\
\hline & & & Exp1, Flume2 & 11 & 0.99 & 26.87 & 0.61 \\
\hline & & & Exp2, Flume1 & 11 & 0.65 & 10.18 & 0.72 \\
\hline & & & Exp2, Flume2 & 11 & 1.71 & 35.65 & -0.11 \\
\hline & Cell & & Exp2, Flume1 & 11 & 1.09 & 204.89 & 0.49 \\
\hline & & & Exp2, Flume2 & 11 & 0.65 & 18.63 & 0.68 \\
\hline P22 & DNA & & Exp1, Flume1 & 11 & 0.88 & 11.87 & 0.27 \\
\hline
\end{tabular}




\begin{tabular}{|c|c|c|c|c|c|c|c|}
\hline Surrogate & Target & Phase & Data set & $\mathbf{n}$ & RMSE & Av. Error \% & Adj. $R^{2}$ \\
\hline & & & Exp1, Flume2 & 11 & 1.49 & 17.46 & 0.13 \\
\hline & & & Exp2, Flume1 & 11 & 0.20 & 2.32 & 0.72 \\
\hline & & & Exp2, Flume2 & 11 & 0.16 & 1.93 & 0.96 \\
\hline & Cell & & Exp2, Flume1 & 11 & 0.48 & 96.23 & 0.82 \\
\hline & & & Exp2, Flume2 & 11 & 0.50 & 72.70 & 0.86 \\
\hline \multirow[t]{4}{*}{ E. faecalis } & DNA & & Exp1, Flume1 & 11 & 1.18 & 21.68 & 0.61 \\
\hline & & & Exp1, Flume2 & 11 & 1.04 & 20.00 & 0.82 \\
\hline & Cell & & Exp2, Flume1 & 11 & 0.62 & 408.79 & 0.84 \\
\hline & & & Exp2, Flume2 & 11 & 0.88 & 156.48 & 0.71 \\
\hline
\end{tabular}



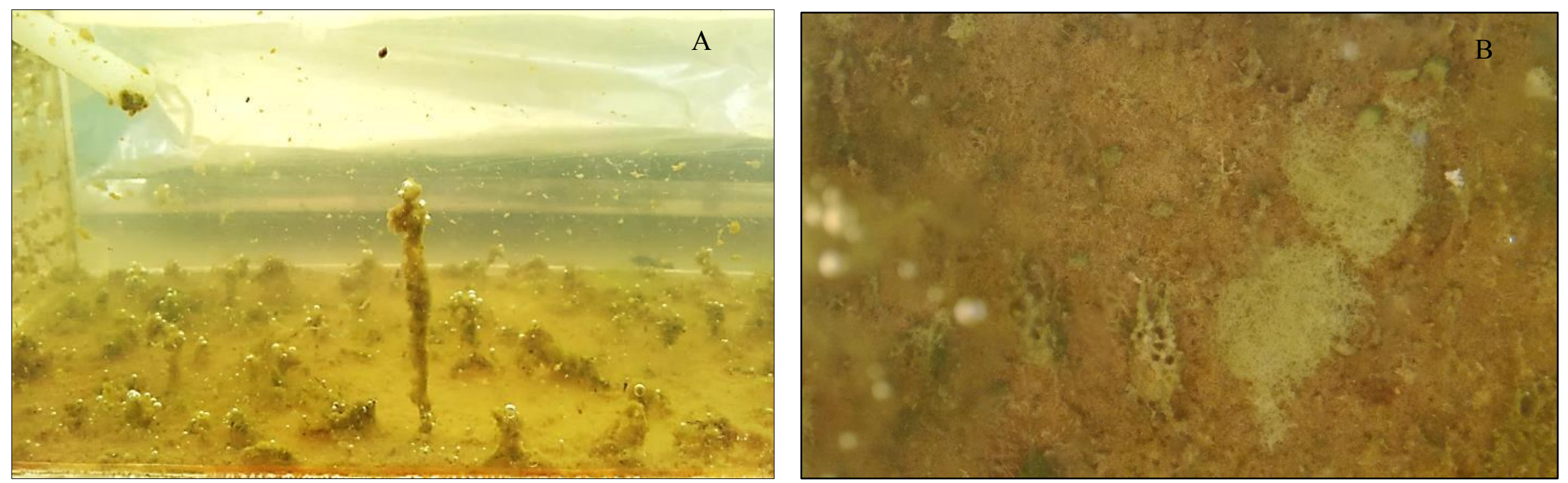

Figure S.2.1 Biofilm on the flume bed at 1X magnification (A) side view during early stages; (B) top view during the experiment 

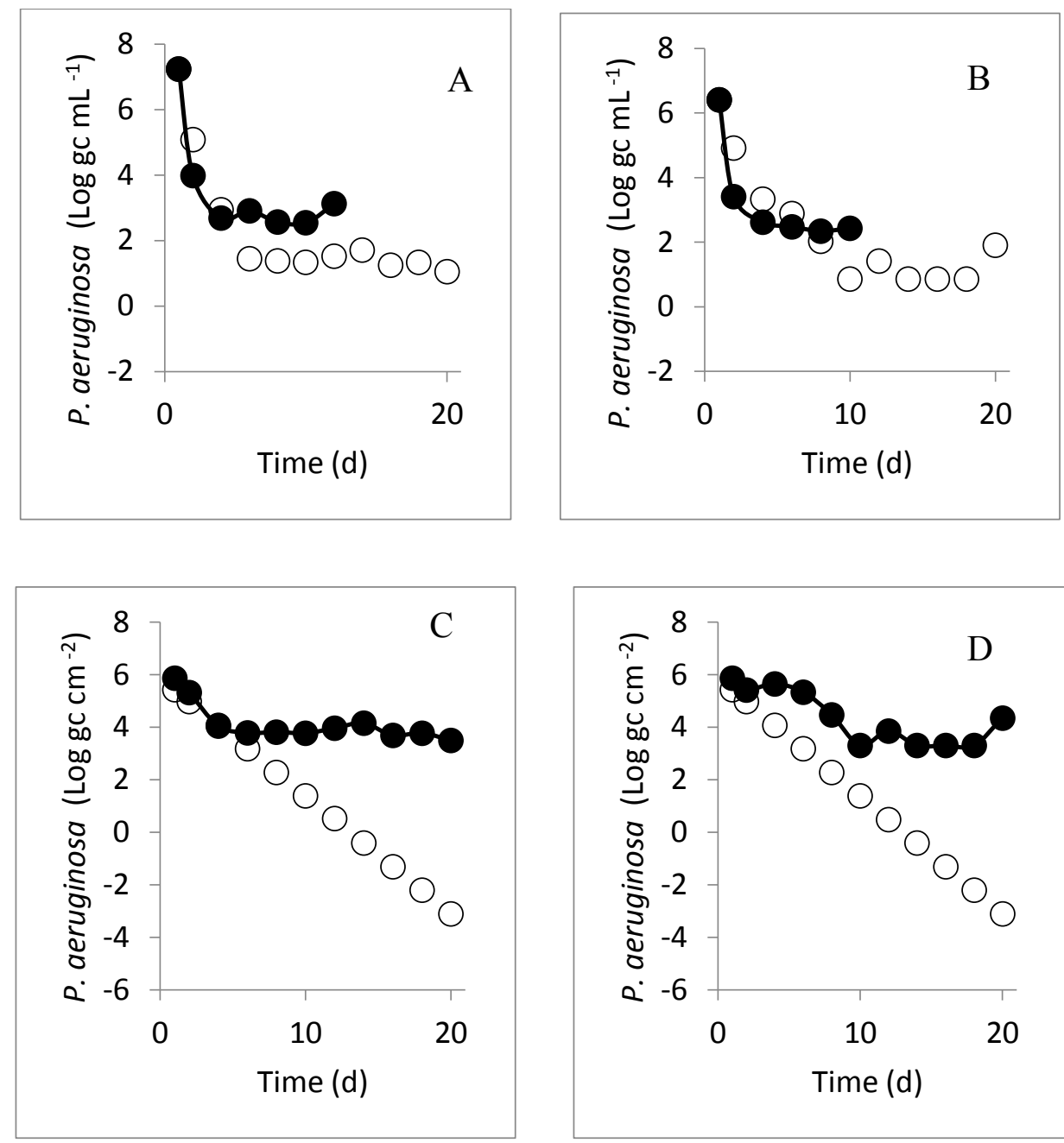

Figure S.2.2 Modeling of P. aeruginosa concentrations in water (A and B) and biofilm (C and D) in repeat experiment. Closed symbols indicate actual measurements whereas open markers indicate model predictions. 

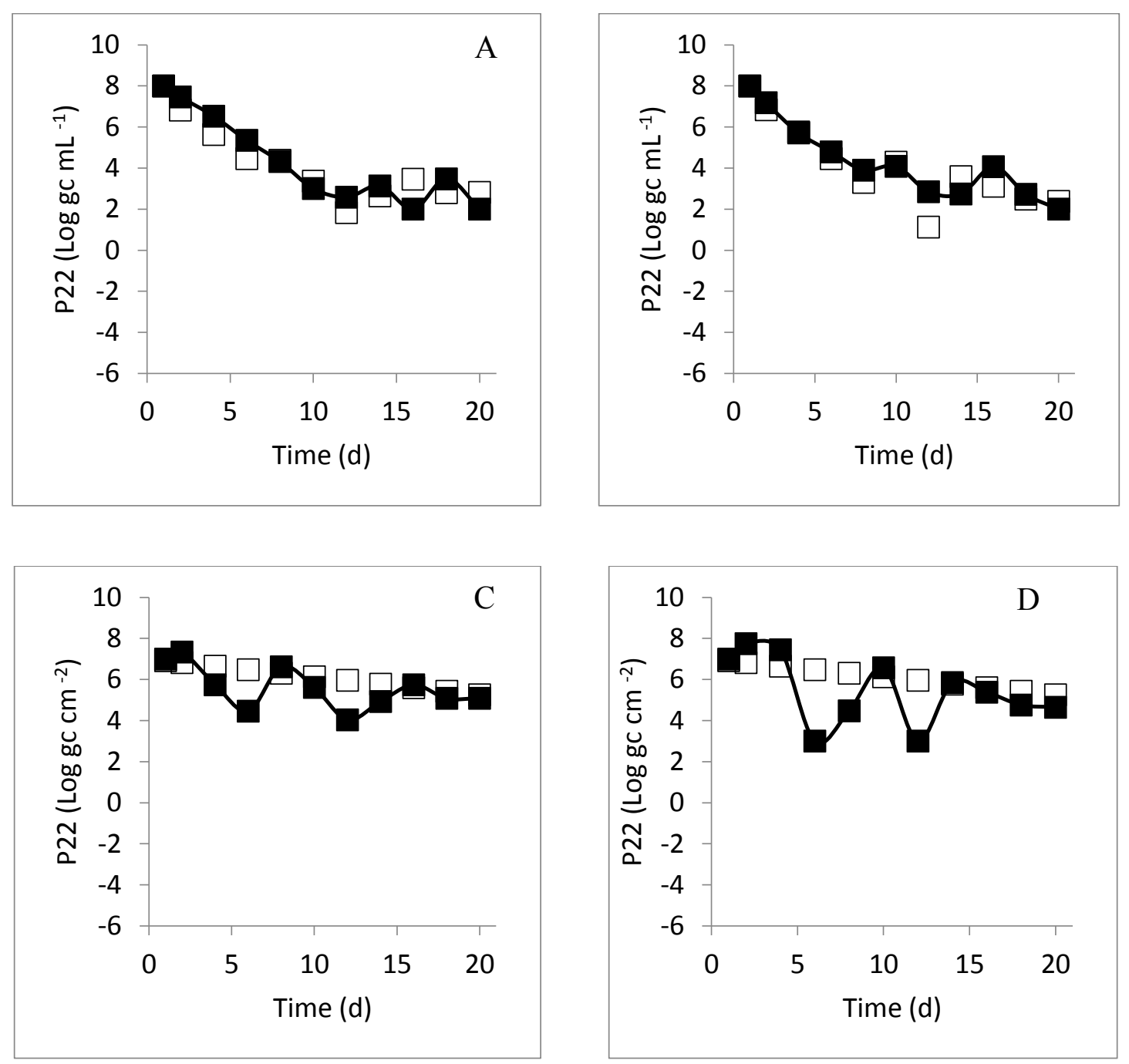

Figure S.2.3 Modeling of P22 concentrations in water (A and B) and biofilm (C and D) in repeat experiment. Closed symbols indicate actual measurements whereas open markers indicate model predictions. 

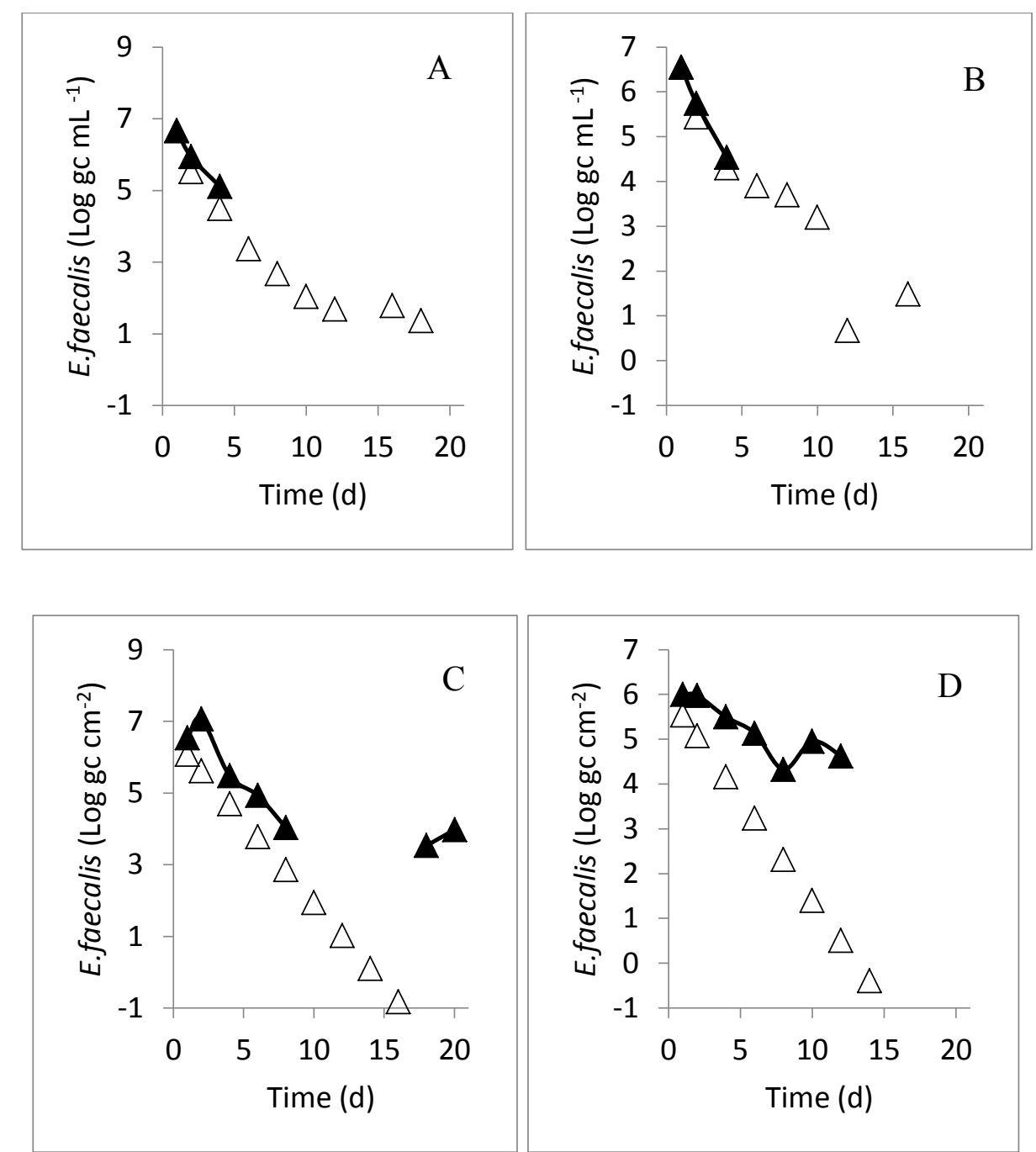

Figure S.2.4 Modeling of E. faecalis concentrations in water (A and B) and biofilm (C and D) in repeat experiment. Closed symbols indicate actual measurements whereas open markers indicate model predictions. 


\section{References}

Arndt H, Schmidt-Denter K, Auer B, Weitere M (2003). Protozoans and Biofilms. In: Krumbein WE, Paterson DM, Zavarzin GA (eds). Fossil and recent biofilms: A natural history of life on earth. Springer Netherlands: Dordrecht. pp 161-179.

Arnon S, Marx LP, Searcy KE, Packman AI (2010). Effects of overlying velocity, particle size, and biofilm growth on stream-subsurface exchange of particles. Hydrological Processes 24: $108-114$.

Aw T, Gin KH (2011). Prevalence and genetic diversity of waterborne pathogenic viruses in surface waters of tropical urban catchments. Journal of Applied Microbiology 110: 903-914.

Aw TG, Gin KY-H, Oon LLE, Chen EX, Woo CH (2009). Prevalence and genotypes of human noroviruses in tropical urban surface waters and clinical samples in Singapore. Applied and Environmental Microbiology 75: 4984-4992.

Bae S, Wuertz S (2012). Survival of host-associated bacteroidales cells and their relationship with Enterococcus spp., Campylobacter jejuni, Salmonella enterica serovar Typhimurium, and adenovirus in freshwater microcosms as measured by propidium monoazide-quantitative PCR. Applied and Environmental Microbiology 78: 922-932.

Bai S, Lung W-S (2005). Modeling sediment impact on the transport of fecal bacteria. Water Research 39: 5232-5240.

Banin E, Brady KM, Greenberg EP (2006). Chelator-induced dispersal and killing of Pseudomonas aeruginosa cells in a biofilm. Applied and Environmental Microbiology 72: 2064-2069.

Battin TJ, Kaplan LA, Newbold JD, Cheng X, Hansen C (2003). Effects of current velocity on the nascent architecture of stream microbial biofilms. Applied and Environmental Microbiology 69: 5443-5452.

Battin TJ, Sloan WT, Kjelleberg S, Daims H, Head IM, Curtis TP et al. (2007). Microbial landscapes: new paths to biofilm research. Nature Reviews Microbiology 5: 76-81.

Benham BL, Baffaut C, Zeckoski RW, Mankin KR, Pachepsky YA, Sadeghi AM et al. (2006). Modeling bacteria fate and transport in watersheds to support TMDLs. Transactions of the ASABE 49: 987-1002.

Boulêtreau S, Garabétian F, Sauvage S, SÁNCHEZ-PÉREZ JM (2006). Assessing the importance of a self-generated detachment process in river biofilm models. Freshwater Biology 51: 901-912. 
Bouvy M, Bettarel Y, Bouvier C, Domaizon I, Jacquet S, Le Floc'h E et al. (2011). Trophic interactions between viruses, bacteria and nanoflagellates under various nutrient conditions and simulated climate change. Environmental Microbiology 13: 1842-1857.

Brookes JD, Antenucci J, Hipsey M, Burch MD, Ashbolt NJ, Ferguson C (2004). Fate and transport of pathogens in lakes and reservoirs. Environment International 30: 741-759.

Buswell CM, Herlihy YM, Lawrence LM, McGuiggan JT, Marsh PD, Keevil CW et al. (1998). Extended survival and persistence of Campylobacter spp. in water and aquatic biofilms and their detection by immunofluorescent-antibody and-rRNA staining. Applied and Environmental Microbiology 64: 733-741.

Byappanahalli MN, Shively DA, Nevers MB, Sadowsky MJ, Whitman RL (2003). Growth and survival of Escherichia coli and enterococci populations in the macro-alga Cladophora (Chlorophyta). FEMS Microbiology Ecology 46: 203-211.

Chang W-S, van de Mortel M, Nielsen L, de Guzman GN, Li X, Halverson LJ (2007). Alginate production by Pseudomonas putida creates a hydrated microenvironment and contributes to biofilm architecture and stress tolerance under water-limiting conditions. Journal of Bacteriology 189: 8290-8299.

Chapra SC (2008). Surface water-quality modeling. Waveland press.47-76

Cho KH, Cha SM, Kang J-H, Lee SW, Park Y, Kim J-W et al. (2010). Meteorological effects on the levels of fecal indicator bacteria in an urban stream: A modeling approach. Water Research 44: 2189-2202.

Costerton JW, Lewandowski Z, Caldwell DE, Korber DR, Lappin-Scott HM (1995). Microbial biofilms. Annual Reviews in Microbiology 49: 711-745.

Craun GF, Calderon RL, Craun MF (2005). Outbreaks associated with recreational water in the United States. International Journal of Environmental Health Research 15: 243-262.

Decho AW (2000). Microbial biofilms in intertidal systems: an overview. Continental Shelf Research 20: 1257-1273.

Drummond JD, Davies-Colley RJ, Stott R, Sukias JP, Nagels JW, Sharp A et al. (2015). Microbial transport, retention, and inactivation in streams: A combined experimental and stochastic modeling approach. Environmental Science \& Technology 49: 7825-7833.

Elasri MO, Miller RV (1999). Study of the response of a biofilm bacterial community to UV Radiation. Applied and Environmental Microbiology 65: 2025-2031. 
Ferguson C, Husman AMdR, Altavilla N, Deere D, Ashbolt N (2003). Fate and transport of surface water pathogens in watersheds. Critical Reviews in Environmental Science and Technology 33(3): 299-360

Fries JS, Characklis GW, Noble RT (2006). Attachment of fecal indicator bacteria to particles in the Neuse River Estuary, NC. Journal of Environmental Engineering 132: 1338-1345.

Fux C, Costerton J, Stewart P, Stoodley P (2005). Survival strategies of infectious biofilms. Trends in Microbiology 13: 34-40.

Gonenc IE, Wolflin JP (2004). Coastal lagoons: ecosystem processes and modeling for sustainable use and development. CRC Press: 143

Harvey RW, Ryan JN (2004). Use of PRD1 bacteriophage in groundwater viral transport, inactivation, and attachment studies. FEMS Microbiology Ecology 49: 3-16.

Horswill AR, Stoodley P, Stewart PS, Parsek MR (2007). The effect of the chemical, biological, and physical environment on quorum sensing in structured microbial communities. Analytical and Bioanalytical Chemistry 387: 371-380.

Huws S, McBain A, Gilbert P (2005). Protozoan grazing and its impact upon population dynamics in biofilm communities. Journal of Applied Microbiology 98: 238-244.

Khan NH, Ishii Y, Kimata-Kino N, Esaki H, Nishino T, Nishimura M et al. (2007). Isolation of Pseudomonas aeruginosa from open ocean and comparison with freshwater, clinical, and animal isolates. Microbial Ecology 53: 173-186.

Kim M, Wuertz S (2015). Survival and persistence of host-associated Bacteroidales cells and DNA in comparison with Escherichia coli and Enterococcus in freshwater sediments as quantified by PMA-qPCR and qPCR. Water Research 87: 182-192.

Kropinski AM, Mazzocco A, Waddell TE, Lingohr E, Johnson RP (2009). Enumeration of bacteriophages by double agar overlay plaque assay. Bacteriophages: Methods and Protocols, Volume 1: Isolation, Characterization, and Interactions: 69-76.

Lee K, Periasamy S, Mukherjee M, Xie C, Kjelleberg S, Rice SA (2014). Biofilm development and enhanced stress resistance of a model, mixed-species community biofilm. ISME J 8: 894-907.

Legnani P, Leoni E, Rapuano S, Turin D, Valenti C (1999). Survival and growth of Pseudomonas aeruginosa in natural mineral water: a 5-year study. International Journal of Food Microbiology 53: 153-158. 
Leid JG, Willson CJ, Shirtliff ME, Hassett DJ, Parsek MR, Jeffers AK (2005). The exopolysaccharide alginate protects Pseudomonas aeruginosa biofilm bacteria from IFN- $\gamma$ mediated macrophage killing. The Journal of Immunology 175: 7512-7518.

Masago Y, Shibata T, Rose JB (2008). Bacteriophage P22 and Staphylococcus aureus attenuation on nonporous fomites as determined by plate assay and quantitative PCR. Applied and Environmental Microbiology 74: 5838-5840.

Matz C, Kjelleberg S (2005). Off the hook - how bacteria survive protozoan grazing. Trends in Microbiology 13: 302-307.

McBride GB, Stott R, Miller W, Bambic D, Wuertz S (2013). Discharge-based QMRA for estimation of public health risks from exposure to stormwater-borne pathogens in recreational waters in the United States. Water Research 47: 5282-5297.

McDougald D, Rice SA, Barraud N, Steinberg PD, Kjelleberg S (2012). Should we stay or should we go: mechanisms and ecological consequences for biofilm dispersal. Nature Reviews Microbiology 10: 39-50.

Mwanamoki PM, Devarajan N, Thevenon F, Atibu EK, Tshibanda JB, Ngelinkoto P et al. (2014). Assessment of pathogenic bacteria in water and sediment from a water reservoir under tropical conditions (Lake Ma Vallée), Kinshasa Democratic Republic of Congo. Environmental Monitoring and Assessment 186: 6821-6830.

Ogorzaly L, Gantzer C (2006). Development of real-time RT-PCR methods for specific detection of F-specific RNA bacteriophage genogroups: application to urban raw wastewater. Journal of Virological Methods 138: 131-139.

Pirnay JP, Matthijs S, Colak H, Chablain P, Bilocq F, Van Eldere J et al. (2005). Global Pseudomonas aeruginosa biodiversity as reflected in a Belgian river. Environmental Microbiology 7: 969-980.

Purevdorj B, Costerton J, Stoodley P (2002). Influence of hydrodynamics and cell signaling on the structure and behavior of Pseudomonas aeruginosa biofilms. Applied and Environmental Microbiology 68: 4457-4464.

Rajal VB, McSwain BS, Thompson DE, Leutenegger CM, Kildare BJ, Wuertz S (2007). Validation of hollow fiber ultrafiltration and real-time PCR using bacteriophage PP7 as surrogate for the quantification of viruses from water samples. Water Research 41: 14111422 .

Ralston EP, Kite-Powell H, Beet A (2011). An estimate of the cost of acute health effects from food-and water-borne marine pathogens and toxins in the USA. Journal of Water and Health 9: 680-694. 
Santo Domingo JW, Siefring SC, Haugland RA (2003). Real-time PCR method to detect Enterococcus faecalis in water. Biotechnology Letters 25: 261-265.

Sauer K, Camper AK, Ehrlich GD, Costerton JW, Davies DG (2002). Pseudomonas aeruginosa displays multiple phenotypes during development as a biofilm. Journal of Bacteriology 184: 1140-1154.

Sauer K, Cullen M, Rickard A, Zeef L, Davies D, Gilbert P (2004). Characterization of nutrient-induced dispersion in Pseudomonas aeruginosa PAO1 biofilm. Journal of Bacteriology 186: 7312-7326.

Saxena G (2014). Adaptation of microbial communities and their functions to environmental pressures in an urban waterways system.

Schijven JF, Hassanizadeh SM (2000). Removal of viruses by soil passage: Overview of modeling, processes, and parameters. Critical Reviews in Environmental Science and Technology 30: 49-127.

Schillinger JE, Gannon JJ (1985). Bacterial adsorption and suspended particles in urban stormwater. Journal (Water Pollution Control Federation) 57: 384-389.

Schriewer A, Wehlmann A, Wuertz S (2011). Improving qPCR efficiency in environmental samples by selective removal of humic acids with DAX-8. Journal of Microbiological Methods 85: 16-21.

Shen C, Phanikumar MS, Fong TT, Aslam I, McElmurry SP, Molloy SL et al. (2008). Evaluating bacteriophage P22 as a tracer in a complex surface water system: the Grand River, Michigan. Environmental Science \& Technology 42: 2426-2431.

Singer G, Besemer K, Hödl I, Chlup A, Hochedlinger G, Stadler P et al. (2006). Microcosm design and evaluation to study stream microbial biofilms. Limnology and Oceanography: Methods 4: 436-447.

Sinton LW, Finlay RK, Lynch PA (1999). Sunlight inactivation of fecal bacteriophages and bacteria in sewage-polluted seawater. Applied and Environmental Microbiology 65: 36053613.

Stewart PS, William Costerton J (2001). Antibiotic resistance of bacteria in biofilms. The Lancet 358: 135-138.

Stoodley P, K. Sauer, D. G. Davies, Costerton JW (2002). Biofilms as complex differentiated communities. Annual Review of Microbiology 56: 187-209. 
Suttle CA, Chen F (1992). Mechanisms and rates of decay of marine viruses in seawater. Applied and Environmental Microbiology 58: 3721-3729.

Tufenkji N (2007). Modeling microbial transport in porous media: Traditional approaches and recent developments. Advances in Water Resources 30: 1455-1469.

UNEP (2013). Global Environment Outlook 2000, vol. 1. Routledge.

van Veen JA, van Overbeek LS, van Elsas JD (1997). Fate and activity of microorganisms introduced into soil. Microbiology and Molecular Biology Reviews 61: 121-135.

Venugopalan V, Kuehn M, Hausner M, Springael D, Wilderer P, Wuertz S (2005). Architecture of a nascent Sphingomonas sp. biofilm under varied hydrodynamic conditions. Applied and Environmental Microbiology 71: 2677-2686.

Volkmann H, Schwartz T, Kirchen S, Stofer C, Obst U (2007). Evaluation of inhibition and cross-reaction effects on real-time PCR applied to the total DNA of wastewater samples for the quantification of bacterial antibiotic resistance genes and taxon-specific targets. Molecular and Cellular Probes 21: 125-133.

Weinbauer MG, Höfle MG (1998). Significance of viral lysis and flagellate grazing as factors controlling bacterioplankton production in a eutrophic lake. Applied and Environmental Microbiology 64: 431-438.

WHO http://www.who.int/heli/risks/water/water/en/.

Wommack KE, Hill RT, Muller TA, Colwell RR (1996). Effects of sunlight on bacteriophage viability and structure. Applied and Environmental Microbiology 62: 1336-1341. 


\section{Link between flow regime, biofilm properties and pathogen fate in freshwater mesocosm flumes in an urban tropical setting}

\subsection{Abstract}

Biofilms can act as a reservoir of pathogens in natural aquatic systems and biofilm properties like community composition and architecture are influenced by the flow regime in the system. However, the impacts of change in flow on biofilm properties and the link with pathogen interception, persistence and detachment are little studied. In this study, we addressed two research questions: (i) how does a high flow rate affect the fate of pathogens in the presence of biofilms and (ii) are pathogen kinetics like detachment, decay and growth rates altered at different flow rates? We monitored the fate of common waterborne pathogens using suitable surrogates - Pseudomonas aeruginosa, Enterococcus faecalis and bacteriophage P22. We compared results from this study and an earlier study of identical design but different flow rate (see Chapter 2). Four open channel flumes with partial recirculation (laminar range) were studied in duplicate experiments with a high and a low flow rate corresponding to $\mathrm{Re}=359$ and 718 , respectively. These conditions refer to dry weather flow and average annual flow in a tropical urban canal in Singapore. In each experiment, two flumes were spiked once with surrogates at the beginning, and the concentrations of viable cell or phage populations and their nucleic acids in water and biofilm were followed for $21 \mathrm{~d}$. At either flow rate, the surrogates entered the biofilm within the first $24 \mathrm{~h}$. Detachment of the bacterial strains, especially P. aeruginosa, from the biofilm at low flow was random, suggesting sloughing to be the dominant mechanism, whereas at high flow, the detachment was more continuous, pointing toward erosion as mechanism. The time required to remove $99 \%$ of the surrogates from water (or $\mathrm{T}_{99}$ ) was lengthened by $24-57 \%$ at the high flow rate. In contrast, the respense time $\mathrm{T}_{99}$ in biofilms was $35-500 \%$ shorter at this flow rate. The detachment rates of P. aeruginosa and P22 DNA were 
approximately $80 \%$ higher at the high flow rate. Decay in biofilms was also heightened at high flow rate with corresponding decay rate constants increasing between 22 and $83 \%$ compared to the low flow rate. P. aeruginosa was found to grow at low flow but not at high flow, whereas $E$. faecalis grew at both flow rates, growth rate being more than $50 \%$ higher at the high flow rate. To the best of our knowledge, this is the first study to show quantitatively the link between hydrodynamic variability and the role of biofilms in pathogen fate and transport in freshwater systems. 


\subsection{Introduction}

Pathogen contamination of natural waterbodies is an emerging threat. According to a recent report by US Environmental Protection Agency (EPA), Center for Disease Control and prevention (CDC) and the Council of State and Territorial Epidemiologists' on waterborne outbreaks in the United States, a total of 259 outbreaks, 21740 cases of estimated illness, 36 cases requiring emergency unit admission, 206 cases requiring hospital care and 28 cases of death were recorded from 1971 to 2000 in the US alone (Yoder et al. 2008). Most of these cases were caused by pathogens like Shigella sp. (Gram negative bacterium), followed by Naeglaria fowleri (amoeba), E.coli O157:H7 (Gram negative), Schistosoma sp. (parasitic flatworm), Norovirus (single stranded RNA virus), Leptospira spp (Gram negative bacteria), Giardia sp. (protozoa) and Cryptosporidium spp. (protozoa) (Wymer 2007). However, mere detection of pathogens in water bodies is not sufficient to predict the associated risks. A better risk estimation would be based on knowledge of pathogen inactivation and distribution in natural systems.

Pathogen inactivation in natural aquatic systems occurs due to sunlight exposure (Davies et al. 2009, Misstear and Gill 2012, Sinton et al. 1999), predation by grazers (Huws et al. 2005, Matz and Kjelleberg 2005, Weinbauer and Höfle 1998) and sudden changes in water or bed chemistry (Benham et al. 2006, Brookes et al. 2004). Pathogen distribution depends on concentration and nature of the input, for example, whether it is a point or diffused source, and hydrodynamic processes like settling and resuspension (de Brauwere et al. 2014). Black box models developed for predicting bacterial concentrations in water have identified the amount of rainfall, mean daily discharge, time since peak of hydrograph and hydrograph slope and flow rates as key variables (He and He 2008, Heberger et al. 2008, Olyphant et al. 2003). In most cases, the changes in hydrodynamics, such as increase in discharge volume, lead to an increase in pathogen input in the system. However, even if input is controlled, flow 
regimes impact pathogen fate in a multitude of different ways. For example, deposition and resuspension of sediments, which often have microorganisms associated with them, are directly related to flow rate in the system (Kim et al. 2010). Flow conditions can also affect processes like hyporheic exchange (Packman and Salehin 2003), which in turn impacts pathogen fate (Searcy et al. 2006). Hydrodynamics further influences pathogen fate by modifying retention characteristics of various sources and sinks such as sediments and biofilms (Lau and Droppo 2000).

Sediment erosion is also influenced by growth of biofilms, which generally reduces resuspension (Decho 2000, Yallop et al. 2000). Additionally, biofilms often are a source of pathogens in aquatic environments (Arnon et al. 2010, Balzer et al. 2010, Buswell et al. 1998, Drummond et al. 2015) and flow conditions impact biofilm properties including community composition (Besemer et al. 2009) and architecture (Battin et al. 2003, Pereira et al. 2002), which impacts interception (van Veen et al. 1997) and release (Boulêtreau et al. 2006, Stoodley et al. 2002) of pathogens in these systems. Fate in biofilms is also dependent on activities of grazers and bacteriophages, which are likewise influenced by the hydrodynamics of the system (Barros et al. 2010, Levandowsky et al. 1988).

Flow conditions in natural water bodies, although considered to be the "master variable" controlling different ecological and geomorphological processes (Ceola et al. 2013), are not constant. They vary over wide ranges, daily and seasonally, depending on net precipitation and demand (Dettinger and Diaz 2000). In the long term, hydrology of waterbodies can change due to changes in anthropogenic activities such as land use patterns (Tong and Chen 2002). Even climate change is likely to cause major changes in flow regimes of many waterbodies (Arnell 1999). 
Most models developed for understanding pathogen fate are mechanistic models that include key processes such as settling, resuspension and decay as source and sink terms. Such models are either based on conditions prevailing in natural systems (Chapra 2008, Kim et al. 2010) or developed by studying controlled systems in order to study perturbations (Bai and Lung 2005, Gao et al. 2011). Most of them also treat the different source and sink terms as discrete physical processes and do not connect the effect of hydrodynamic variability with a role of biofilms in pathogen fate. In this study, we investigated whether in freshwater systems, hydrodynamic conditions affect settling, integration and detachment behavior of pathogens in the presence of a photosynthetic biofilm. We also explored whether biofilm kinetic processes can be different due to different flow rates and if they can, in turn, impact the fate of pathogens. Using mesocosm flumes, we studied the behavior of Pseudomonas aeruginosa, Enterococcus faecalis and bacteriophage P22 in the presence of mature photosynthetic biofilms, grown at a high flow rate that referred to the average flow conditions prevailing in urban canals and compared this scenario with an identical experimental set up at a low flow rate referring to the low flow conditions (as detailed in Chapter 2). As pathogens can enter a viable but non-culturable form in natural aquatic systems, we studied the fate of both viable populations and nucleic acids of these surrogates of bacterial pathogens.

\subsection{Materials and methods}

\subsubsection{Experimental set up}

A total of four experiments were performed in order to study the effects of two different flow rates on the fate of P. aeruginosa, E. faecalis, phages P22 and GA (Fig 3.1). In each experiment, four mesocosm flumes were used. The flumes were set up at Van Kleef Center, an outdoor research facility located next to an urban canal (Sungei Ulu Pandan) in Singapore. The details on design of the flumes can be found elsewhere (Chapter 2). Briefly, the flumes were operated in partial recirculation mode. The flow rates inside the flumes were 
controlled with the recirculation flow rate. The two flow rates selected were $6 \mathrm{~L} \mathrm{~min}^{-1}$ (low) and $12 \mathrm{~L} \mathrm{~min}^{-1}$ (high) which translate to a dimensionless Reynolds number, $R e$, of 359 and 718 , respectively. The flow rates represent dry weather flow rate and annual average flow rate in Singapore's urban canals (Saxena et al. 2015).

Prior to each experiment, the flumes were prepared by operating them continuously with raw canal water for three weeks. The microbial inoculum in the canal water facilitated the growth of a photosynthetic benthic biofilm that resembled biofilms generally present at shallow depths of natural waterbodies. After three weeks of operation, two of the four flumes were spiked with four surrogates of pathogens, namely, Pseudomonas aeruginosa (SS1, environmental isolate), Enterococcus faecalis (ATCC 47077), P22 phage (ATCC 97541) and GA (SW1) phage. The remaining two flumes were used as procedural controls. The details on cultivation of these surrogates, spiking procedure and sample collection can be found elsewhere (Chapter 2). GA phage was not detected in the flumes after inoculation due to insufficient particles available for quantification. Hence results are reported only for the two bacterial strains and P22 phage.

\subsubsection{Sample collection and processing}

After spiking the two flumes with surrogates, water and biofilm samples were collected on alternate days and cultivable cell, infectious bacteriophage and surrogate nucleic acid concentrations were measured as previously described. Briefly, P. aeruginosa was cultivated using the membrane filter technique and Cetrimide agar as the selective medium (Legnani et al. 1999). The same technique was used for estimating viable E. faecalis populations but using MEI agar (Messer and Dufour 1998). Infectious bacteriophages were estimated using the double agar layer method, which involved growing the phages on a lawn of their respective host bacteria (Kropinski et al. 2009). Salmonella enterica serovar Typhimurium and E. coli were used as hosts for P22 and GA bacteriophage respectively. 
Nucleic acid concentrations were measured using qPCR as described before (Chapter 2). Briefly, biofilm samples were first homogenized using a bead beating procedure. Next, nucleic acids were extracted from both water and biofilm samples using Purelink viral DNA/RNA Minikit by following the manufacturer's protocol. Each $25 \mu 1$ qPCR reaction volume contained $12.5 \mu \mathrm{l}$ of Taqman Universal Mastermix II with UNG (Applied Biosystems, Foster City, CA, USA), $5 \mu 1$ of extracted nucleic acids and appropriate concentrations of primers and probes, and DNAse and RNAse free water to complete the reaction volume. Negative controls were prepared in a similar manner using water in place of nucleic acids. Thermal cycling conditions were $2 \min$ at $50{ }^{\circ} \mathrm{C}$ followed by 10 min at $95{ }^{\circ} \mathrm{C}$, followed by 40 cycles of $15 \mathrm{~s}$ at $95^{\circ} \mathrm{C}$ and $1 \mathrm{~min}$ at $60^{\circ} \mathrm{C}$.

Additionally, physicochemical variables of the canal water, such as, $\mathrm{pH}$, temperature, TDS, conductivity, redox potential, DO, DOC, nitrate, nitrite, phosphate and sulfate were monitored daily. Temperature, $\mathrm{pH}$, TDS, conductivity, redox potential and DO were measured using a portable DO/pH/EH/T meter (YSI Professional Plus, United States). For DOC, nitrite, nitrate, phosphate and sulfate, water was filtered on site using $0.22-\mu \mathrm{m}$ disposable sterile filters and frozen. DOC was measured using a TOC analyzer (TOC-L series, Shimadzu) and the remaining parameters were determined using ion chromatography (Dionex ICS-5000 Ion Chromatography System). Four biofilm surface properties - hydrophobicity (Rosenberg 1984), rheology (Klapper et al. 2002), zeta potential (Wilson et al. 2001) and chlorophyll content (Chl-a) (Battin et al. 2003) - were measured using standard analytical procedures.

\subsubsection{Surrogate mass balance in water and biofilm phases}

Details of surrogate mass balance calculations in water and biofilm phases were described previously (Chapter 2). Briefly, a simple hydrodynamic model was developed where the target concentration in the water phase was a function of the inflow and outflow from the system, settling, detachment and decay, where outflow, settling and decay were the 
main sinks and detachment from biofilm was a source. Overall, the surrogate concentrations in water were represented as follows:

$V \frac{d C_{i}^{w}}{d t}=Q_{s p} C_{i}^{s p}+Q_{\text {in }} C_{i}^{i n}+Q_{b} \rho C_{i}^{b}-Q_{\text {out }} C_{i}^{\text {out }}-Q_{s} C_{i}^{w}-k_{i} C_{i}^{w} V$

The decay constant was experimentally determined as explained previously in Chapter 2 .

The surrogate budget in the biofilms was calculated similarly, including settling from water as a source and detachment and decay as the sink terms. Mathematically, surrogate concentrations in the biofilms were represented as follows:

$C_{i}^{b}=C_{i, 0}^{b} e^{-\lambda^{b} t}+\frac{v_{S} F_{P} C_{i}^{w}}{\lambda^{b}}\left(1-e^{-\lambda^{b} t}\right)$

\subsubsection{Calculation of decay rate and $T_{99}$, growth rate and detachment rates}

\subsubsection{Decay rate and $T_{99}$}

The rate of net loss in water and biofilms was quantified as the net decay rate and corresponds to losses due to all physical and biological processes in the system. Quantitatively, it can be derived from equation 3.2 as follows:

$C_{b}=\frac{W_{2}}{\lambda^{A_{s}}}\left(1-e^{-\lambda t}\right)$

Where, the net decay rate constant in biofilms, $\lambda=v_{r} \rho+k$

Eq. 3.4

The decay rate was calculated from the experimental data using a first order exponential decay model, represented as follows:

$C=C_{0} \times e^{-\lambda t}$

Where, $C$ (cfu, pfu or $\mathrm{gc} \mathrm{mL}^{-1}$ ) is concentration of surrogates at time $t(\mathrm{~d})$ and $C_{0}(\mathrm{cfu}$, pfu or $\left.\mathrm{gc} \mathrm{mL}^{-1}\right)$ is the initial concentration.

$\mathrm{T}_{99}$ is defined as the time required for the system to recover from a pollutant release, by removal of $99 \%$ of the pollutant (Chapra 2008). $\mathrm{T}_{99}$ was calculated as follows: 


\subsubsection{Growth rate of surrogates in biofilm}

Net growth rate in biofilms, where appropriate, was calculated using a first order model as follows:

$\mu=\frac{1}{t} \ln \left(\frac{C}{C_{0}}\right)$

Where, $\mu\left(\mathrm{d}^{-1}\right)=$ specific growth rate, $t(\mathrm{~d})=$ time, $C\left(\mathrm{cfu}, \mathrm{pfu}\right.$ or $\left.\mathrm{gc} \mathrm{mL}^{-1}\right)=$ observed

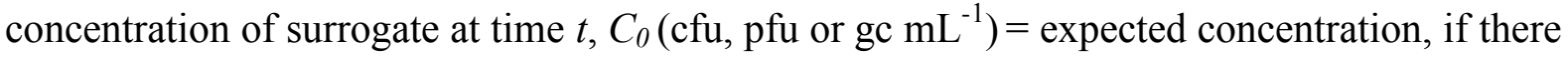
was no growth at time $t$, derived from the mass balance model.

\subsubsection{Detachment rate of surrogates from biofilms}

Detachment rates, where applicable, were calculated as per the following equation (Jamieson et al. 2005):

$R S=\frac{C_{w} \times Q}{C_{b} \times A_{s}}$

Where, $R S$ is the detachment rate, $C_{w}\left(\mathrm{cfu}, \mathrm{pfu}\right.$ or $\mathrm{gc} \mathrm{mL}^{-1}$ ) is the concentration of surrogate in water, $C_{b}$ (cfu, pfu or $\left.\mathrm{gc} \mathrm{mL}^{-1}\right)$ is the concentration of surrogates in biofilm, $Q(\mathrm{~L}$ $\left.\min ^{-1}\right)$ is the flow rate in the flumes, and $A_{s}\left(\mathrm{~cm}^{2}\right)$ is the flume surface area. We normalized $C_{w}$ against $C_{b}$ to account for differences in biofilm concentrations in different experiments. We calculated the detachment rates for P. aeruginosa and P22 DNA only because in the case of E. faecalis, there was an additional source of cells in the feed. Even though E. faecalis detachment rates can be theoritically calculated by adjusting for the feed concentration, in practice, any E. faecalis present in the water has equal chances of being released from biofilm or being non-settled autochthonous population. Error margins in such cases would be high. All non-linear regression analysis and curve fitting was done using SigmaPlot ${ }^{\mathrm{TM}} 12$ (Systat Software Inc, San Jose, CA). 


\subsection{Results and Discussion}

\subsubsection{Fate of $P$. aeruginosa, $\mathrm{P} 22$ and $E$. faecalis in the aqueous phase at high and low flow}

rates

In the water phase, P. aeruginosa cells were detected for one week (Fig 3.2 A) at high flow as they were at low flow (see Chapter 2, Fig 2.3 A). In contrast, the DNA was detected for a longer period (16 to $20 \mathrm{~d}$ ) at high flow (Fig $3.3 \mathrm{~A})$ than at low flow, (10-12 d; see Fig 2.3 A). The cultivable fraction of P22 in water was detected for $8 \mathrm{~d}$ (Fig $3.2 \mathrm{~B}$ ) at high flow similar to results at low flow (Fig 2.3 B). In contrast, P22 DNA was detected for 16-18 d at high flow (Fig $3.3 \mathrm{~B}$ ), but at low flow it was detected for the entire experimental duration (Fig 2.3 B). Enterococcus faecalis cells were detected until day 16 (Fig 3.2 C) at high flow, while they were detected for $20 \mathrm{~d}$ at low flow (Fig $2.3 \mathrm{C}$ ). In all experiments a viable autochthonous E. faecalis population was present in the feed water $\left(10^{0}-10^{1}\right.$ at low flow, 0 $10^{1} \mathrm{cfu} \mathrm{mL}^{-1}$ at high flow). At both flow rates, E. faecalis DNA was detected for 4-6 d (Fig 3.3 C and 2.3 C).

Even though it is well known that microorganisms undergo rapid decay in the water column (Fergusson et al., 2003), the initial concentration of surrogates added to the system can impact the length of time it is detected. Hence we adopted two-log reduction time $\left(\mathrm{T}_{99}\right)$ for comparison. In general, the $\mathrm{T}_{99}$ in water was higher at high flow if there had been any detachment from biofilms. For example, for P. aeruginosa cells the $\mathrm{T}_{99}$ was similar at both flow rates (Table 3.1) and according to our mass balance analysis, the P. aeruginosa cells did not detach from biofilms at either flow rate during weeks 2 and 3. In fact, at high flow, concentrations observed in the water phase could be explained by outflow and estimates for settling and decay rates, suggesting that detachment of cells from the biofilm was not a significant source to the water during this interval. At low flow, however, detachment contributed to the observed concentration in water during week 1 (Chapter 2). 
The P22 viable population did not detach in the later phase at any flow rate (Fig 3.2 B and 2.5 A and B) but there were more instances when the surrogates detached from biofilms at high flow rate during the early phase. Consequently, the $\mathrm{T}_{99}$ in water was higher at high flow for the P22 viable fraction (24\%). Significantly, the $\mathrm{T}_{99}$ of viable E. faecalis cells in water was about $10 \mathrm{~d}$ at high flow and $>20 \mathrm{~d}$ at low flow (Table 3.1). Since autochthonous E. faecalis cells were present in the feed water, we cannot link observed $\mathrm{T}_{99}$ values to detachment from biofilm alone. However, the autochthonous E. faecalis population was higher and continuously present for the entire duration of the experiment during the low flow experiments, which explains the increased detection time during low flow experiments.

$\mathrm{T}_{99}$ was also higher at high flow for $P$. aeruginosa DNA (39\%) and E. faecalis DNA (48\%). P22 DNA showed detachment from biofilm at high flow (Fig 3.3 B), as previously seen for low flow (Fig 2. $5 \mathrm{C}$ and D), but the $\mathrm{T}_{99}$ was higher at low flow for P22 DNA (24\%). At low flow, phages detached continuously from biofilms and reentered the water column until the end of the experiment. In contrast, the biofilm sink was depleted much earlier at high flow which explains the paradox. Increased detachment is known to be caused by higher erosion at high flow (Grabowski et al. 2011) if the targets are not attached or deeply embedded in the biofilm. Additionally, detachment frequency is inversely related to target size, which would explain the different behaviour of the phage and bacteria (Stoodly et al., 2001). Bacteria are also known to undergo controlled cell lysis during biofilm development (Bayles, 2007). The flow rate in our system may have been sufficient to transport such extracellular DNA from the biofilm to the water column, but not larger aggregates of cells deeply embedded within the biofilm. For example, P. aeruginosa is known to form strongly adhering biofilms and biofilm formation often leads to increased critical shear stress of a system (Purevdorj et al. 2002). In our flumes, existant biofilms did not comprise of single species but mixed communities of eukaryotic and prokaryotic cells that firmly embedded viable $P$. aeruginosa 
cells. The lack of detachment of this surrogate during week 1 at high flow resembles that of fine sediments, which are more resistant to erosion when deposited at high flow, compared to low flow (Lau and Droppo, 2000).

Finally, at high flow, detachment of $P$. aeruginosa DNA lasted until the end of the experiment (Fig 3.3A). In contrast, at low flow, the $P$. aeruginosa DNA present in biofilms mostly did not detach during later phases of the experiment (Fig 2.4 C and D). E. faecalis cells and DNA showed similar underestimations of the detached fraction at high flow (Fig $3.2 \mathrm{C}$ and $3.3 \mathrm{C}$ ) compared to low flow (Fig 2.6 A-D). These trends were explained by analyzing the biofilm kinetics as explained below.

\subsubsection{Fate of $P$. aeruginosa, $\mathrm{P} 22$ and $E$. faecalis viable populations and DNA in biofilms at high and low flow rates}

\subsubsection{Detection and $T_{99}$ of $P$. aeruginosa, $P 22$ and $E$. faecalis in biofilm at high and low flow} rates

At both flow rates, all surrogates entered the biofilm within $24 \mathrm{~h}$. Cultivable $P$. aeruginosa cells (Fig 3.4 A) and DNA (Fig 3.5 A) were detected in biofilms for the entire experimental period of $20 \mathrm{~d}$ at high flow as well as low flow (Fig $2.3 \mathrm{D}$ ). In contrast, cultivable P22 phages were detected for $8 \mathrm{~d}$ at high flow (Fig $3.4 \mathrm{~B}$ ) and for about $14 \mathrm{~d}$ at low flow (Fig $2.3 \mathrm{E}$ ). P22 DNA was measured for $20 \mathrm{~d}$ at both flow rates (Fig $3.5 \mathrm{~B}$ and 2.3E). Finally, viable Enterococcus faecalis cells were detected during the entire 20-d period at high flow (Fig 3.4 C). E. faecalis DNA was undetectable after $12 \mathrm{~d}$ at high flow (Fig $3.5 \mathrm{C}$ ), with one exception when the DNA was detected until $20 \mathrm{~d}$. Both cells and DNA were present for a similar duration ( $20 \mathrm{~d}$ and $12 \mathrm{~d}$ for cells and DNA respectively) at low flow (Fig $2.3 \mathrm{~F}$ ).

In general, at low flow, the mass balance predictions for biofilms were lower than the observed values at low flow rates. In contrast, the same model, with appropriate adjustments for the change in flow rate, predicted the concentrations of viable $P$. aeruginosa and P22 more accurately (Fig $3.4 \mathrm{~A}$ and B) at high flow rates. In contrast, the model underestimated 
the concentrations of E. faecalis cells at high flow after $10 \mathrm{~d}$ (Fig 3.4 C). E. faecalis DNA concentrations corresponding to the time after $10 \mathrm{~d}$ were below the detection limit. The DNA concentrations of all three surrogates were closer to predicted values at high flow (Fig 3.5 A, B and C). In order to explain the observed trends in surrogate concentrations, we estimated the $\mathrm{T}_{99}$, detachment rates, decay rates and growth rates of surrogates in biofilms at both flow rates (Table 3.1).

$\mathrm{T}_{99}$ values in biofilms were uniformly lower at high flow compared to low flow for all surrogates except for E. faecalis cells. The $\mathrm{T}_{99}$ of E. faecalis cells were lower at low flow, as E. faecalis concentrations (cells and DNA) in biofilms were higher at high flow than at low flow. Mass balance analysis showed that the higher concentrations were not due to higher concentrations of the autochthonous population but due to growth in the biofilms. For the remaining targets, at high flow, the $\mathrm{T}_{99}$ values in biofilms were $67 \%$ lower for $P$. aeruginosa cells, 46\% lower for P. aeruginosa DNA, over 500\% lower for viable P22, 35\% lower for P22 DNA, and 38\% lower for E. faecalis DNA (during week 1) at high flow. E. faecalis DNA was below the detection limit during the late phases of the experiment.

\subsubsection{Detachment of P. aeruginosa and P22 at high and low flow rates}

We calculated that $P$. aeruginosa DNA detachment rates were $80 \%$ higher at high flow rate whereas those of P22 DNA were $78 \%$ higher at high flow rate. In terms of percentage of surrogates released back into the aqueous phase, at low flow, around 5.23\% ( $\mathrm{SD}=5.1)$ and at high flow, $13.34 \%(\mathrm{SD}=7.54)$ of $P$. aeruginosa $\mathrm{DNA}$ was detached. At low flow, $2 \%$ (SD $=1.8)$ and at high flow, $12.45 \%(\mathrm{SD}=3.0)$ of P22 DNA was detached. The fraction of surrogates released in high flow flumes was similar to that reported for rotating disc reactors with mature multispecies biofilms $(\approx 20 \%)$ (Okabe et al. 1997). Additionally, we observed that at low flow rates towards the last phase of the experiment, detachment of $P$. aeruginosa cells and DNA was a random event, when they were released in high concentrations from the 
biofilm. On the contrary, detachment of DNA was a continuous process at high flow rates and the concentrations were lower than those observed during random detachments at low flow rate. This observation is in agreement with earlier studies suggesting that in low shear environments, biofilms are removed mainly through sloughing but as shear is increased, erosion is the more dominant removal process (Van Loosdrecht et al. 2002). Researchers have also found that the detachment rate of bacteria in a biofilm system doubled with a doubling of flow velocity (Tsai 2005). Research on particle and contaminant transport in sediment based systems, on the other hand, has shown that sediment deposited under higher shear is more resistant to erosion (Lau and Droppo 2000).

Detachment rates at high flow were approximatey ten times lower than expected based on model calculations. Lower than expected detachment rates were also reported by researchers tracking detachment of micro-beads from a P. aeruginosa biofilm (Drury et al. 1993). We have seen that at high flow, biofilms tend to be marginally more hydrophobic than their low flow counterparts (Fig. 3.6 B), and hydrophobicity increased over time. Even though the observed differences were not significant, as hydrophobicity influences adhesion (Van Loosdrecht et al. 1990, Van Loosdrecht et al. 1987), such differences can alter the number of cells or DNA released in the system. These differences show that the fate of pathogens in biofilms cannot be fully predicted by treating microorganisms as particles using sediment transport models.

\subsubsection{Decay rate constants of P. aeruginosa, P22 and E. faecalis at high and low flow rates}

In general, the net decay rate constants in biofilms were higher at high flow rates for all surrogates (Table 3.1), with the exception of E. faecalis cells. Decay rate constants of $P$. aeruginosa cells and DNA were $37 \%$ and $26 \%$ higher, respectively, at high flow compared to low flow. The decay rate of viable P22 was $83 \%$ higher at high flow. The difference was less drastic for P22 DNA, where the decay rate was only 34\% higher at high flows. The decay rate 
of E. faecalis DNA was $22 \%$ higher at high flow rate. Mass balance analyses confirmed that this increased decay was not coupled to increased loss through biofilm detachment at high flow rates. This is in contrast to a recent finding, where a higher shear led to reduced decay (Walters et al. 2014), as at higher stress the biofilm were thicker and provided better protection to the embedded bacteria. Higher flow rates, however, do not a always lead to a thick biofilm but often result in denser biofilms, and lower shear stress leads to formation of rough and porous biofilms (Van Loosdrecht et al. 2002). Biofilm models like BIOSIM consider detachment rates to be a function of biofilm thickness where a $100 \%$ increase in biofilm thickness translates to a 50\% decrease in detachment rate (Peyton and Characklis 1992). Lower release rates translates to particles being more entrapped. Hence, in low flow flumes such a trend would mean surrogates will be better protected in biofilms compared to more compact ones formed at higher flow rates. Additionally, in our flumes, DOC (Fig 3.6A), DO, nitrite, nitrate and sulfate concentrations were also marginally lower whereas chlorophyll concentrations were higher at high flow rates (Sup. Table S. 1). Chlorophyll concentrations give an idea of the amount of algae present in the system, which can form elaborate structures that can entrap surrogates, causing secondary losses. The other parameters show that high flow rate led to a nutrient poorer system. Though the differences in concentrations were not biologically relevant, conditions for surrogate survival were comparatively less favourable at high flow rates. In contrast, decay rates of E. faecalis cells were higher at low flow rates $(28 \%)$, which is coupled to differential growth of this bacterium at different flow rates, as discussed shortly.

Additionally, biological decay $(k)$ in biofilms at both flow rates was higher than that observed in batch systems and it was adjusted for predatorial activity by adding a factor $k_{g}$ as explained previously (Chapter 2). Even though predator activity causing additional losses of FIB concentrations in natural waerbodies has been reported earlier (Walters et al. 2014), decay 
rates are generally lesser in sediment beds (Craig et al. 2004). Free floating bacteria also decay faster than particle associated bacteria (Liu et al. 2006). Decay is reduced in these systems mainly because the sediment protects the microorganisms against decay from sunlight, salinity, and so forth. However, biofilms being dynamic systems, the behaviour of pre-grown biofilms toward an invading microorganism can be both beneficial and harmful (Hall-Stoodley et al. 2004). Net decay ( $\lambda$ ) in our system was indeed higher in water than in the biofilm phase. This is expected as in our system settling was more dominant than detachment from biofilm.

\subsubsection{Growth rates of P. aerugiosa and $E$. faecalis at high and low flow rates}

According to mass balance analysis, the persistant fractions of $P$. aeruginosa and E. faecalis showed possibilities of re-growth in biofilms during the later phases thus reducing the net decay. Both bacteria are commonly found in freshwater and have been shown to coexist in multispecies biofilms (O'Toole et al. 2000). Studies have also shown that $P$. aeruginosa can regrow in aquatic environments (Khan et al. 2007) and Enterococcus sp. can regrow in natural waterbodies in tropical and subtropical environments (Byappanahalli et al. 2003).

At low flow, we estimated the growth rates of $P$. aeruginos a cells and DNA to be $2.71 \mathrm{~d}^{-1}$ and $5.2 \mathrm{~d}^{-1}$ respectively (Table 3.1$)$. The growth rate of P.aeruginosa cells $\left(2.71 \mathrm{~d}^{-1}\right)$ at low flow was higher than that of E. faecalis $\left(1.9 \mathrm{~d}^{-1}\right)$, a trend similar to that for their planktonic counterparts ( $P$. aeruginosa $=0.8 \mathrm{~h}^{-1}$, E. faecalis $0.6 \mathrm{~h}^{-1}$ ). However, no regrowth of the bacteria was observed at high flow rate. As previously disussed, at high flow, the flumes had lower nutrient concentrations. Under such conditions, net growth and decay of $P$. aeruginosa could be more balanced, and decay can even be the dominant mechanism. The decay rates of P. aeruginosa were up to $37 \%$ higher at high flow rates, whereas for E. faecalis, it was a $28 \%$ increase. Additionally, high flow promotes formation of a smoother more compact biofilm where the deeper layers of biofilms are oxygen limited. $P$. aeruginosa are known to limit 
growth under low oxygen concentrations (Werner et al. 2004). Hypothetically, if the biofilms at high flow in our experiments were similar, it would explain the growth pattern of $P$. aeruginosa in the flumes. Since, we did not determine biofilm thickness, it is not possible to confirm this hypothesis here.

E. faecalis cells grew at both flow rates. Growth rates of E. faecalis cells were higher at high flow $\left(4.4 \mathrm{~d}^{-1}\right)$ compared to low flow $\left(1.9 \mathrm{~d}^{-1}\right)$. Growth rates on the basis of increase in DNA could not be estimated due to lack of sufficient detection, resulting from lower sensitivity of DNA detection compared to cell detection of E. faecalis. In stressed environments, $E$. faecalis are often found to have a competitive advantage over bacteria like E. coli (Barcina et al. 1990). Certain algae (Byappanahalli et al. 2003) and copepods (Signoretto et al. 2005) that are common in freshwater and are sensitive to flow, are also known to assist E. faecalis survival. A combination of these factors could have resulted in a better growth environment for E. faecalis at high flow. P22 bacteriophage did not grow in our system due to the absence of host bacteria (Salmonella enterica serovar Typhimurium).

The $\mathrm{R}^{2}$ value in our exponential decay models ranged from 0.2 to 0.99 . Poor fits are often associated with models predicting biological contaminants in natural waterbodies and emphasize the high variability in these system (Nevers and Whitman 2011, Serrano et al. 1998). In our flumes, variations in daily feed water quality that can introduce bacteriophages and predators as well as the possibility of growth and survival of cells in the VBNC form added to uncertainty.

\subsection{Conclusions}

- Increased flow rate leads to increased detachment and higher decay of pathogens in the biofilm. This is important especially if there has been a change in flow regime of a waterbody due to flow modification or seasonal change. This would be a worst case scenario, as under low flow conditions more pathogens will survive in the biofilms 
due to lower decay rates. Subsequently, these pathogens will get mobilized when flow rates increased thus increasing the $\mathrm{T}_{99}$ to more than what is expected if the flows remained constant.

- In waterbodies with uniform flow regime, an event of pathogen detachment would pose a threat for longer periods at high flows compared to lower flows. However, for microorganisms like $P$. aeruginosa, low flow conditions will be worse. $P$. aeruginosa can be released abruptly long after the initial release at low flows, whereas it decays faster and does not grow at high flow, thereby leading to quicker depletion in biofilm reservoirs.

- It is important to consider biofilms as source and sink of pathogens and incorporate kinetic parameters like detachment rates and decay rates as state variables in predictive models. As most of these parameters will vary for the same substratum depending on the hydrodynamics, it is important to estimate them in situ. We also showed that decay kinetics can be biphasic, or be a combination of growth and decay, with one process dominating the other at different times. Hence, assuming decay to be an exponential first order reaction in models can be erroneous.

- Low flow favoured the growh of P. aeruginosa, whereas high flow favoured the growth of E. faecalis. Hence growth rate should be incorporated in predictive analysis only if there is experimental evidence of growth in the system. 


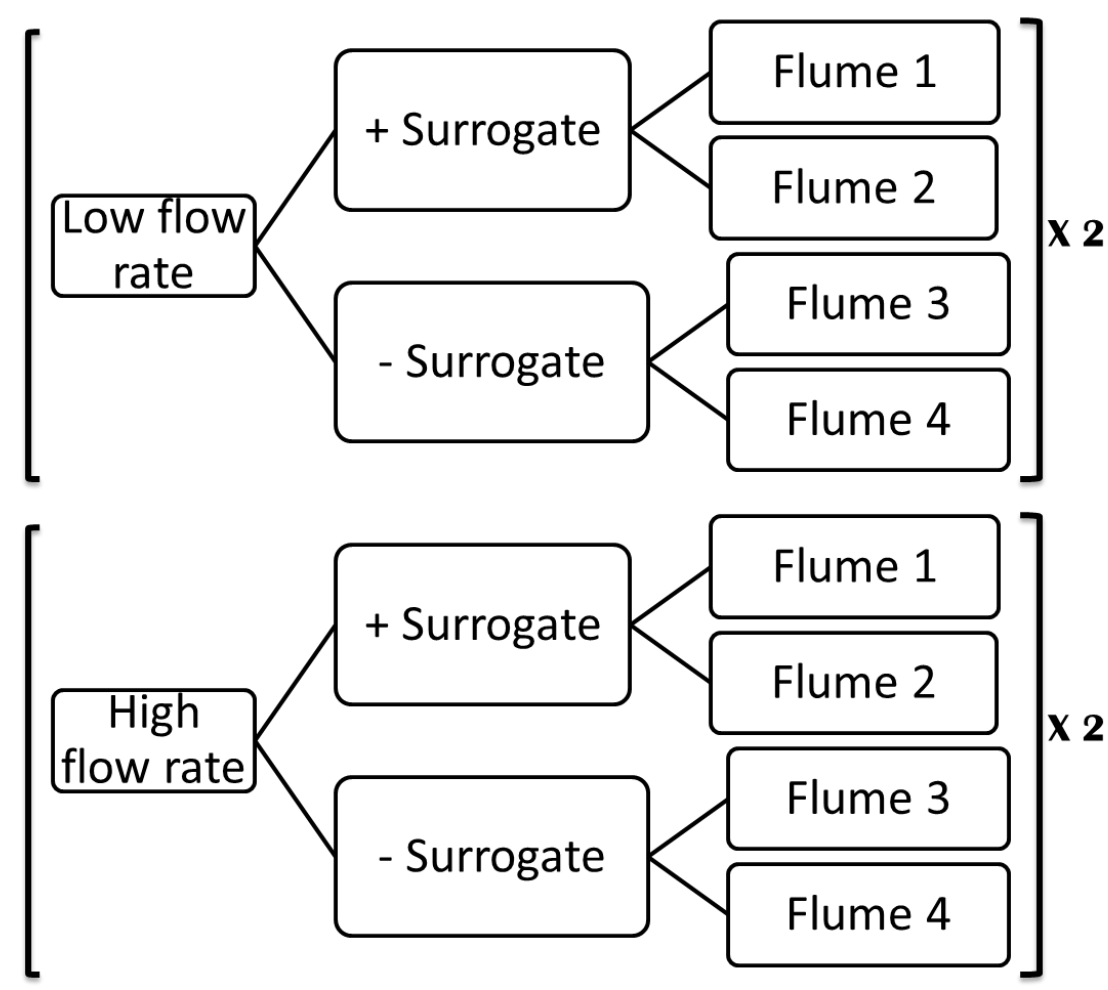

Figure 3.1: Schematic diagram of experimental plan for studying effect of flow rate on fate of surrogates in four different experiments using four mesocosm flumes each time. 

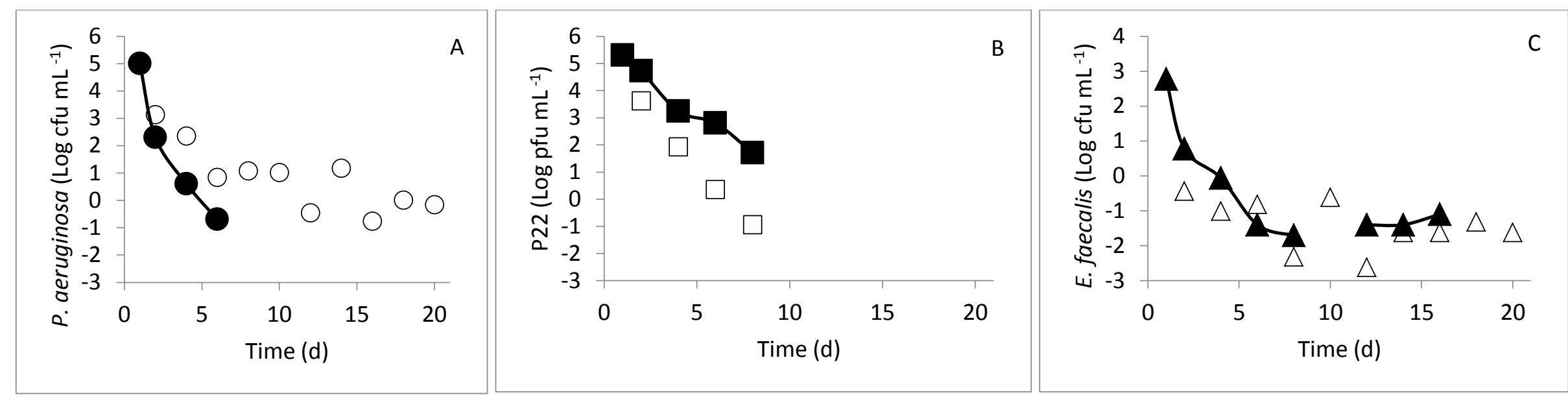

Fig 3.2: Measured (closed symbols) and predicted (open symbols) viable populations in aqueous phase at a high flow rate $(\mathrm{Re}=718)-(\mathrm{A}) P$. aeruginosa, (B) P22 and (C) E. faecalis.
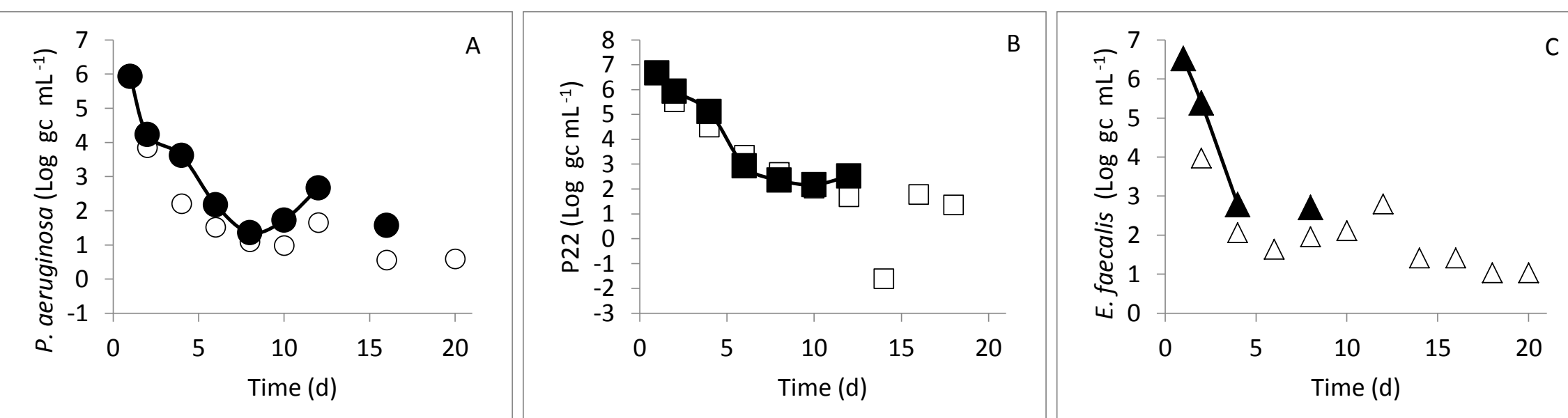

Figure 3.3: Measured (closed symbols) and predicted (open symbols) DNA concentrations in aqueous phase at a high flow rate $(\mathrm{Re}=718)-(\mathrm{A})$ P. aeruginosa, (B) $\mathrm{P} 22$ and (C) E. faecalis. 


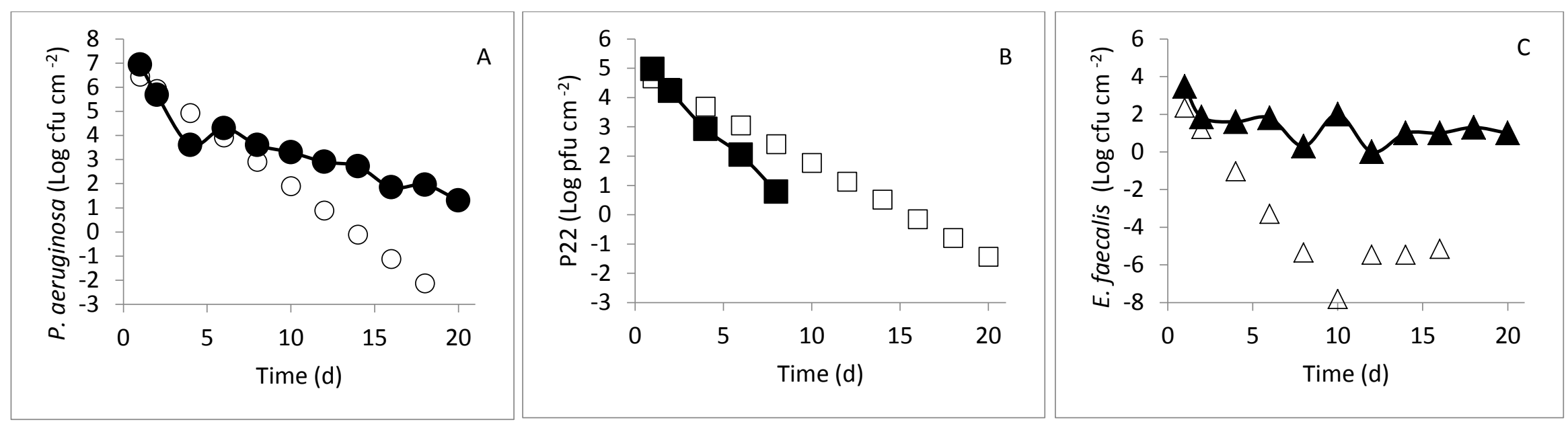

Figure 3.4: Measured (closed symbols) and predicted (open symbols) biofilm concentrations of cultivable surrogates at a high flow rate $($ Re $=$ 718) - (A) P. aeruginosa, (B) P22 and (C) E. faecalis.

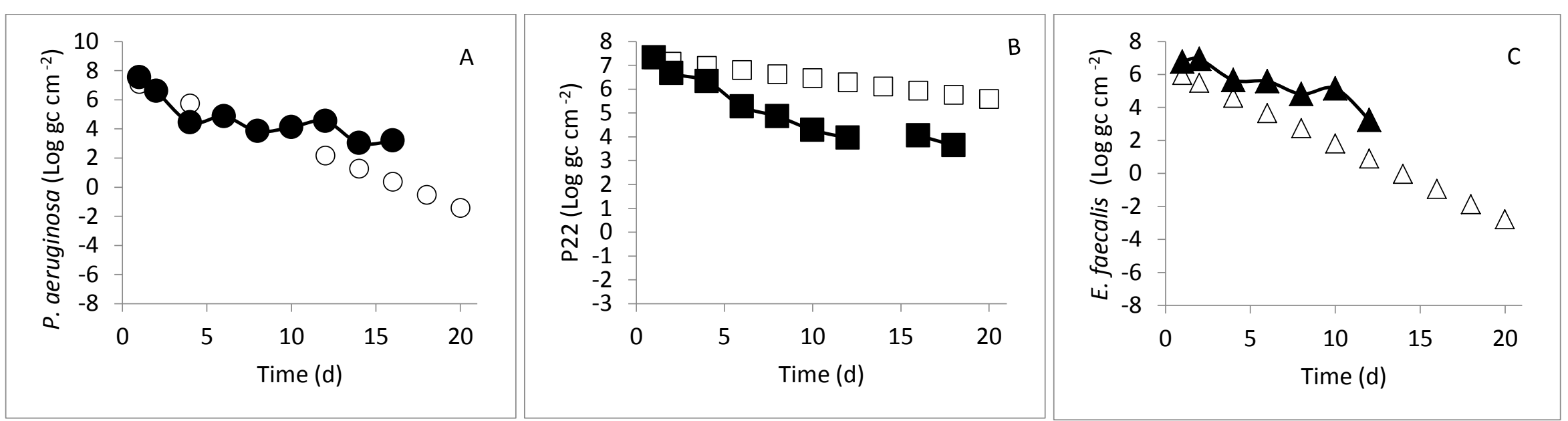

Figure 3.5: Measured (closed symbols) and predicted (open symbols) biofilm concentrations of surrogate DNA at a high flow rate $($ Re $=718)$ (A) P. aeruginosa, (B) P22 and (C) E. faecalis. 

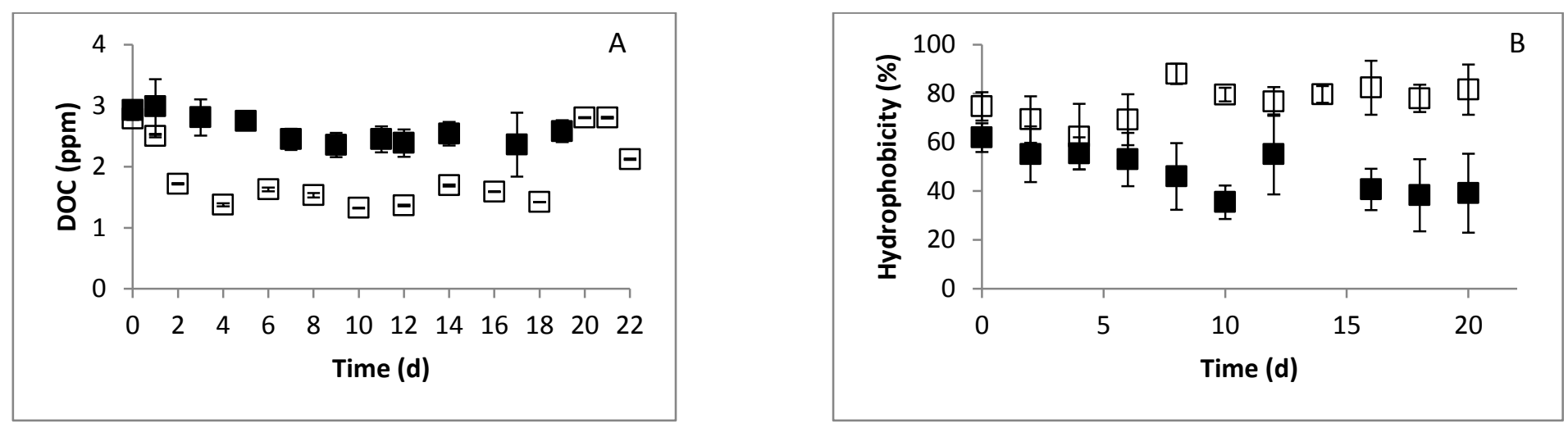

Figure 3.6. (A) DOC concentration in water and (B) hydrophobicity of biofilms grown at low and high flow rates. Open symbols represent high flows and closed symbols represent low flows, error bars show standard errors. At high flow, biofilms are more hydrophobic and more nutrient stressed. 
Table 3.1. Comparison of $T_{99}$, detachment rate, decay rate and growth rate of Paeruginosa, $P 22$ and $E$. faecalis at low and high flow conditions

\begin{tabular}{|c|c|c|c|c|c|c|}
\hline \multirow[t]{2}{*}{ Surrogate } & \multirow[t]{2}{*}{ Phase } & \multirow[t]{2}{*}{ Characteristic } & \multicolumn{2}{|c|}{ Low Flow ${ }^{1}$} & \multicolumn{2}{|c|}{ High Flow $^{2}$} \\
\hline & & & Mean (SD) & $\mathbf{R}^{2^{*}}$ & Mean (SD) & $\mathbf{R}^{2}$ \\
\hline$\overline{P .}$ & Water & Response time $\left(\mathrm{T}_{99}\right)$, cells $(\mathrm{d})$ & $1.9(0.14)$ & & $1.9(0.14)^{* *}$ & \\
\hline \multirow[t]{9}{*}{ aeruginosa } & & Response time ( $\left.\mathrm{T}_{99}\right)$, DNA (d) & $5.53(1.54)$ & & $9.08(0.86)$ & \\
\hline & Biofilm & Detachment rate, DNA & $0.143(0.14)$ & & $0.728(0.41)$ & \\
\hline & & $\left(\mathrm{cm}^{-2} \min ^{-1}\right)$ & & & & \\
\hline & & Response time $\left(\mathrm{T}_{99}\right)$, cells $(\mathrm{d})$ & $15.00(4.24)$ & & $9.00(1.41)$ & \\
\hline & & Response time $\left(\mathrm{T}_{99}\right)$, DNA (d) & $17.13(6.21)$ & & $11.70(2.67)$ & \\
\hline & & Decay rate, cells $\left(\mathrm{d}^{-1}\right)$ & $0.32(0.08)$ & $0.6,0.7$ & $0.51(0.06)$ & $0.7,0.9$ \\
\hline & & Decay rate, DNA $\left(\mathrm{d}^{-1}\right)$ & $0.31(0.22)$ & $0.5,0.7,0.8,0.4$ & $0.41(0.11)$ & $0.5,0.5,0.7,0.7$ \\
\hline & & Growth rate, cells $\left(\mathrm{d}^{-1}\right)$ & $2.71(1.28)$ & & $\mathrm{ND}^{3}(\mathrm{NA})^{4}$ & \\
\hline & & Growth rate, DNA $\left(\mathrm{d}^{-1}\right)$ & $5.17(1.85)$ & & ND (NA) & \\
\hline \multirow[t]{2}{*}{$\mathbf{P} 22$} & Water & Response time $\left(\mathrm{T}_{99}\right)$, cells $(\mathrm{d})$ & $2.65(0.35)$ & & $3.5(0.71)$ & \\
\hline & & Response time $\left(\mathrm{T}_{99}\right)$, DNA (d) & $7.43(0.57)$ & & $4.73(1.02)$ & \\
\hline
\end{tabular}




\begin{tabular}{|c|c|c|c|c|c|c|}
\hline \multirow[t]{2}{*}{ Surrogate } & \multirow[t]{2}{*}{ Phase } & \multirow[t]{2}{*}{ Characteristic } & \multicolumn{2}{|c|}{ Low Flow ${ }^{1}$} & \multicolumn{2}{|c|}{ High Flow $^{2}$} \\
\hline & & & Mean (SD) & $\mathbf{R}^{2^{*}}$ & Mean (SD) & $\mathbf{R}^{2}$ \\
\hline & Biofilm & Detachment rate, DNA & $0.12(0.3)$ & & $0.52(0.31)$ & \\
\hline & & $\left(\mathrm{cm}^{-2} \min ^{-1}\right)$ & & & & \\
\hline & & Response time $\left(\mathrm{T}_{99}\right)$, cells $(\mathrm{d})$ & $21.50(4.95)$ & & $3.5(0.71)$ & \\
\hline & & Response time $\left(\mathrm{T}_{99}\right)$, DNA (d) & $17.38(3.00)$ & & $12.83(5.38)$ & \\
\hline & & Decay rate, viable $\left(\mathrm{d}^{-1}\right)$ & $0.23(0.05)$ & $0.9,0.6$ & $1.30(0.14)$ & $0.9,0.99$ \\
\hline & & Decay rate, DNA $\left(\mathrm{d}^{-1}\right)$ & $0.27(0.05)$ & $0.4,0.2,0.98,0.95$ & $0.40(0.17)$ & $0.5,0.4,0.9,0.8$ \\
\hline \multirow[t]{7}{*}{ E. faecalis } & Water & Response time $\left(\mathrm{T}_{99}\right)$, cells $(\mathrm{d})$ & $33.50(6.36)$ & & $10.50(0.71)$ & \\
\hline & & Response time $\left(\mathrm{T}_{99}\right)$, DNA (d) & $2.33(4.45)$ & & $4.45(1.86)$ & \\
\hline & Biofilm & Response time $\left(\mathrm{T}_{99}\right)$, cells $(\mathrm{d})$ & $16.0(2.83)$ & & $20.50(4.95)$ & \\
\hline & & Response time $\left(\mathrm{T}_{99}\right)$, DNA (d) & $17.75(4.60)$ & & $12.85(2.42)$ & \\
\hline & & Decay rate, cells $\left(\mathrm{d}^{-1}\right)$ & $0.30(0.05)$ & $0.4,0.3$ & $0.23(0.06)$ & $0.3,0.4$ \\
\hline & & Decay rate, DNA $\left(\mathrm{d}^{-1}\right)$ & $0.27(0.07)$ & $0.6,0.8,0.9,0.6$ & $0.35(0.06)$ & $0.8,0.9,0.8,0.6$ \\
\hline & & Growth rate, cells $\left(\mathrm{d}^{-1}\right)$ & $1.88(0.84)$ & & $4.37(2.52)$ & \\
\hline
\end{tabular}

\footnotetext{
${ }^{1} \mathrm{Re}=359 ; \mathrm{Q}=6 \mathrm{Lmin}^{-1} ;{ }^{2} \mathrm{Re}=718 ; \mathrm{Q}=12 \mathrm{Lmin}^{-1} ;{ }^{3} \mathrm{ND}:$ Not detected; ${ }^{4}$ NA: Not applicable; * Calculated for each of the replicate flumes in duplicate experiments **Standard deviations within parenthesis
} 


\subsection{Supplementary Materials}

Table S.3.1. Average water chemistry and biofilm properties at low and high flow ${ }^{2}$ rates

\begin{tabular}{|c|c|c|c|}
\hline \multirow[t]{2}{*}{ Phase } & \multirow[t]{2}{*}{ Characteristics } & \multirow{2}{*}{$\begin{array}{l}\text { Low Flow }{ }^{1} \\
\text { Mean (SD) }\end{array}$} & \multirow{2}{*}{$\begin{array}{l}\text { High Flow } \\
\text { Mean (SD) }\end{array}$} \\
\hline & & & \\
\hline Water & Temperature $\left({ }^{\circ} \mathrm{C}\right)$ & $29(0.1)$ & $29(0.74)$ \\
\hline \multirow[t]{8}{*}{ chemistry } & $\mathrm{pH}$ & $8.6(0.3)$ & $8.5(0.37)$ \\
\hline & Conductivity $\left(\mathrm{mS} \mathrm{cm}^{-1}\right)$ & $0.26(0.04)$ & $0.31(0.07)$ \\
\hline & $\mathrm{DO}\left(\mathrm{mgL}^{-1}\right)$ & $7.5(0.6)$ & $6.9(0.63)$ \\
\hline & $\operatorname{DOC}\left(\mathrm{mgL}^{-1}\right)$ & $2.6(0.3)$ & $1.7(0.65)$ \\
\hline & Nitrate $\left(\mathrm{mgL}^{-1}\right)$ & $0.6(0.4)$ & $0.4(0.4)$ \\
\hline & Nitrite $\left(\mathrm{mgL}^{-1}\right)$ & $0.06(0.01)$ & ND (NA) \\
\hline & Phosphate $\left(\mathrm{mgL}^{-1}\right)$ & $\mathrm{ND}^{3}(\mathrm{NA})^{4}$ & ND (NA) \\
\hline & Sulfate $\left(\mathrm{mgL}^{-1}\right)$ & $26(6.5)$ & $20(5.1)$ \\
\hline Biofilm & Hydrophobicity (\%) & $48(9.2)$ & $76.5(7.2)$ \\
\hline \multirow[t]{3}{*}{ properties } & Zeta potential $(\mathrm{mV})$ & $-10.54(0.87)$ & $-14.7(1.1)$ \\
\hline & Storage modulus $(\mathrm{Pa})$ & $4.5 \times 10^{5}\left(2.8 \times 10^{5}\right)$ & $4.8 \times 10^{5}\left(3.8 \times 10^{5}\right)$ \\
\hline & Chl-a $\left(\mathrm{mgL}^{-1}\right)$ & $7.9(8.1)$ & $8.2(7.02)$ \\
\hline
\end{tabular}




\subsection{References}

Arnell NW (1999). Climate change and global water resources. Global Environmental Change 9: S31-S49.

Arnon S, Marx LP, Searcy KE, Packman AI (2010). Effects of overlying velocity, particle size, and biofilm growth on stream-subsurface exchange of particles. Hydrological Processes 24: $108-114$.

Bai S, Lung W-S (2005). Modeling sediment impact on the transport of fecal bacteria. Water Research 39: 5232-5240.

Balzer M, Witt N, Flemming H-C, Wingender J (2010). Faecal indicator bacteria in river biofilms. Water Science and Technology 61: 1105-1111.

Barcina I, Gonzalez J, Iriberri J, Egea L (1990). Survival strategy of Escherichia coli and Enterococcus faecalis in illuminated fresh and marine systems. Journal of Applied Bacteriology 68: 189-198.

Barros N, Farjalla VF, Soares MC, Melo RC, Roland F (2010). Virus-bacterium coupling driven by both turbidity and hydrodynamics in an Amazonian floodplain lake. Applied and Environmental Microbiology 76: 7194-7201.

Battin TJ, Kaplan LA, Newbold JD, Cheng X, Hansen C (2003). Effects of current velocity on the nascent architecture of stream microbial biofilms. Applied and Environmental Microbiology 69: 5443-5452.

Bayles, K. W. (2007). The biological role of death and lysis in biofilm development. Nature Reviews Microbiology, 5(9), 721-726.

Benham BL, Baffaut C, Zeckoski RW, Mankin KR, Pachepsky YA, Sadeghi AM et al. (2006). Modeling bacteria fate and transport in watersheds to support TMDLs. Transactions of the ASABE 49: 987-1002.

Besemer K, Singer G, Hödl I, Battin TJ (2009). Bacterial community composition of stream biofilms in spatially variable-flow environments. Applied and Environmental Microbiology 75: 7189-7195.

Boulêtreau S, Garabétian F, Sauvage S, Sanchez-Perez JM (2006). Assessing the importance of a self-generated detachment process in river biofilm models. Freshwater Biology 51: 901912.

Brookes JD, Antenucci J, Hipsey M, Burch MD, Ashbolt NJ, Ferguson C (2004). Fate and transport of pathogens in lakes and reservoirs. Environment International 30: 741-759. 
Buswell CM, Herlihy YM, Lawrence LM, McGuiggan JTM, Marsh PD, Keevil CW et al. (1998). Extended survival and persistence of Campylobacter spp. in water and aquatic biofilms and their detection by immunofluorescent-antibody and -rRNA staining. Applied and Environmental Microbiology 64: 733-741.

Byappanahalli MN, Shively DA, Nevers MB, Sadowsky MJ, Whitman RL (2003). Growth and survival of Escherichia coli and enterococci populations in the macro-alga Cladophora (Chlorophyta). FEMS Microbiology Ecology 46: 203-211.

Ceola S, Hödl I, Adlboller M, Singer G, Bertuzzo E, Mari L et al. (2013). Hydrologic variability affects invertebrate grazing on phototrophic biofilms in stream microcosms. PLoS ONE 8: e60629.

Chapra SC (2008). Surface water-quality modeling. Waveland press.

Craig DL, Fallowfield H, Cromar NJ (2004). Use of microcosms to determine persistence of Escherichia coli in recreational coastal water and sediment and validation with in situ measurements. Journal of Applied Microbiology 96: 922-930.

Davies CM, Roser DJ, Feitz AJ, Ashbolt NJ (2009). Solar radiation disinfection of drinking water at temperate latitudes: Inactivation rates for an optimised reactor configuration. Water Research 43: 643-652.

de Brauwere A, Ouattara NK, Servais P (2014). Modeling fecal indicator bacteria concentrations in natural surface waters: a review. Critical Reviews in Environmental Science and Technology 44: 2380-2453.

Decho AW (2000). Microbial biofilms in intertidal systems: an overview. Continental Shelf Research 20: 1257-1273.

Dettinger MD, Diaz HF (2000). Global characteristics of stream flow seasonality and variability. Journal of Hydrometeorology 1: 289-310.

Drummond JD, Davies-Colley RJ, Stott R, Sukias JP, Nagels JW, Sharp A et al. (2015). Microbial transport, retention, and inactivation in streams: A combined experimental and stochastic modeling approach. Environmental Science \& Technology 49: 7825-7833.

Drury WJ, Stewart PS, Characklis WG (1993). Transport of $1-\mu \mathrm{m}$ latex particles in Pseudomonas aeruginosa biofilms. Biotechnology and Bioengineering 42: 111-117.

Ferguson C, Husman AMdR, Altavilla N, Deere D, Ashbolt N (2003). Fate and transport of surface water pathogens in watersheds. Critical Reviews in Environmental Science and Technology 33(3): 299-360 
Gao G, Falconer RA, Lin B (2011). Numerical modelling of sediment-bacteria interaction processes in surface waters. Water Research 45: 1951-1960.

Grabowski RC, Droppo IG, Wharton G (2011). Erodibility of cohesive sediment: the importance of sediment properties. Earth-Science Reviews 105: 101-120.

Hall-Stoodley L, Costerton JW, Stoodley P (2004). Bacterial biofilms: from the natural environment to infectious diseases. Nature Reviews Microbiology 2: 95-108.

He L-ML, He Z-L (2008). Water quality prediction of marine recreational beaches receiving watershed baseflow and stormwater runoff in southern California, USA. Water Research 42: 2563-2573.

Heberger MG, Durant JL, Oriel KA, Kirshen PH, Minardi L (2008). Combining real-time bacteria models and uncertainty analysis for establishing health advisories for recreational waters. Journal of Water Resources Planning and Management 134: 73-82.

Huws S, McBain A, Gilbert P (2005). Protozoan grazing and its impact upon population dynamics in biofilm communities. Journal of Applied Microbiology 98: 238-244.

Jamieson RC, Joy DM, Lee H, Kostaschuk R, Gordon RJ (2005). Resuspension of sedimentassociated in a natural stream. Journal of Environmental Quality 34: 581-589.

Khan NH, Ishii Y, Kimata-Kino N, Esaki H, Nishino T, Nishimura M et al. (2007). Isolation of Pseudomonas aeruginosa from open ocean and comparison with freshwater, clinical, and animal isolates. Microbial Ecology 53: 173-186.

Kim J-W, Pachepsky YA, Shelton DR, Coppock C (2010). Effect of streambed bacteria release on E. coli concentrations: Monitoring and modeling with the modified SWAT. Ecological Modelling 221: 1592-1604.

Klapper I, Rupp CJ, Cargo R, Purvedorj B, Stoodley P (2002). Viscoelastic fluid description of bacterial biofilm material properties. Biotechnology and Bioengineering 80: 289-296.

Kropinski AM, Mazzocco A, Waddell TE, Lingohr E, Johnson RP (2009). Enumeration of bacteriophages by double agar overlay plaque assay. Bacteriophages: Methods and Protocols, Volume 1: Isolation, Characterization, and Interactions: 69-76.

Lau YL, Droppo IG (2000). Influence of antecedent conditions on critical shear stress of bed sediments. Water Research 34: 663-667. 
Legnani P, Leoni E, Rapuano S, Turin D, Valenti C (1999). Survival and growth of Pseudomonas aeruginosa in natural mineral water: a 5-year study. International Journal of Food Microbiology 53: 153-158.

Levandowsky M, Klafter J, White B (1988). Swimming behavior and chemosensory responses in the protistan microzooplankton as a function of the hydrodynamic regime. Bulletin of Marine Science 43: 758-763.

Liu L, Phanikumar MS, Molloy SL, Whitman RL, Shively DA, Nevers MB et al. (2006). Modeling the transport and inactivation of $E$. coli and enterococci in the near-shore region of Lake Michigan. Environmental Science \& Technology 40: 5022-5028.

Matz C, Kjelleberg S (2005). Off the hook - how bacteria survive protozoan grazing. Trends in Microbiology 13: 302-307.

McDougald D, Rice SA, Barraud N, Steinberg PD, Kjelleberg S (2012). Should we stay or should we go: mechanisms and ecological consequences for biofilm dispersal. Nature Reviews Microbiology 10: 39-50.

Messer JW, Dufour AP (1998). A rapid, specific membrane filtration procedure for enumeration of enterococci in recreational water. Applied and Environmental Microbiology 64: $678-680$.

Misstear DB, Gill LW (2012). The inactivation of phages MS2, ФX174 and PR772 using UV and solar photocatalysis. Journal of Photochemistry and Photobiology B: Biology 107: 1-8.

Nevers MB, Whitman RL (2011). Efficacy of monitoring and empirical predictive modeling at improving public health protection at Chicago beaches. Water Research 45: 1659-1668.

O'Toole G, Kaplan HB, Kolter R (2000). Biofilm formation as microbial development. Annual Reviews in Microbiology 54: 49-79.

Okabe S, Yasuda T, Watanabe Y (1997). Uptake and release of inert fluorescence particles by mixed population biofilms. Biotechnology and Bioengineering 53: 459-469.

Olyphant GA, Thomas J, Whitman RL, Harper D (2003). Characterization and statistical modeling of bacterial (Escherichia coli) outflows from watersheds that discharge into southern Lake Michigan. Coastal Monitoring through Partnerships. Springer. pp 289-300.

Packman AI, Salehin M (2003). Relative roles of stream flow and sedimentary conditions in controlling hyporheic exchange. The Interactions between Sediments and Water. Springer. pp 291-297. 
Pereira MO, Kuehn M, Wuertz S, Neu T, Melo LF (2002). Effect of flow regime on the architecture of a Pseudomonas fluorescens biofilm. Biotechnology and Bioengineering 78: 164-171.

Peyton BM, Characklis W (1992). Kinetics of biofilm detachment. Water Science and Technology 26: 1995-1998.

Purevdorj B, Costerton J, Stoodley P (2002). Influence of hydrodynamics and cell signaling on the structure and behavior of Pseudomonas aeruginosa biofilms. Applied and Environmental Microbiology 68: 4457-4464.

Rosenberg M (1984). Bacterial adherence to hydrocarbons: a useful technique for studying cell surface hydrophobicity. FEMS Microbiology Letters 22: 289-295.

Saxena G, Marzinelli EM, Naing NN, He Z, Liang Y, Tom L et al. (2015). Ecogenomics reveals metals and land-use pressures on microbial communities in the waterways of a megacity. Environmental science \& technology 49: 1462-1471.

Searcy KE, Packman AI, Atwill ER, Harter T (2006). Deposition of Cryptosporidium oocysts in streambeds. Applied and environmental microbiology 72: 1810-1816.

Serrano E, Moreno B, Solaun M, Aurrekoetxea J, Ibarluzea J (1998). The influence of environmental factors on microbiological indicators of coastal water pollution. Water Science and Technology 38: 195-199.

Signoretto C, Burlacchini G, Pruzzo C, Canepari P (2005). Persistence of Enterococcus faecalis in aquatic environments via surface interactions with copepods. Applied and Environmental Microbiology 71: 2756-2761.

Sinton LW, Finlay RK, Lynch PA (1999). Sunlight inactivation of fecal bacteriophages and bacteria in sewage-polluted seawater. Applied and Environmental Microbiology 65: 36053613.

Stoodley, P., Wilson, S., Hall-Stoodley, L., Boyle, J. D., Lappin-Scott, H. M., \& Costerton, J. W. (2001). Growth and detachment of cell clusters from mature mixed-species biofilms. Applied and Environmental Microbiology, 67(12), 5608-5613.

Stoodley P, Cargo R, Rupp CJ, Wilson S, Klapper I (2002). Biofilm material properties as related to shear-induced deformation and detachment phenomena. Journal of Industrial Microbiology and Biotechnology 29: 361-367.

Tong ST, Chen W (2002). Modeling the relationship between land use and surface water quality. Journal of Environmental Management 66: 377-393. 
Tsai Y-P (2005). Impact of flow velocity on the dynamic behaviour of biofilm bacteria. Biofouling 21: 267-277.

Van Loosdrecht M, Lyklema J, Norde W, Schraa G, Zehnder A (1987). Electrophoretic mobility and hydrophobicity as a measured to predict the initial steps of bacterial adhesion. Applied and Environmental Microbiology 53: 1898-1901.

Van Loosdrecht MM, Norde W, Lyklema J, Zehnder AB (1990). Hydrophobic and electrostatic parameters in bacterial adhesion. Aquatic Sciences 52: 103-114.

Van Loosdrecht M, Heijnen J, Eberl H, Kreft J, Picioreanu C (2002). Mathematical modelling of biofilm structures. Antonie van Leeuwenhoek 81: 245-256.

van Veen JA, van Overbeek LS, van Elsas JD (1997). Fate and activity of microorganisms introduced into soil. Microbiology and Molecular Biology Reviews 61: 121-135.

Walters E, Kätzl K, Schwarzwälder K, Rutschmann P, Müller E, Horn H (2014). Persistence of fecal indicator bacteria in sediment of an oligotrophic river: Comparing large and lab-scale flume systems. Water Research 61: 276-287.

Weinbauer MG, Höfle MG (1998). Significance of viral lysis and flagellate grazing as factors controlling bacterioplankton production in a eutrophic lake. Applied and Environmental Microbiology 64: 431-438.

Werner E, Roe F, Bugnicourt A, Franklin MJ, Heydorn A, Molin S et al. (2004). Stratified growth in Pseudomonas aeruginosa biofilms. Applied and Environmental Microbiology 70: 6188-6196.

Wilson WW, Wade MM, Holman SC, Champlin FR (2001). Status of methods for assessing bacterial cell surface charge properties based on zeta potential measurements. Journal of Microbiological Methods 43: 153-164.

Wymer LJ (2007). Statistical framework for recreational water quality criteria and monitoring, vol. 65. John Wiley \& Sons.

Yallop M, Paterson D, Wellsbury P (2000). Interrelationships between rates of microbial production, exopolymer production, microbial biomass, and sediment stability in biofilms of intertidal sediments. Microbial Ecology 39: 116-127.

Yoder JS, Hlavsa MC, Craun GF, Hill V, Roberts V, Yu PA et al. (2008). Surveillance for waterborne disease and outbreaks associated with recreational water use and other aquatic facility-associated health events-United States, 2005-2006. MMWR Surveill Summ 57: 129. 


\section{Effect of Pseudomonas aeruginosa, Enterococcus faecalis and bacteriophage}

P22 on freshwater biofilm community assembly in replicate mesocosm flumes under high and low flow conditions

\subsection{Abstract}

In macro-ecology, the introduction of alien species often leads to changes in community structure and functioning. We asked whether freshwater microbial communities are similarly affected and whether such effects depend on the flow regime. Mature photosynthetic biofilms grown in mesocosm flumes were exposed to four allochthonous microorganisms, Pseudomonas aeruginosa, Enterococcus faecalis, and the bacteriophages P22 and GA. The biofilm was sampled for $21 \mathrm{~d}$ and the effects on both eukaryotic and prokaryotic communities were studied using a combination of metagenomic sequencing and environmental monitoring. Prokaryotic communities were not affected by surrogate addition at either high or low flow rates. Eukaryotic communities showed similar resilience. However, in two experiments, when Podocopida and Haplotaxida were present, a significant effect of surrogate addition was observed. The abundance of these organisms was related to the presence of surrogates, even though the surrogates used were not pathogenic for any of them. Eukaryotic communities that were not affected by surrogates showed a temporal change in community abundance. The communities on days 1 and 3 were different from those collected afterwards. Such differences were due to algal growth. Finally, abundances of both prokaryotes and eukaryotes were explained by water chemistry. Our results showed that freshwater microbial communities are resilient to pathogen exposure. The pathogens are, however, integrated within the biofilm communities, thus showing that pathogen release in freshwater is a case of co-existence and not invasion. 


\subsection{Introduction}

Pathogens released into water bodies may become incorporated into freshwater biofilms (Balzer et al. 2010), which can aid in pathogen survival (Flemming et al. 2007) and increase health risks to the recreating public. If the pathogens survive in the biofilms for long durations, they will interact with the autochthonous microbial communities. The latter are "both drivers and indicators of perturbations" of an ecosystem (Jeffries et al. 2015). They are responsible for many ecosystem processes like biogeochemical transformations, primary production and nutrient fluxes (Wakelin et al. 2008), which are crucial for ecosystem health. Ecosystem health is also indirectly related to human water security (Vitousek et al. 1997). For example, many emerging diseases, biodiversity loss and degradation of the aesthetic value of water are related to degrading ecosystem health (Millenium ecosystem assessment, World Resource Institute, 2005).

Many anthropogenic activities that alter pathogen fate, like land use patterns (Saxena et al. 2015), flow modifications (Wei et al. 2009) and wastewater discharges (Wakelin et al. 2008), are also known to affect existing microbial communities. Multiple studies have also reported changes in community composition and functioning due to wastewater discharge (Drury et al. 2013), which is a major source of pathogens in freshwater. Cyanobacteria blooms in freshwater systems are also known to change community composition and function at all trophic levels (O'neil et al. 2012). Due to established causal relationships, metagenomic variability is sometimes considered as an index to monitor contamination of waterbodies (Van Rossum et al. 2015). However, in most studies, the effects of abiotic factors like nutrient concentrations and of pathogens are coupled. Impacts of pathogens alone on aquatic ecosystems remain less studied.

In host based systems, like animal skins (Jani and Briggs 2014) and plant (Erlacher et al. 2015) microbiomes, pathogen invasion has been found to shift community composition and 
abundance. In aquatic systems, invasion by macroscopic organisms like mussels (Wittmann et al. 2010) and plants (Angeloni et al. 2006) is often known to change community composition at macro- and micro-scales. However, similar information on microbial invasions of communities that do not have a suitable host is rare and controversial. For example, it was observed that of the diverse bacteria present in waste water treatment plant effluent, ammonia oxidizing bacteria of the Nitrosomonas oligotropha/ureae lineage and nitrite oxidizing bacteria of Nitrospira sublineage I could colonize biofilms present in the mesocosms and increase their nitrification potential (Mußmann et al. 2013). Few successful colonization events have also affected the existing communities, for example, certain allochthonous fungi have been reported to change the native fungal communities (Wolfe et al. 2010).

In general, the success of invasion depends on few key characteristics, like high growth rates and multiple resource utilization capabilities of the invaders, and the diversity of the autochthonous community (Litchman 2010). Hence in this study, we addressed the research question: does the introduction of pathogens affect the benthic biofilm community in terms of composition and function? We further asked whether such an effect is related to hydrodynamic conditions. Finally, we addressed if there are any environmental parameters that explain the observed biological patterns in the communities. Mature photosynthetic biofilms in mesocosms were chosen to represent a preexisting freshwater community, and Pseudomonas aeruginosa, Enterococcus faecalis and bacteriophage P22 acted as surrogates of waterborne pathogens. We analyzed the effect of the surrogates on both prokaryotic and eukaryotic communities using metagenomic sequencing. The two different flow rates represented a low flow scenario and the average flow condition prevailing in the urban canals. 


\subsection{Materials and Methods}

\subsubsection{Flume set up and sampling}

A set of four experiments was performed (Fig 3.1). Each time, four open channel flumes $\left(15 \times 10 \times 200 \mathrm{~cm}^{3}\right)$ were used at a fixed flow rate, in a partial recirculation mode. Two different flow rates, $6 \mathrm{~L} \mathrm{~min}{ }^{-1}$ and $12 \mathrm{~L} \mathrm{~min}^{-1}(\mathrm{Re}=359$ and 718), were tested in duplicate experiments. The flumes were located at an outdoor shed, next to an urban canal (Van Kleef Center), receiving on average $12 \mathrm{~h}$ of indirect sunlight every day. The flow rates were chosen to represent (i) conditions in Singapore's waterways in the absence of rain and (ii) the yearly average flow rate (Saxena et al. 2015). Every alternate day, water was drawn from the canal and stored in two feed tanks, from where it was channeled into the flumes using peristaltic pumps. The experiments were performed in December 14 (L.E 1), June 15 (H.E 1), December 15 (L.E 2) and February 15 (H.E 2) and each low flow experiment was followed by a high flow experiment to avoid batch effects.

The flumes were operated for a total of six weeks. In the first three weeks no samples were collected to facilitate the growth of a photosynthetic biofilm. After three weeks, two flumes were spiked with surrogates of common waterborne pathogens. The remaining two flumes were operated as procedural controls and sterile media were added in volumes equal to those added to the two spiked flumes. The surrogates were added once at the beginning of the experiment. They were Pseudomonas aeruginosa (SS1), Enterococcus faecalis (ATCC 47077) and two bacteriophages, P22 (ATCC 97541) and GA (SW1). P22 is a bacteriophage of Salmonella enterica serovar Typhimurium and the host for GA is Escherichia coli. Each feed tank was connected to two flumes, one with and the other without surrogates in order to avoid batch effects. 
Biofilm samples were collected from the flumes at six different time points: Day 0, which was immediately before adding the surrogates, and after the addition, on days $1,3,7,14$ and 21. The time points were selected in order to represent three different phases, early (D1 and 3), intermediate (D7 and 14) and late phase (D21). As mentioned in Chapters 2 and 3, the surrogates exhibited exponential decay. Hence the concentrations of surrogates in water were high during the early phase (days 1 and 3), low during the intermediate phase (days 7 and 14) and during the late phase, they approached or were below the detection limit (day 21). Biofilm samples were immediately frozen in liquid nitrogen and transferred to the laboratory where genomic DNA was extracted. Details on flume operation and the surrogates and sample collection are found in Chapter 2. Environmental and water quality parameters were monitored daily (see Chapters 2 and 3).

\subsubsection{DNA extraction, library preparation and sequencing}

Genomic DNA was extracted from biofilms using the Purelink genomic (g) DNA kit (Invitrogen ${ }^{\mathrm{TM}}$, USA) following the manufacturers' protocol. Prior to extraction, biofilms were homogenized by bead beating, performed using a combination of glass, ceramic and silica beads (FastPrep Lysing matrix E, FastPrep homogenizer, MP BioMedicals). The extracted gDNA concentrations were measured on a Qubit 2.0 fluorometer using the High Sensitivity (HS) assay protocol. The purity and quality of the DNA was checked with NanoDrop and the Agilent TapeStation (2200) system.

Following the gDNA quality check, a sequencing library was prepared using the Illumina Truseq Nano protocol. The multiplexed libraries were pooled and sequenced on the Illumina HiSeq2500 sequencing platform, with a read length of $250 \mathrm{bp}$ and paired ended reads. The samples were sequenced in two separate Illumina runs. In each run, samples from two consecutive experiments (one at low flow and one at high flow) were sequenced together. Metagenomic sequencing of total genomic DNA was chosen over amplicon sequencing in 
order to avoid any PCR bias. Additionally, metagenomic sequencing allowed simultaneous detection of both prokaryotic and eukaryotic DNA, which was preferable for studying the effects of surrogate addition on the total microbial community.

\subsubsection{Processing and analysis of metagenomic sequencing datasets}

The quality of the raw sequencing reads in fastq format was checked using the FastQC program (Andrews 2010). Low quality bases were trimmed and adapter removal was done using cutadapt (Martin 2011). The resulting data were further processed using two programs: (i) RiboTagger for taxonomic analysis (Xie et al., 2016) and (ii) MEGAN (Huson et al. 2007) for in silico functional analysis. RiboTagger is based on the 16/18S rRNA variable regions (V4) and MEGAN is based on read binning via the lowest common ancestor (LCA) algorithm. Ribotags (OTU equivalents) identified using RiboTagger were taxonomically assigned, whenever required, using the SINA aligner against the SILVA SSU database. For MEGAN, the fastq sequences underwent a homology search against the NCBINR database, using DIAMOND (Buchfink et al. 2015), followed by mapping the reads to KEGG Orthology (KO) identifiers.

\subsubsection{Statistical analysis based on microbial community profile}

Taxonomic assignments (down to the lowest taxonomic level wherever possible) and abundance matrices resembling overall microbial community compositions were generated based on ribotags (or OTUs), which was the output from Ribotagger analysis. Changes in alpha diversity were measured in terms of the generalized first and second Hill number (N1 and N2) (Hill M, 1973). Hill numbers were selected as they provide useful information on degrees of change taking into account both abundant and rare OTUs. Eukaryotic ribotags were analyzed separately from the prokaryotic ribotags. OTU abundance data was standardized against the sample total to account for the differences in sequencing depth, 
followed by square root transformation of the matrix, to reduce the weight of the most abundant OTUs. Statistical significance of the effects of the surrogates and time on the microbial community composition was tested using permutational multivariate analysis of variance (PERMANOVA), where observations units are exchangeable under the null hypothesis.

A two-factor PERMANOVA design was used for the analysis, where surrogates (present and absent) and time (days 1, 3, 7, 14, 21) were the fixed factors. Two different resemblance matrices, Bray Curtis and Jaccard, were used in PERMANOVA analysis. The Bray-Curtis matrix is based on relative abundance of the community members, whereas Jaccard is based on presence and absence of individual members. By using these two different matrices, we determined whether there were effects of surrogate addition or time on both abundance and composition. Following PERMANOVA, homogeneity of multivariate dispersion was tested with PERMDISP. For communities or groups that showed a significant effect of time $(\mathrm{p}<0.05)$, a posteriori contrasts were done using pairwise testing to understand where the differences occurred.

Data were visualized using an ordination method (non-metric multidimensional scaling (nMDS). Pearson correlation vectors $(\mathrm{r}>0.7)$ were generated from standardized and transformed OTU abundance data in order to understand if certain OTUs or groups of microorganisms were enriched in any of the sample groups. OTUs accounting for most of the observed differences were additionally identified using SIMPER and tested for statistical significance using ANOVA.

The functional potential of the communities was studied with in silico analysis using MEGAN. Read counts obtained from MEGAN data at KEGG Orthology (KO) and pathways 
levels were standardized against the sample total and then square root transformed. The downstream analysis of these matrices was similar to the processing of abundance matrices.

The relationship between abundance data and environmental and physicochemical data was analyzed using DistLM with marginal tests. Model selection was based on corrected AIC (Akaike information correction, AICc) as the selection criterion. AICc was chosen to account for the lack of sufficient sample size required for the number of variables being tested. Environmental variables tested were sulphate, nitrate, DOC, conductivity, DO, hydrophobicity and rheology. Chla, zeta potential and TDS were excluded from the analysis as they were dependent on some of the variables already taken into account, such as DO for Chla, hydrophobicity for zeta potential and conductivity for TDS. All analyses were done using PRIMER (v.6) with PERMANOVA+ (primer-e Ltd, Ivybridge, UK).

\subsection{Results}

\subsubsection{Overall microbial community structure of the freshwater biofilms in the flumes}

RiboTagger analysis identified roughly 2,939 ribotags (equivalent to OTUs) from the sequencing dataset, of which almost $75 \%$ belonged to prokaryotes and the remaining $25 \%$ to eukaryotes. Depending on the date of collection, $0-32 \%$ of the ribotags remained unclassified at the phylum level. Mostly, samples collected during the initial periods (e.g. day 0 to day 1) contained a higher relative abundance of unclassified sequences than those collected in the later stage of the experimental period.

\subsubsection{Prokaryotic community}

Among the prokaryotes, Cyanobacteria and Proteobacteria were the dominant microbial phyla, comprising on average $70 \%$ of the communities (Fig. 4.1A). Other microbial phyla present were as follows: Planctomycetes, Verrumicrobia, Firmicutes and Bacteroidetes, each present in the sample at less than $10 \%$ on average. 
Under high flow, on day 1 (24 h after surrogate spiking), the relative abundance of Proteobacteria (40\% to $60 \%)$ was higher than that of Cyanobacteria (13\% to $20 \%)$ in all samples. Under low flow, the relative abundance of Proteobacteria increased as well, but was mostly similar to that of Cyanobacteria (20\%-30\%). On all other days, cyanobacterial sequences were more abundant compared to those of Proteobacteria.

Total cyanobacterial ribotags identified were composed of true Cyanobacteria and chloroplasts. The relative abundance of sequences belonging to true Cyanobacteria was generally higher than those belonging to chloroplasts, with the exception of the flumes operated at low flow rate in one experiment (L. E 1). Chloroplast sequences in these samples often represented the majority $(70 \%$ to $95 \%$ of all sequences identified as Cyanobacteria at phylum level; on day 7, Cyanobacteria was more prevalent). Some of the ribotags $(20-30 \%$ in the beginning and $10-20 \%$ later) identified as Cyanobacteria could not be further assigned to lower taxonomic classifications. After removing chloroplast sequences, the remaining Cyanobacteria OTUs were found to be mainly belonging to Subsection 3, followed by Subsection 1, and some remained as unclassified sequences. The Subclass 3 was mostly represented by OTUs classified as the genus Leptolyngbya.

Among the sequences belonging to Proteobacteria, most were identified as alphaProteobacteria, followed by beta-, gamma- and delta-Proteobacteria. On day 1 , the relative abundance of beta- and gamma-Proteobacteria was higher than that of alpha-Proteobacteria. Among the alpha-, beta-, delta- and gamma-Proteobacteria, Burkholderiales, Rhodospirillales, Rhodobacterales, Rhizobiales and Shingomondales were present in all samples at both flow rates. Ribotags belonging to Neisseriales, Chromatiales and Pseudomondales, were present in higher proportions in the early stages of the biofilm and slowly decreased over time. Caulobacteriales was present in most samples at low flow, but 
only in the early phases at high flow. Enterobacteriales were present in some samples at low flow but not at high flow.

We did not detect any of our surrogates in the communities except on Day 1. However, as previously discussed in Chapters 2 and 3, using qPCR all bacterial surrogates were detected in the biofilms from day 1 to day 21 and P22 was detected for approximately 2 weeks. We did not detect the host species for added bacteriophages (E. coli and $S$. enterica serovar Typhimurium) in any sample.

\subsubsection{Eukaryotic community}

As the samples were not size fractionated, all samples contained both macro- and micro-communities of eukaryotes. Almost $50 \%$ of eukaryotic sequences could not be classified using the SINA aligner using the default parameters. Most of the sequences could be assigned to the subkingdom Eumetazoa and the class Chlorophyceae (Fig. 4.1B). A few OTUs belonging to Diatomea and Phragmophyta were also detected. Among the Eumetazoa, Annelida, Arthropoda, Nematoda and Rotifera were detected and Arthropoda sequences dominated the matrix at both flow rates, major representatives belonging to Podocopida and Cyclopoida.

Based on the Hill number (N1) eukaryotes had less variability within flumes as well as with time than prokaryotes (Fig. 4.2). Prokaryotes had a higher N1 compared to eukaryotes. At few sampling time points, N1 varied between the flumes with and without surrogates in prokaryotes but not in eukaryotes. These variations were not found to be statistically significant when analyzed using single factor ANOVA $(p>0.05)$. The average N1 of prokaryotes was higher at high flow rates compared to those at low flow rates while the eukaryotic N1 was similar (Table 4.1). The N1 of prokaryotes was also lower in flumes 
without surrogates in the second experiment for both flow rates. The eukaryotic N1 was again similar. The second order Hill number (N2) showed similar trends (data not shown).

\subsubsection{Effect of surrogate addition and time on the pre-grown biofilm community}

Multivariate analysis was done separately for prokaryotes and eukaryotes. In order to check whether data from duplicate experiments (having similar flow rates) could be pooled, a preliminary three-factor PERMANOVA analysis was done with "experiment", "surrogate addition" and "time" as the factors. As there was significant interaction between "experiment" and both other factors, the data from duplicate experiments at similar flow rates were not pooled but analyzed separately.

\subsubsection{Effect of surrogate addition on community}

There was no significant effect of surrogate addition on the prokaryotic communities at either flow rate $(p>0.05)$ using either Bray Curtis or Jaccard resemblance (Table 4.2). The eukaryotic community showed similar trends in the first of the two experiments (L. E 1 and H. E 1) at both flow rates (Table 4.2). In the other two experiments, there was a significant effect $(p=0.004$ and $p=0.001)$ of surrogate addition based on Bray Curtis resemblance. There was no dispersion effect on the samples in these experiments. The Jaccard matrix based analysis for the eukaryotes at low flow was similar. However, at high flow, no effect was found when using Jaccard resemblance. A strong clustering was observed for these experiments when data were visualized with NMDS plots (Fig. $4.3 \mathrm{~A}$ and B).

Based on SIMPER analysis, at low flow, Podocopida (OTU1) contributed most to the observed pattern at low flow. Along with OTU1, Haplotaxida (OTU8), unclassified OTU5, Haplotaxida (OTU2), Saccaromyceteles (OTU3), unclassified OTU12, OTU26, Chlorophycaceae (OTU10), unclassified OTU9 and OTU19 cumulatively contributed to 35\% of the dissimilarity in eukaryotes (Figure 4.4 A). At high flow rate, the key drivers belonged 
to Podocopida (OTU1), Podocopida (OTU4), Haplotaxida (OTU8), Cryptomycota (OTU27), unclassified OTU9, Diatomea (OTU23), unclassified OTU19, OTU26, Chlophycaceae (OTU10), unclassified OTU22, Chlorophycaceae (OTU21) and Cryptomycota (OTU46) (Fig. 4.4B). These OTUs cumulatively accounted for up to $35 \%$ of the observed differences.

Based on single factor ANOVA, out of all these OTUs, the effect of surrogate addition on abundance was significant for only OTU8 $(p=0.001)$ and OTU1 $(p=0006)$ under low flow and OTU4 $(p=0.0003)$ and OTU1 $(p=0.0002)$ at high flow. The average relative abundance of OTU1 was higher in flumes with surrogates, whereas those of OTU4 and OTU8 were higher in flumes without surrogates. OTU1 was absent in any samples collected during L. E 1 and present only in two flumes, one with and the other without surrogates in $\mathrm{H}$. E 1.

\subsubsection{Effect of time on biofilm community}

A significant effect of time $(p>0.05)$ on prokaryotic communities was found at both flow rates based on PERMANOVA. However, according to PERMDISP analysis, these differences were associated with significant dispersion $(p<0.05)$ effects and were thus not considered relevant. For eukaryotes, one of the experiments at each flow rate, which had no significant effect of surrogate addition (L. E 1 and H. E 1), showed a significant effect of time ( $p=0.02$ and 0.006$)$ without dispersion effects, based on Bray Curtis resemblance (Table 4.2). Based on Jaccard resemblance, only experiment 1-high showed significant effect of time.

Pairwise comparisons revealed that in most cases, these observed effects were due to the differences between the early phase communities (Day 1 and/or 3) and those in the intermediate or late phase (Table 4.3). A moderate partitioning was observed in the NMDS plot based on time at both flow rates (Fig. 4.5 A and B), showing samples collected on Day 1 
and 3 and the remainder of the samples clustered separately. No significant interactions were found between surrogate addition and time in any of the experiments.

\subsubsection{Effect of surrogate addition and time on the functional capability of total microbial} community

Results from previous sections indicated that there was no change in microbial community abundance and composition due to surrogate addition in the first low and high flow rate experiments. As such, microbial community functional profiles were analyzed from these experiments (L.E 1 and H. E 1) in order to understand whether there were any effects of surrogate addition on community functions. Functional gene profiles in each of these experiments were analyzed separately.

The microbial communities in the different flumes were functionally $97-98 \%$ similar at pathway levels at both flow rates, based on SIMPER analysis. At low flow rate, the average dissimilarity between flumes with and without surrogates was around $3 \%$, while at high flow rate, the average dissimilarity between the flumes with and without surrogates was slightly higher $(6 \%)$. However, in both cases the effect was not significant (PERMANOVA, $p$-values were 0.646 and 0.276 at low and high flow rate, respectively). At both flow rates, pathways contributing to the similarity of the communities belonged to photosynthesis, metabolism, signaling pathways and other pathways that could not be classified by the KEGG database.

The functional potential of the communities changed with time in L. E 1 and H. E 1 (Supplementary Fig. S.4.1), a trend earlier seen with the abundance of eukaryotic OTUs as well. PERMANOVA analysis showed a significant effect of time at both flow rates (low flow: $p=0.029$, PERMDISP $p$ value: 0.728 ; high flow: $p=0.006$, PERMDISP $p$ value: 0.115 ). Pairwise comparisons revealed that at high flows, significant differences were found between samples collected on day 1 and the remainder of the samples. Genes related to photosynthesis 
were found to be one of the major factors driving the dissimilarity as per SIMPER analysis. At high flow, however, no significant relationship was identified by the pair wise tests, even though samples collected on days 1 and 3 clustered separately in the NMDS plot. Similar trends were obtained when the analyses were done at KO levels (data not shown).

\subsubsection{Contribution of environmental and physicochemical factors to community patterns}

Based on the DistLM marginal tests, in the first low flow experiment (L.E 1), eukaryotic abundance patterns were significantly related to nitrate $(p=0.004)$, conductivity $(p=0.001)$, DO $(p=0.001)$ and rheology $(0.024)$. Prokaryotic patterns had significant relationships with nitrate $(p=0.001)$, conductivity $(p=0.001)$ and DO $(p=0.001)$. Together they were able to explain $34.5 \%$ of the eukaryotic and $24 \%$ of the variability of prokaryotic communities. In the first high flow experiment (H. E 1), sulfate and conductivity had a significant relationship with observed eukaryotic abundance and together they explained 15\% of the eukaryotic variation. No significant relationship was found between physicochemical factors and prokaryotic abundance. Sulfate had the lowest $p$ value among the parameters tested $(p=0.09)$

In the second low flow experiment (L.E 2$)$, only DO $(p=0.031)$ was a significant parameter for the eukaryotes, and both conductivity $(p=0.002)$ and DO $(p=0.001)$ had significant relationships with the prokaryotic community pattern. DO alone explained $9.1 \%$ and $9.4 \%$ of the variation in eukaryotes and prokaryotes, respectively. In the second high flow experiment (H.E 2), no significant relationship was present between the physicochemical parameters tested and eukaryotic abundance patterns. Sulfate concentrations were found to be significantly affecting prokaryotic abundance $(p=0.006)$ and explained $8 \%$ of the variation. 


\subsection{Discussion}

\subsubsection{Community composition in flume biofilms}

The flume biofilm resembled microbial communities present in natural waterbodies which are dominated by the classes alpha-, beta- and gamma-Proteobacteria and the phyla Bacteroidetes, Actinobacteria, Cyanobacteria, Cytophaga and Flavobacteria, Planctomycetes, Verrucomicrobia and Firmicutes (Besemer et al. 2012, Humbert et al. 2009, Zwart et al. 2002). A few classes known to be phototrophic or photoheterotrophic, like Rhodospirillales, Rhodobacterales, Rhizobiales and Sphingomondales, were present in all samples. In contrast, heterotrophs, like Enterobacteriales, were present in higher proportions only during the initial phases. Such a trend highlights that conditions in our flumes were favorable for growth of phototrophs. The absence of added surrogates in the metagenomic matrix, even though they were detectable in most samples by using qPCR, suggests that the surrogates were present in very low proportions as compared to the autochthonous community members. Such patterns are also seen in freshwater biofilms where FIB and pathogens, even if integrated within the biofilms, are present at very low concentrations (Balzer et al. 2010). The eukaryotic community was dominated by phototrophic algae (Chlorophycaceae), Annelida, Arthropoda and Diatomea, which are also common in freshwater environments (Fechner et al. 2010). In the presence of light, communities are initially dominated by Chlorophycaceae, then by diatoms and, finally, by Cyanobacteria (Sekar et al. 2002), which explains our observations of increasing relative abundance of Cyanobacteria compared to Chlorophycaceae and diatoms over time. 


\subsubsection{Effect of surrogate addition and time on prokaryotic and eukaryotic communities in}

\section{flume biofilms}

In the first set of experiments (L.E 1 and H.E 1), there was no difference in N1 diversity between the communities that received surrogates vs. communities without them. Multivariate analysis agreed with these observations. Surrogate additions did not change prokaryotic or eukaryotic abundance and composition at either flow rate in the first set of experiments. Additionally, based on in silico functional analysis, these experiments also did not show any change in functional potential due to the presence of surrogates.

These observations are in agreement with studies on drinking water biofilms, where a low number of allochthonous pathogens did not lead to any significant change in the existing community (Buse et al. 2014). Resilience of microbial communities is also seen in the gut microbiome where short term perturbations like dietary changes, alien species invasion and antibiotic administration have often failed to cause any change, or the communities have returned to pre-perturbation states rapidly (Lozupone et al. 2012). Even in freshwater systems, protozoan and rotifer communities are seen to be resilient to pulse disturbances if the disturbed community is connected to an undisturbed one, to be used as refuge (Altermatt et al. 2011). Likewise, microbial communities in freshwater environments are more resilient, if there is continuous dispersal of microbial inoculum from an undisturbed source (Baho et al. 2012), which in our system was the fresh feed water carrying microbial inoculum. Based on DistLM results, none of the parameters selected to be strong predictors of the communities were likely to be influenced by the added surrogates. They were more related to feed water chemistry and algal growth. Together, these observations suggest that freshwater biofilm communities were resilient to allochthonous microorganisms and evolved in response to environmental conditions, water chemistry and inoculum received from the feed, similar to 
natural ecosystems (Besemer et al. 2007, Jackson et al. 2001, Lyautey et al. 2005, Sekar et al. 2002).

Although surrogate addition did not alter the communities in the LE 1 and H. E 1, time was found to have a statistically significant effect on the eukaryotic community and on the total functional potential. The samples collected closer to the spiking event were different from the rest. In addition, the functional potential of these communities also changed with time and genes related to photosynthesis were gradually enriched. Together, these observations suggested that the effect of time was due to the growth of photosynthetic organisms in response to prevailing environmental conditions.

Similar patterns are often observed in controlled systems where the microbial community is monitored from the beginning or during early stages of colonization (Besemer et al. 2007, Lee et al. 2015, Lyautey et al. 2005, Sekar et al. 2002). However, such effects are gradually obscured as the community matures (Besemer et al. 2007), which is why the samples collected after day 1 and/or 3 were not significantly different from each other. Alternatively, the effect of time could also be due to the low nutrient addition to the flumes during the spiking event. The spiking would act as a pulse disturbance from which the community recovered with time, a trait often encountered in nature (Shade et al. 2011, Steinman and McIntire 1990). However, since we did not have absolute controls, i.e., flumes which were not disturbed at all, these two factors are not separable in this study. Similar effects were not observed for prokaryotes, since prokaryotic communities can be more resilient than eukaryotic ones (Litchman 2010). In fact, several eukaryotic organisms present in our flumes, like copepods and diatoms, are frequently used to monitor subtle changes in water quality (Raffaelli and Mason 1981). 
In contrast to L. E 1 and H. E 1, the effect of surrogates on the eukaryotic abundance and composition was significant at low flow in the second experiment. The OTUs affected significantly at low flow belonged to Podocopida and Haplotaxida. Podocopida was enriched in flumes with surrogates, whereas Haplotaxida were present in higher concentrations in flumes without surrogates. These organisms were absent in the first low flow experiment. Variations in DO were a strong predictor of the abundance pattern of these eukaryotes, while both DO and conductivity explained the prokaryotic trends.

There was also an effect on eukaryotic abundance at high flow, in the H. E 2, although no effect was observed on composition. Two different species of Podocopida were found to correlate with surrogate addition at high flow. OTU1 was enriched in flumes with surrogates at high flow, as previously observed at low flow, whereas Podocopida OTU4 was enriched at low flow in flumes without surrogates. Water chemistry (sulfate concentration) explained prokaryotic abundance as in the previous experiment. No environmental variable was able to predict the eukaryotic pattern at high flow. Additionally, the effect of time, which was present in earlier experiments, was not present in the second set.

Both Podocopida and Haplotaxida are used as water quality indicators because their concentrations can change rapidly in response to pollution (Holguin-Gonzalez et al. 2013, Ruiz et al. 2005). The L. E 2 and H. E 2 were performed in December and February 2015, whereas the L. E 1 and H. E 1 were performed in December 2014 and June 2015 respectively. Hence, the presence of these key eukaryotes in only the second batch could be due to the change in microbial quality of the feed water between the experiments. Since these organisms were gradually enriched in the flumes over time, minimum fluctuations in their concentrations in the feed would be amplified over time. 
To the best of our knowledge, neither Podocopida nor Haplotaxida are known to have any direct predator-prey relationships with the surrogates added or can be infected by them. Hence it is likely that the differential distribution in the flumes with or without surrogates was an indirect effect. Ostracoda, the class to which Podocopida belong, for example, avoids high water velocity and feeds on sediments and green algae (Dole-Olivier et al. 2000). It can be hypothesized that surrogates like $P$. aeruginosa, which are strong biofilm formers, led to formation of EPS enclosed pockets with restricted flow within, which encouraged Podocopida growth. As discussed in Chapter 2, P. aeruginosa was indeed found to be growing in biofilms at low flow. Additionally, these eukaryotes feeding on algae would mask any effect of time in these communities, which in case of L. E 1 and H. E 1, were linked to algal growth. Alternatively, these eukaryotes might feed on certain organism that does in turn feed on the added bacteria, so we might be observing indirect food web effects. It may be possible that predators were enriched, perhaps in the unknown sequences. Also, although the bacterial surrogates are not known to be invertebrate pathogens, they are opportunists. Therefore there is a possibility of a direct antagonistic effect between $P$. aeruginosa, $E$. faecalis and responsive eukaryotes.

Diversity is often associated with community change, the general consensus being that communities with lower diversity are more susceptible to perturbations in the system (van Elsas et al. 2012). However, we observed no significant difference in N1 between these communities. Since the effect of surrogate addition was only visible in the abundance of Podocopida and Haplotaxida, when they were present in the system, it is more likely that surrogates caused some level of stress, which is identified by these known indicators, but the rest of the eukaryotic community remained resilient. 


\subsection{Conclusions}

- In this study we analyzed the effect of introducing allochthonous microorganisms to a mature freshwater biofilm. We showed that except for one or two eukaryotic organisms, most of the prokaryotic and eukaryotic community does not change even after the added microorganisms are integrated within the biofilm. This means, that in the environments, such pathogen releases are cases of coexistence but not invasion.

- In most studies reporting effect of pathogen release due to anthropogenic activities on microbial ecology, the effects of pathogens alone and other factors such as nutrient concentrations are coupled. We report the effects on pathogens alone and show that freshwater biofilm community is not affected by this short term disturbance. This means, that in a natural system, pathogen release and subsequent persistence within benthic community will not be apparent based on monitoring total microbial communities due to their inherent resilience. This is important in the context of intentional releases or in the context of persistent pathogens in treated water as large numbers of specific biological agents do not seem to affect the biofilm community.

- In this study, relative abundances of few eukaryotic species, such as Podocopida and Hapotaxida were affected by surrogate addition. So, in a natural system, specific indicator organisms for pathogen concentration might be present, but further studies are required before selecting such representative species. 
A

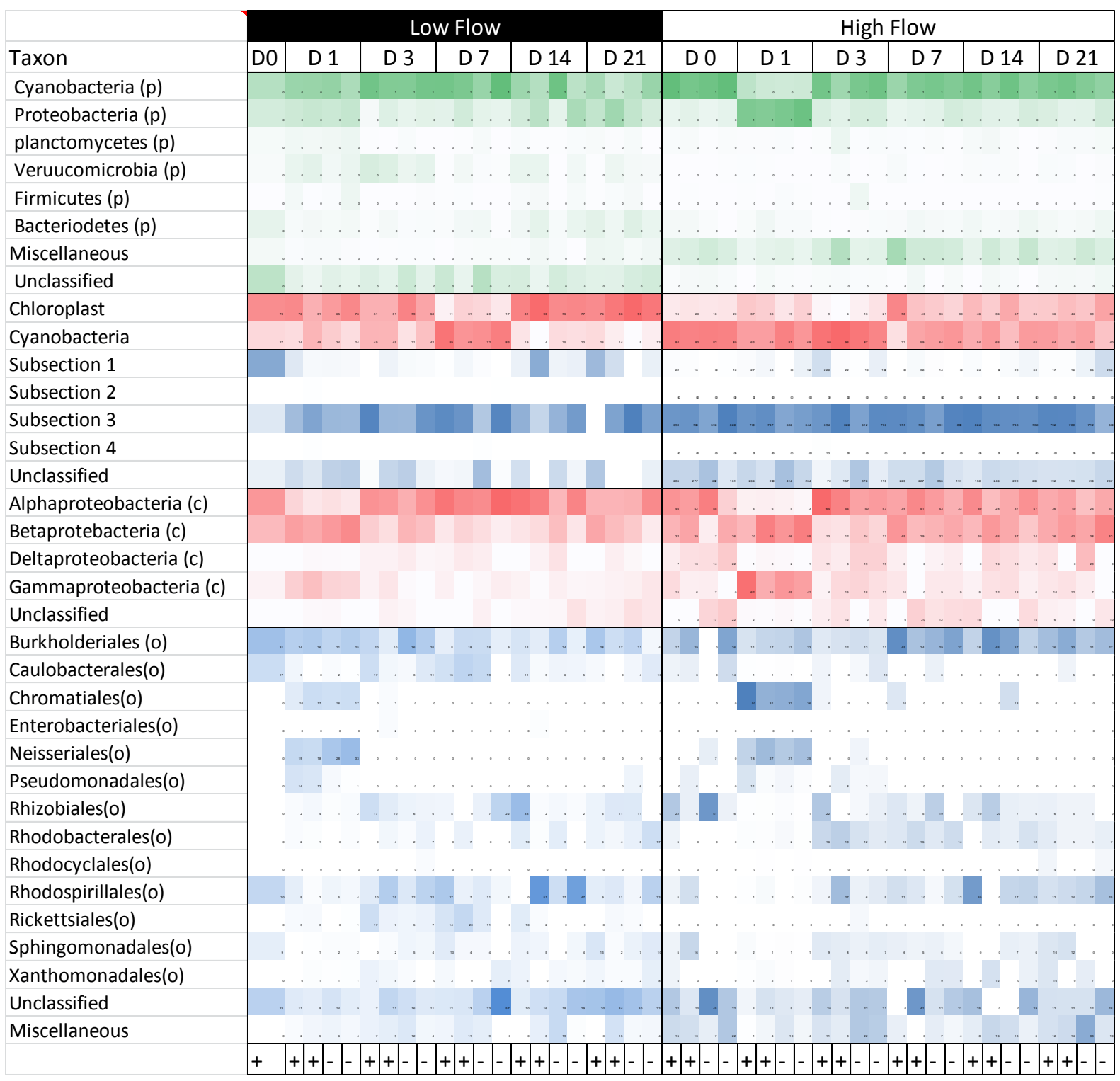

B

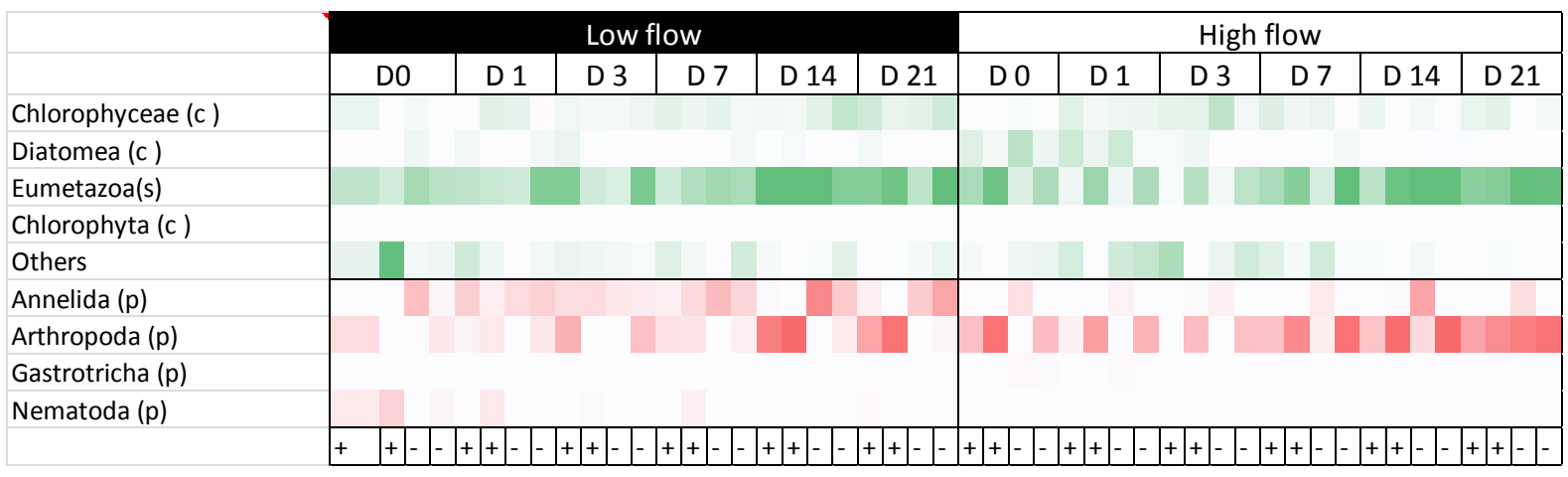

Figure 4.1: Temporal dynamics of (A) prokaryotic and (B) eukaryotic biofilm communities in the flumes under low and high flow conditions. Different colors indicate different taxonomic ranks ( $s=$ subkingdom, $p=$ phylum, $o=$ order, $c=$ class); Color intensity signifies relative abundance (for each column), with lightest to darkest corresponding to lowest to highest abundance. (+) and (-) represent flumes with and without surrogates, respectively. Black corresponds to biofilms grown at low flow and white to biofilms grown at high flow conditions. Each sample is standardized against sample total and each column in a given 
color adds up to $100 \%$. D0 represents a sample collected immediately before adding surrogates and D1-D21 refer to sampling days after the addition of surrogates. Total number of samples $(n)=45$ corresponding to two experiments with replicate flumes per treatment for high or low flow rates. 

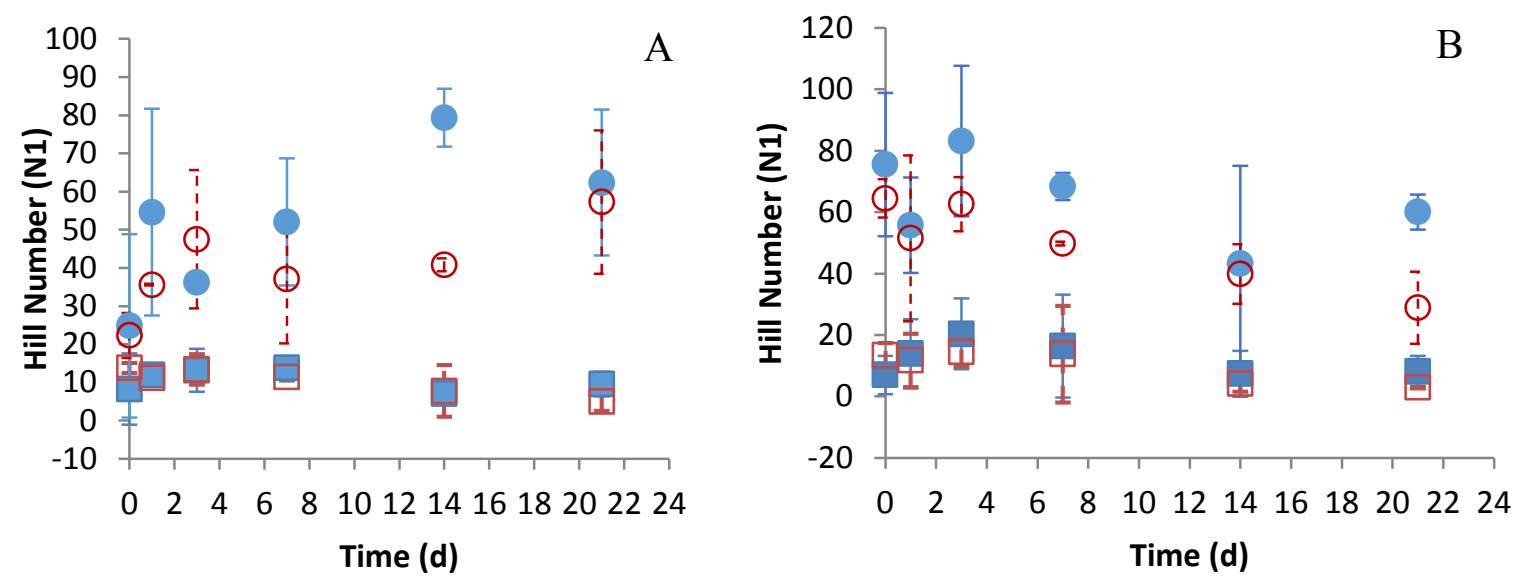

Figure 4.2: Temporal changes in community alpha diversity in terms of Hill number (N1) at (A) low flow and (B) high flow. Squares denote eukaryotes and circles represent prokaryotes. Red, open symbols denote flumes without surrogates and blue closed symbols represent flumes with surrogates.

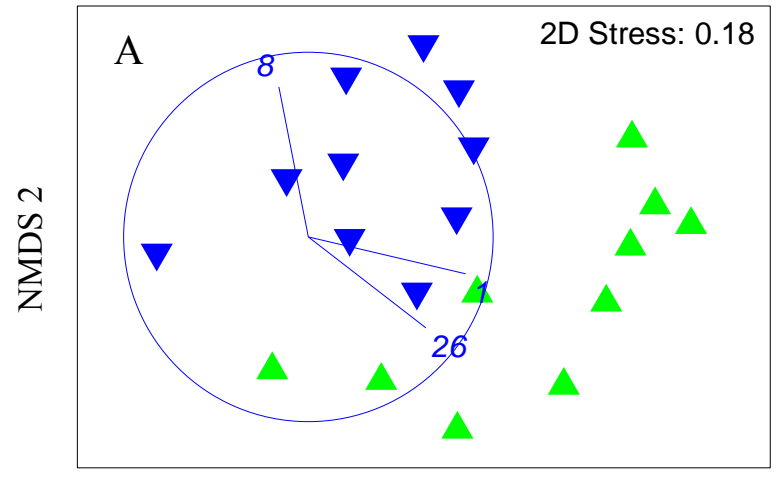

NMDS 1

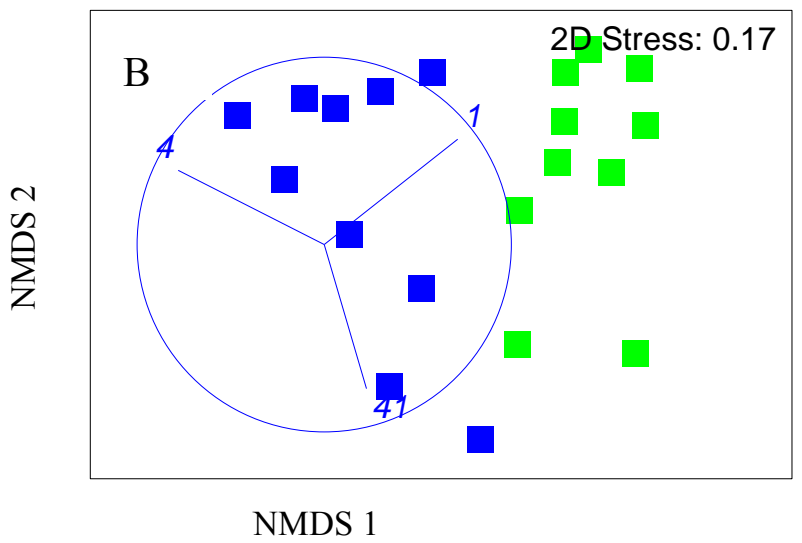

Figure 4.3: Clustering of eukaryotic communities in flumes in the presence and absence of surrogates in the second batch of (A) low and (B) high flow experiments. Each symbol represents the community from a particular flume on a particular day $(n=20)$. Green symbols represent all flumes with surrogates and blue symbols represent all flumes without surrogates. Triangles represent low flow and squares represent high flow. Overlay vectors show OTUs (assigned arbitrary numbers) that explain the patterns (Pearson correlation vectors when $r>$ 0.8 ) with direction implying the direction of increasing abundance of that OTU. OTU classifications: 1= Podocopida (order), 4= Podocopida (order), 8= Haplotaxida (order), 26= Unclassified, 41- Cryptomycota (phylum) 


\begin{tabular}{|l|}
\hline Taxon \\
\hline Podocopida (OTU1) \\
\hline Haplotaxida (OTU2) \\
\hline Saccaromyceteles (OTU3) \\
\hline Unclassified OTU5 \\
\hline Haplotaxida (OTU8) \\
\hline Unclassified OTU9 \\
\hline Chlorophycaceae (OTU10) \\
\hline Unclassified OTU12 \\
\hline Unclassified OTU26 \\
\hline
\end{tabular}

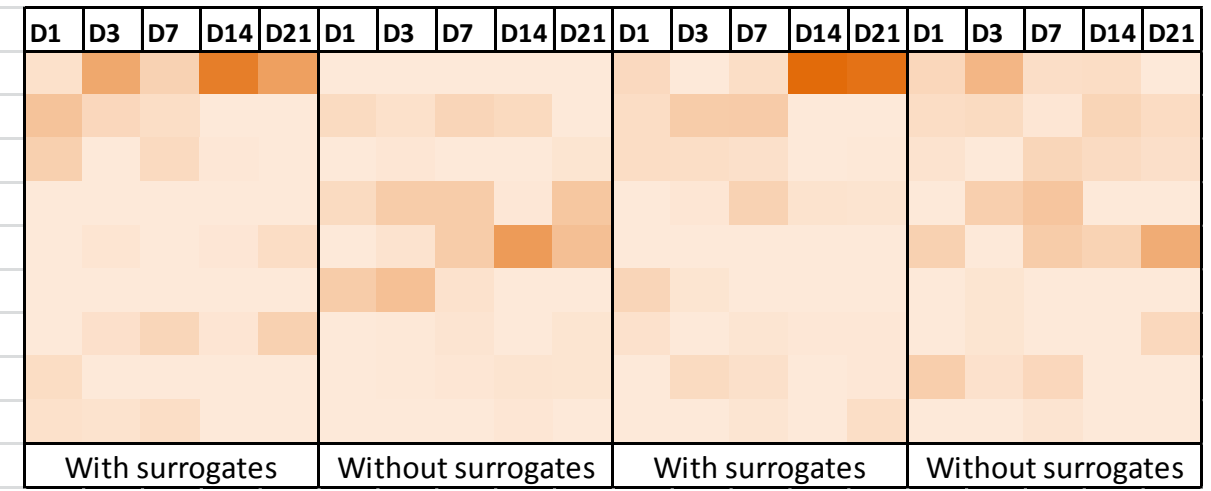

B

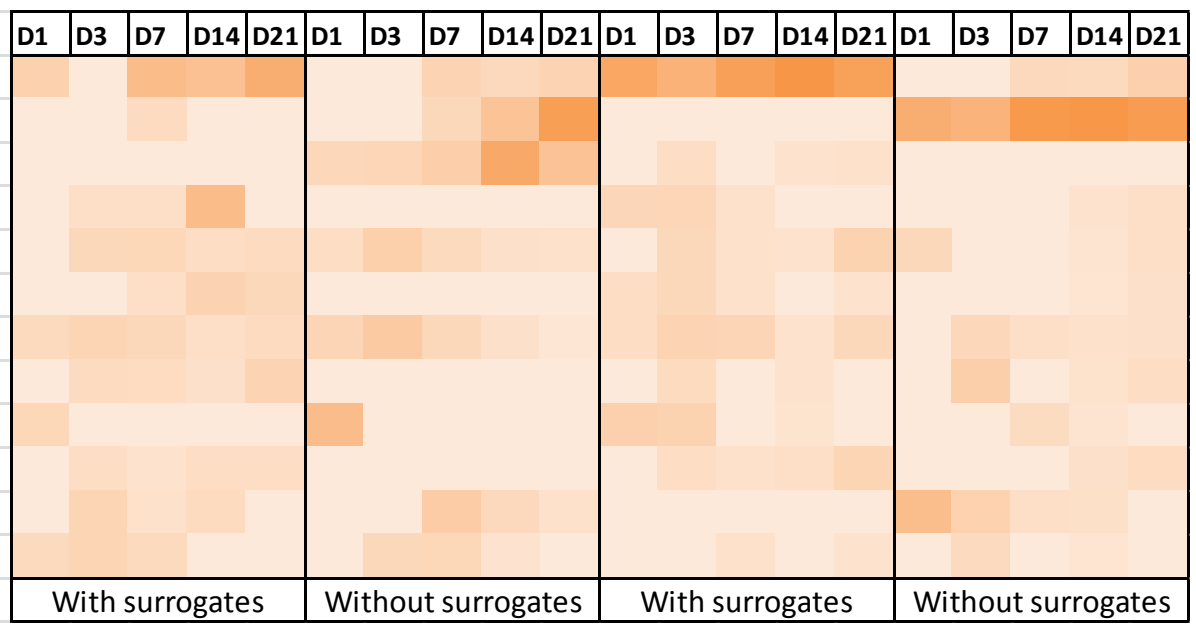

Figure 4.4: Change in relative abundance of key eukaryotic OTUs in the second experiment for (A) low flow and (B) high flow conditions. Color intensity signifies relative abundance (for each column), with lightest to darkest corresponding to lowest to highest abundance. 


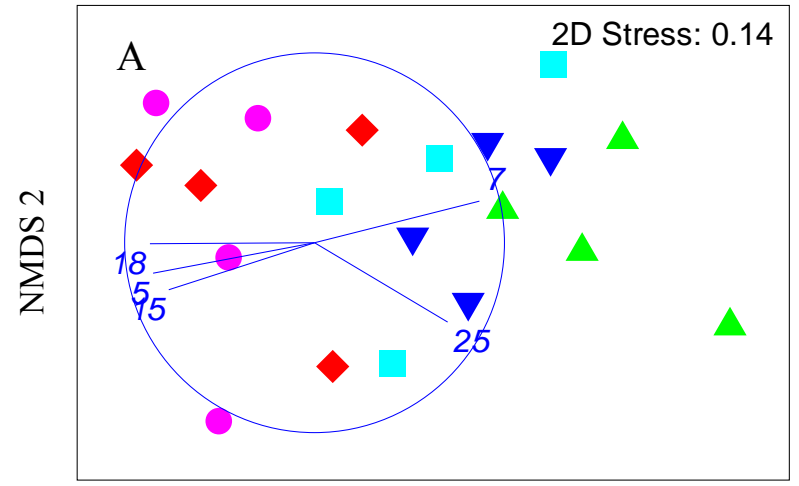

NMDS 1

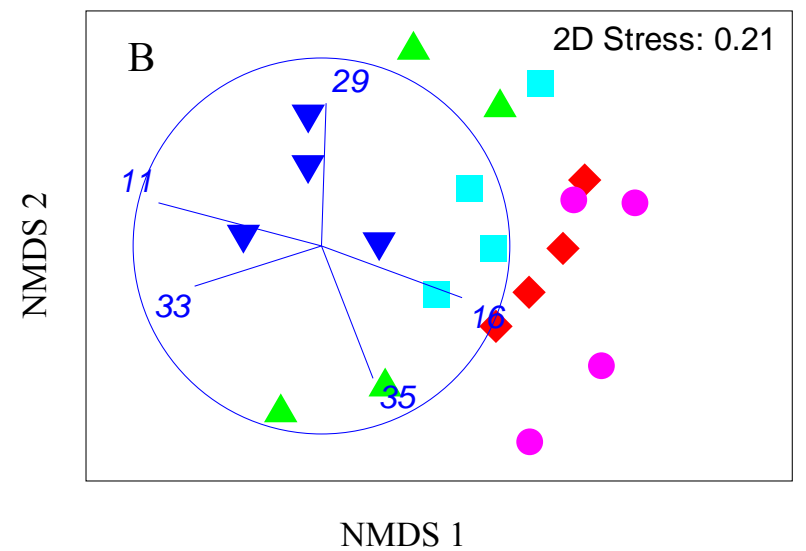

Figure 4.5: Clustering of eukaryotic communities at (A) low and (B) high flow on different days since addition of surrogates. Each symbol represents the community from a particular flume on a particular day $(n=20)$. Colors signify the day of sample collection. Day $1=$ green, Day 3 = blue, Day 7 = light blue, Day $14=$ red and Day $21=$ pink. Each day, samples were collected from four flumes, two with surrogates and two without surrogates. Overlay vectors show OTUs that explain the patterns (Pearson correlation vectors when $r>0.8$ and $>0.7$ for panels A and B, respectively) with direction from the center to the circumference implying the direction of increasing abundance. Vector numbers represent the OTUs identified; $18=$ unclassified, $5=$ Metazoa, $15=$ unclassified, $7=$ unclassified, $25=$ unclassified, $11=$ unclassified, $33=$ Rotifera, $29=$ Diatomea, $16=$ Chlorophycaceae, and $35=$ Metazoa. 
Table 4.1. Univariate analysis of alpha diversity based on the first order Hill number (N1) in flumes with and without surrogates in repeat experiments conducted at two different flow rates.

\begin{tabular}{|c|c|c|c|c|c|c|c|c|c|}
\hline \multicolumn{2}{|c|}{ Statistical parameter } & \multicolumn{8}{|c|}{ Alpha diversity } \\
\hline & & \multicolumn{4}{|c|}{ Prokaryotes } & \multicolumn{4}{|c|}{ Eukaryotes } \\
\hline & & \multicolumn{2}{|c|}{ Experiment 1} & \multicolumn{2}{|c|}{ Experiment 2} & \multicolumn{2}{|c|}{ Experiment 1} & \multicolumn{2}{|c|}{ Experiment 2} \\
\hline & & $+{ }^{1}$ & - & + & - & + & - & + & - \\
\hline \multirow[t]{3}{*}{ Low flow } & Mean N1 & 40.13 & 41.27 & 51.58 & 40.10 & 14.69 & 16.78 & 10.66 & 10.46 \\
\hline & $\mathrm{SD}^{2}$ & 15.21 & 10.60 & 19.20 & 11.78 & 4.64 & 5.09 & 2.75 & 3.42 \\
\hline & p-value ${ }^{3}$ & \multicolumn{2}{|c|}{0.89} & \multicolumn{2}{|c|}{0.24} & \multicolumn{2}{|c|}{0.49} & \multicolumn{2}{|c|}{0.91} \\
\hline \multirow[t]{3}{*}{ High flow } & Mean N1 & 64.17 & 62.01 & 64.35 & 49.51 & 15.53 & 14.55 & 12.18 & 10.09 \\
\hline & SD & 9.42 & 5.07 & 14.38 & 13.55 & 2.23 & 2.25 & 5.56 & 5.18 \\
\hline & p-value & \multicolumn{2}{|c|}{0.6} & \multicolumn{2}{|c|}{0.09} & \multicolumn{2}{|c|}{0.47} & \multicolumn{2}{|c|}{0.52} \\
\hline
\end{tabular}

1 +/- indicates flumes with and without added surrogates.

${ }^{2}$ Standard deviation

${ }^{3}$ Comparison of Hill numbers obtained from flumes in the same experiment either receiving or not receiving surrogates. 
Table 4.2: Statistical analyses of prokaryotic and eukaryotic communities to determine effect of surrogate addition or time on abundance and composition of the communities at two different flow rates

\begin{tabular}{|c|c|c|c|c|c|c|c|c|c|c|}
\hline \multirow[t]{3}{*}{ Factor } & \multirow[t]{3}{*}{ Analysis $^{1}$} & \multirow[t]{3}{*}{$\operatorname{Exp}^{2}$} & \multicolumn{4}{|c|}{$p$-value based on Bray Curtis resemblance } & \multicolumn{4}{|c|}{$p$-value based on Jaccard resemblance } \\
\hline & & & \multicolumn{2}{|c|}{ Low Flow } & \multicolumn{2}{|c|}{ High Flow } & \multicolumn{2}{|c|}{ Low Flow } & \multicolumn{2}{|c|}{ High Flow } \\
\hline & & & Prokaryotes & Eukaryotes & Prokaryotes & Eukaryotes & Prokaryotes & Eukaryotes & Prokaryotes & Eukaryotes \\
\hline \multirow{4}{*}{$\begin{array}{l}\text { Surrogate } \\
\text { addition }\end{array}$} & PERMANOVA & 1 & 0.189 & 0.071 & 0.303 & 0.654 & 0.344 & 0.171 & 0.323 & 0.511 \\
\hline & & 2 & 0.072 & 0.004 & 0.373 & 0.001 & 0.218 & 0.032 & 0.404 & 0.094 \\
\hline & PERMDISP & 1 & $\mathrm{NA}^{3}$ & NA & NA & NA & NA & NA & NA & NA \\
\hline & & 2 & NA & 0.581 & NA & 0.683 & NA & 0.756 & NA & NA \\
\hline \multirow[t]{4}{*}{ Time } & PERMANOVA & 1 & 0.003 & 0.02 & 0.001 & 0.006 & 0.036 & 0.136 & 0.007 & 0.012 \\
\hline & & 2 & 0.02 & 0.162 & 0.003 & 0.2 & 0.122 & 0.287 & 0.034 & 0.375 \\
\hline & PERMDISP & 1 & 0.002 & 0.253 & 0.006 & 0.22 & 0.003 & NA & 0.008 & 0.736 \\
\hline & & 2 & 0.042 & NA & 0.002 & NA & NA & NA & 0.001 & NA \\
\hline \multirow[t]{2}{*}{ Interaction } & PERMANOVA & 1 & 0.876 & 0.637 & 0.994 & 0.994 & 0.677 & 0.0 .691 & 0.454 & 0.901 \\
\hline & & 2 & 0.895 & 0.731 & 0.608 & 0.837 & 0.853 & 0.861 & 0.453 & 0.636 \\
\hline
\end{tabular}

${ }^{1}$ Multivariate analysis based on PERMANOVA and PERMDISP on Bray Curtis (to see effect on relative abundance of the OTUs present) and Jaccard resemblance (or presence/absence matrix in order to see effect on composition of the communities)

${ }^{2}$ Serial number of experiment, $1=$ first high/low flow experiment, $2=$ second high/low flow experiment

${ }^{3}$ Not applicable 
Table 4.3: Pair-wise comparisons (PERMANOVA) of eukaryotic communities ${ }^{1}$ in biofilms on different days $(1,3,7,14$ and 21) of the experiments. Samples collected on days 1 and/or 3 are significantly different from the rest.

\begin{tabular}{|c|c|c|}
\hline \multirow[t]{2}{*}{ Compared Groups } & \multicolumn{2}{|c|}{$p$ value } \\
\hline & L. E 1 & H. E 1 \\
\hline 1,3 & 0.237 & 0.053 \\
\hline 1,7 & 0.06 & 0.223 \\
\hline 1,14 & 0.04 & 0.08 \\
\hline 1,21 & 0.035 & 0.122 \\
\hline 3,7 & 0.693 & 0.043 \\
\hline 3,14 & 0.141 & 0.027 \\
\hline 3,21 & 0.045 & 0.039 \\
\hline 7,14 & 0.347 & 0.375 \\
\hline 7,21 & 0.082 & 0.135 \\
\hline 14,21 & 0.938 & 0.657 \\
\hline
\end{tabular}




\subsection{Supplementary Materials}

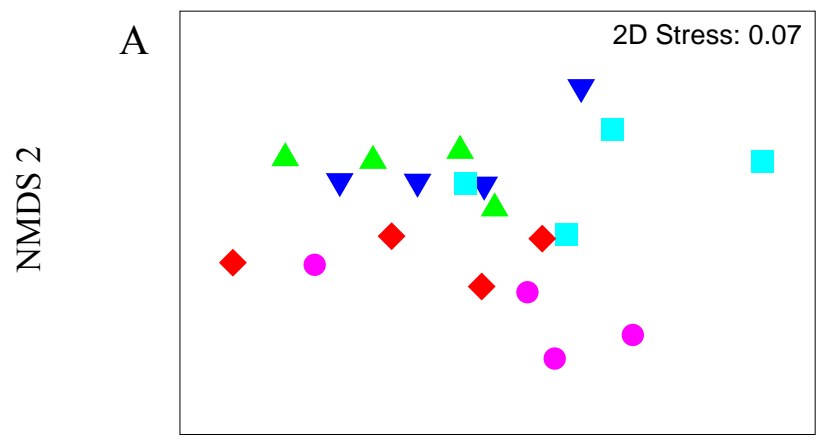

NMDS 1

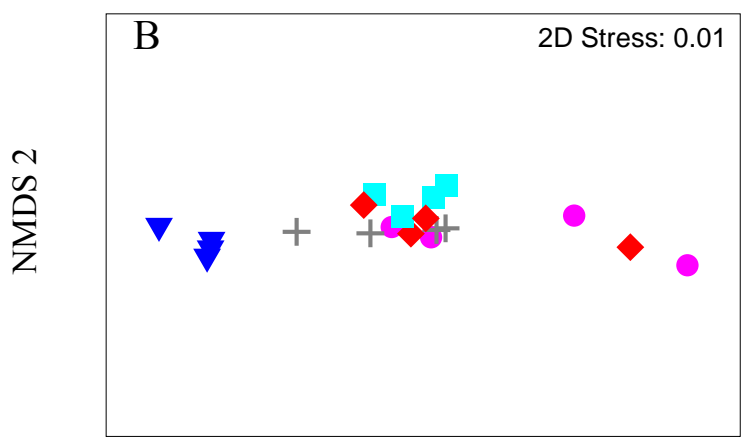

NMDS 1

Figure S. 4.1: Biofilm functionality does not show any clustering based on presence and absence of surrogates. NMDS plots show patterns in (A) low flow and (B) high flow at pathway levels. Colors of symbols signify the day of sample collection. Day $1=$ green, Day 3 = blue, Day $7=$ light blue, Day $14=$ red and Day $21=$ pink.

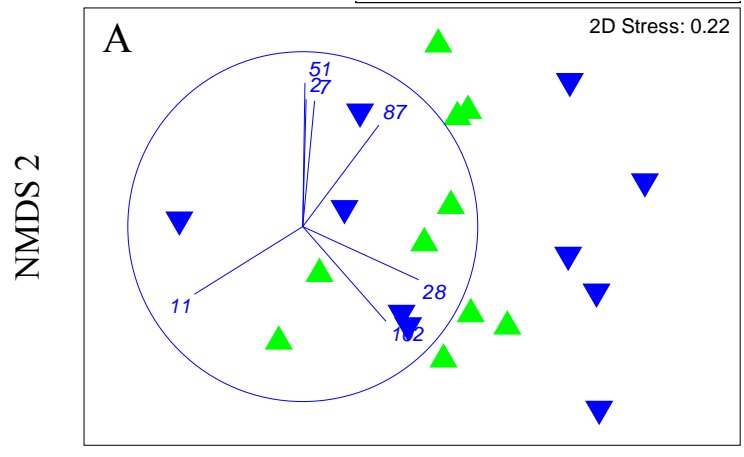

NMDS 1

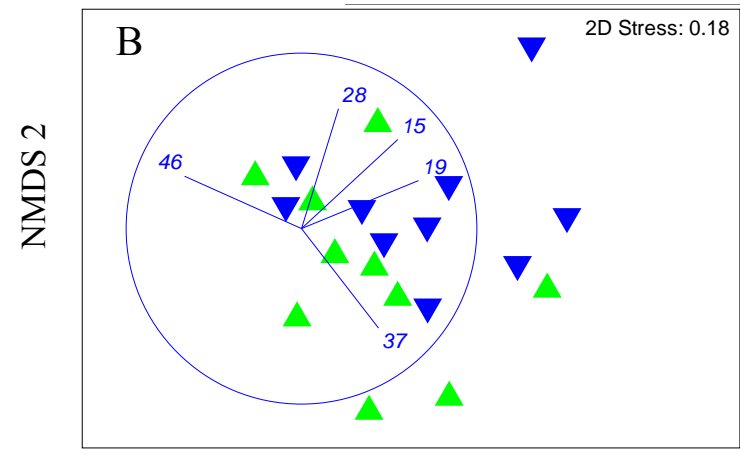

NMDS 1

Figure S. 4.2: Prokaryotic community does not show any effect of surrogate addition. NMDS plots show patterns in (A) Low flow and (B) high flow. Blue and green colours signify flumes with and without surrogates. 


\subsection{References}

Altermatt F, Bieger A, Carrara F, Rinaldo A, Holyoak M (2011). Effects of connectivity and recurrent local disturbances on community structure and population density in experimental metacommunities. PLOS ONE 6: e19525.

Andrews S (2010). FastQC: A quality control tool for high throughput sequence data. Reference Source.

Angeloni NL, Jankowski KJ, Tuchman NC, Kelly JJ (2006). Effects of an invasive cattail species (Typha $\times$ glauca) on sediment nitrogen and microbial community composition in a freshwater wetland. FEMS Microbiology Letters 263: 86-92.

Assessment ME (2003). Ecosystems and human well-being, vol. 200. World Resource Institute, Washington, DC: Island Press.

Baho DL, Peter H, Tranvik LJ (2012). Resistance and resilience of microbial communitiestemporal and spatial insurance against perturbations. Environmental Microbiology 14: 22832292.

Balzer M, Witt N, Flemming H-C, Wingender J (2010). Faecal indicator bacteria in river biofilms. Water Science and Technology 61: 1105-1111.

Battin TJ, Kaplan LA, Newbold JD, Cheng X, Hansen C (2003). Effects of current velocity on the nascent architecture of stream microbial biofilms. Applied and Environmental Microbiology 69: 5443-5452.

Besemer K, Singer G, Limberger R, Chlup A-K, Hochedlinger G, Hödl I et al. (2007). Biophysical controls on community succession in stream biofilms. Applied and Environmental Microbiology 73: 4966-4974.

Besemer K, Peter H, Logue JB, Langenheder S, Lindström ES, Tranvik LJ et al. (2012). Unraveling assembly of stream biofilm communities. The ISME Journal 6: 1459-1468.

Buchfink B, Xie C, Huson DH (2015). Fast and sensitive protein alignment using DIAMOND. Nature Methods 12: 59-60.

Buse HY, Lu J, Lu X, Mou X, Ashbolt NJ (2014). Microbial diversities (16S and 18S rRNA gene pyrosequencing) and environmental pathogens within drinking water biofilms grown on the common premise plumbing materials unplasticized polyvinylchloride and copper. FEMS Microbiology Ecology 88: 280-295. 
Dole-Olivier MJ, Galassi D, Marmonier P, Creuzé des Châtelliers M (2000). The biology and ecology of lotic microcrustaceans. Freshwater Biology 44: 63-91.

Drury B, Rosi-Marshall E, Kelly JJ (2013). Wastewater treatment effluent reduces the abundance and diversity of benthic bacterial communities in urban and suburban rivers. Applied and Environmental Microbiology 79: 1897-1905.

Erlacher A, Cardinale M, Grosch R, Grube M, Berg G (2015). The impact of the pathogen Rhizoctonia solani and its beneficial counterpart Bacillus amyloliquefaciens on the indigenous lettuce microbiome. The plant microbiome and its importance for plant and human health: 117.

Fechner LC, Vincent-Hubert F, Gaubert P, Bouchez T, Gourlay-Francé C, Tusseau-Vuillemin $\mathrm{M}-\mathrm{H}$ (2010). Combined eukaryotic and bacterial community fingerprinting of natural freshwater biofilms using automated ribosomal intergenic spacer analysis. FEMS Microbiology Ecology 74: 542-553.

Flemming H-C, Neu TR, Wozniak DJ (2007). The EPS matrix: the "house of biofilm cells". Journal of Bacteriology 189: 7945-7947.

Hill, Mark O. "Diversity and evenness: a unifying notation and its consequences." Ecology 54.2 (1973): 427-432.

Holguin-Gonzalez JE, Everaert G, Boets P, Galvis A, Goethals PL (2013). Development and application of an integrated ecological modelling framework to analyze the impact of wastewater discharges on the ecological water quality of rivers. Environmental Modelling and Software 48: 27-36.

Humbert JF, Dorigo U, Cecchi P, Le Berre B, Debroas D, Bouvy M (2009). Comparison of the structure and composition of bacterial communities from temperate and tropical freshwater ecosystems. Environmental Microbiology 11: 2339-2350.

Huson DH, Auch AF, Qi J, Schuster SC (2007). MEGAN analysis of metagenomic data. Genome Research 17: 377-386.

Jackson CR, Churchill PF, Roden EE (2001). Successional changes in bacterial assemblage structure during epilithic biofilm development. Ecology 82: 555-566.

Jani AJ, Briggs CJ (2014). The pathogen Batrachochytrium dendrobatidis disturbs the frog skin microbiome during a natural epidemic and experimental infection. Proceedings of the National Academy of Sciences 111: E5049-E5058.

Jeffries TC, Ostrowski M, Williams RB, Xie C, Jensen RM, Grzymski JJ Senstius S J, Givskov M, Hoeke R, Gayle P K (2015). Spatially extensive microbial biogeography of the 
Indian Ocean provides insights into the unique community structure of a pristine coral atoll. Scientific Reports 5: 15383.

Klapper I, Rupp CJ, Cargo R, Purvedorj B, Stoodley P (2002). Viscoelastic fluid description of bacterial biofilm material properties. Biotechnology and Bioengineering 80: 289-296.

Lee PO, McLellan SL, Graham LE, Young EB (2015). Invasive dreissenid mussels and benthic algae in Lake Michigan: characterizing effects on sediment bacterial communities. FEMS Microbiology Ecology 91: 1-12.

Litchman E (2010). Invisible invaders: non-pathogenic invasive microbes in aquatic and terrestrial ecosystems. Ecology Letters 13: 1560-1572.

Lozupone CA, Stombaugh JI, Gordon JI, Jansson JK, Knight R (2012). Diversity, stability and resilience of the human gut microbiota. Nature 489: 220-230.

Lyautey E, Jackson CR, Cayrou J, Rols J-L, Garabétian F (2005). Bacterial community succession in natural river biofilm assemblages. Microbial Ecology 50: 589-601.

Martin M (2011). Cutadapt removes adapter sequences from high-throughput sequencing reads. EMBnet Journal 17: pp. 10-12.

Mußmann M, Ribot M, von Schiller D, Merbt SN, Augspurger C, Karwautz C, Winkel M, Battin T J, Martí E, Daims H (2013). Colonization of freshwater biofilms by nitrifying bacteria from activated sludge. FEMS Microbiology Ecology 85: 104-115.

O'neil J, Davis TW, Burford MA, Gobler C (2012). The rise of harmful cyanobacteria blooms: the potential roles of eutrophication and climate change. Harmful Algae 14: 313-334.

Raffaelli D, Mason C (1981). Pollution monitoring with meiofauna, using the ratio of nematodes to copepods. Marine Pollution Bulletin 12: 158-163.

Rosenberg M (1984). Bacterial adherence to hydrocarbons: a useful technique for studying cell surface hydrophobicity. FEMS Microbiology Letters 22: 289-295.

Ruiz F, Abad M, Bodergat A-M, Carbonel P, Rodríguez-Lázaro J, Yasuhara M (2005). Marine and brackish-water ostracods as sentinels of anthropogenic impacts. Earth-Science Reviews 72: 89-111.

Saxena G, Marzinelli EM, Naing NN, He Z, Liang Y, Tom L, Mitra S, Ping H, Joshi U M, Reuben S (2015). Ecogenomics reveals metals and land-use pressures on microbial communities in the waterways of a megacity. Environmental Science and Technology 49: $1462-1471$. 
Sekar R, Nair K, Rao V, Venugopalan V (2002). Nutrient dynamics and successional changes in a lentic freshwater biofilm. Freshwater Biology 47: 1893-1907.

Shade A, Read JS, Welkie DG, Kratz TK, Wu CH, McMahon KD (2011). Resistance, resilience and recovery: aquatic bacterial dynamics after water column disturbance. Environmental Microbiology 13: 2752-2767.

Steinman AD, McIntire CD (1990). Recovery of lotic periphyton communities after disturbance. Environmental Management 14: 589-604.

van Elsas JD, Chiurazzi M, Mallon CA, Elhottovā D, Krištůfek V, Salles JF (2012). Microbial diversity determines the invasion of soil by a bacterial pathogen. Proceedings of the National Academy of Sciences 109: 1159-1164.

Van Rossum T, Peabody MA, Uyaguari-Diaz MI, Cronin KI, Chan M, Slobodan JR et al. (2015). Year-long metagenomic study of river microbiomes across land use and water quality. Frontiers in Microbiology 6.

Vitousek PM, Aber JD, Howarth RW, Likens GE, Matson PA, Schindler DW et al. (1997). Human alteration of the global nitrogen cycle: sources and consequences. Ecological Applications 7: 737-750.

Wakelin SA, Colloff MJ, Kookana RS (2008). Effect of wastewater treatment plant effluent on microbial function and community structure in the sediment of a freshwater stream with variable seasonal flow. Applied and Environmental Microbiology 74: 2659-2668.

Wei G, Yang Z, Cui B, Li B, Chen H, Bai J et al. (2009). Impact of dam construction on water quality and water self-purification capacity of the Lancang River, China. Water Resources Management 23: 1763-1780.

Wilson WW, Wade MM, Holman SC, Champlin FR (2001). Status of methods for assessing bacterial cell surface charge properties based on zeta potential measurements. Journal of Microbiological Methods 43: 153-164.

Wittmann ME, Chandra S, Caires A, Denton M, Rosen MR, Wong WH et al. (2010). Early invasion population structure of quagga mussel and associated benthic invertebrate community composition on soft sediment in a large reservoir. Lake and Reservoir Management 26: 316-327.

Wolfe BE, Richard F, Cross HB, Pringle A (2010). Distribution and abundance of the introduced ectomycorrhizal fungus Amanita phalloides in North America. New Phytologist 185: $803-816$ 
Xie, C., Goi, C. L. W., Huson, D. H., Little, P. F., \& Williams, R. B. (2016). RiboTagger: fast and unbiased $16 \mathrm{~S} / 18 \mathrm{~S}$ profiling using whole community shotgun metagenomic or metatranscriptome surveys. BMC Bioinformatics, 17(19), 277.

Zwart G, Crump BC, Kamst-van Agterveld MP, Hagen F, Han S-K (2002). Typical freshwater bacteria: an analysis of available 16S rRNA gene sequences from plankton of lakes and rivers. Aquatic Microbial Ecology 28: 141-155. 


\section{Conclusions and Implications}

\subsection{Experimental design}

Pathogen contamination of natural water bodies is one of the most threatening types of pollution in today's world. Each year, such contaminations endanger public health and result in substantial economic losses (Yoder et al. 2008). Even though there are decades of research focusing on fate and transport of pathogens in natural water bodies, as our understanding of microorganisms in general has improved, there are remaining gaps in the domain of pathogen fate and transport:

1. Lack of information on validated relationships between human pathogens and fecal indicator organisms in different matrices.

2. Lack of understanding on role of biofilms in survival of these pathogens.

3. Lack of evidence whether there are any impacts of flow regime changes on fate of pathogens and whether those impacts are governed by hydrodynamics alone or are mediated via changing biofilm properties.

4. No clear verdict on whether pathogens alone can change autochthonous microbial communities as observed in alien species invasion in macro-ecology.

This dissertation is a compilation of research motivated by the need to bridge these gaps by combining our knowledge in Engineering and Microbiology. An elaborate literature review (Chapter 1) confirmed that much of the previous research was done using fecal indicator bacteria in lieu of pathogens. It is known that the fate of microorganisms can vary depending on the type of organism and the environment in which it is released. Hence, I selected four different microorganisms (two bacteria, varying in Gram staining properties, and two phages, varying in nucleic acid type) as surrogates of human pathogens for our study. I chose $P$. aeruginosa, an opportunistic pathogen often associated with recreational water borne illness; E. faecalis, a known fecal indicator bacteria; and the bacteriophages P22 and GA to represent 
dsDNA and RNA phages. I employed open channel flumes located in an outdoor facility, next to an urban canal (Van Kleef Center, Singapore), which allowed for necessary control, without excessive scaling down, while keeping the environmental conditions similar to those present in the canal. Additionally, the flumes were operated with freshly withdrawn canal water, thus providing the surrogates with similar microbial and physicochemical water quality as present in the urban canal.

The second knowledge gap that was evident from scanning the available literature was the role of biofilms in pathogen fate and transport. It has been established in a variety of systems, such as medical implants, waste water reactors and flow chambers, that biofilms are a common mode of life of microorganisms, and the activities of microorganisms in biofilms are more diverse than those of their planktonic counterparts (Rice et al., 2016). Most natural systems include biofilms, such as freshwaters (Battin et al. 2007). Hence, we grew a mature photosynthetic biofilm on the flume bed to represent biofilms present in shallow waters in natural freshwaters. I performed four experiments, using four flumes each time, and spiking two of them with the selected surrogates. Each experiment was conducted for duration of 21 days. The outcome of these experiments is reported in three main chapters, each chapter driven by the need to address one or more of the above gaps. In Chapter 2, I aimed to address this gap and asked the following research questions:

1) Can biofilms in waterways act as a repository of human pathogens?

2) Can pathogen fate in freshwater systems be explained by physicochemical mechanisms (settling, decay and detachment) alone in the presence of biofilms?

Results from Chapter 2 confirmed that biofilms act as source and sink of pathogens at low flow. So, the next step was to address the third gap and find the link between hydrodynamics, biofilm properties and pathogen fate. The outcome of the research was compiled in Chapter 3. I studied pathogen behavior at two different flow rates, $6 \mathrm{~L} \mathrm{~min}^{-1}$ and $12 \mathrm{~L} \mathrm{~min}^{-1}$, which 
represented the flow in urban canals in Singapore during dry weather (low flow rate) and the annual average (high flow rate), respectively. I asked the following research questions:

1) In freshwater system, do hydrodynamic conditions affect settling, integration, growth and detachment of pathogens in biofilms?

2) Can biofilm kinetic processes be different due to different flow rates and in turn impact the fate of pathogens?

The surrogate behavior was found to be affected by flow rate, both directly, and indirectly via modifying biofilm kinetics. Hence, as the final step, I looked into the biofilm community structure to address the last gap pertaining to autochthonous communities:

1) Does the introduction of pathogens affect the benthic biofilm community in terms of composition and function?

2) If so, is such an effect related to hydrodynamic conditions?

In this section (Chapter 4), I analyzed the effects of adding surrogates on biofilm communities by employing metagenomic sequencing. The novelty of the approach was that we uncoupled the effects of variations in nutrient concentrations that generally accompany pathogen release from biological effect of the microorganisms. I further avoided any PCR bias by using high throughput sequencing and by using a combination of $16 \mathrm{~S}$ and $18 \mathrm{~S}$ rRNA gene abundance and in silico functional analysis, interpreted the effects on both prokaryotes and eukaryotes and their net functional potential.

\subsection{Key findings and implications}

\subsubsection{Role of biofilms in fate of surrogates}

The concentrations of cultivable population and nucleic acid of the surrogates were monitored for $20 \mathrm{~d}$ using cultivation based techniques and qPCR, respectively. Environmental conditions and water chemistry were simultaneously monitored to ensure overall similarity of experimental conditions. I then analyzed the role of biofilms in the fate of these surrogates 
using a simple hydrodynamic model based on the principles of mass conservation. The decay rate constants in the aqueous phase for the model were estimated in a separate batch study.

All surrogates settled in the biofilms in all amended flumes within the first $24 \mathrm{~h}$ and were retained there for up to $20 \mathrm{~d}$. Bacteriophage GA was not detected in any of the experiments after spiking. Even though settling, decay and detachment could predict the surrogate concentrations in water, these processes alone could not explain the observed concentrations of the other three surrogates in biofilms. P. aeruginosa and E. faecalis were found to grow within the biofilms. P. aeruginosa is a known biofilm former (Stoodley et al. 2002). Regrowth of E. faecalis within sediments has been reported before in tropical and subtropical environments (de Brauwere et al. 2014). However, no similar records were available for Singapore's canals at the time of this study. P22 phage did not grow due to the absence of its specific host, Salmonella enterica serovar Typhimurium. Based on the batch study, P22 also had a low decay rate constant for viable phages while the DNA did not decay at all. Over time, the retained fraction was released back in to the water, thereby increasing the time required to purge surrogates from the system for up to one week depending on the surrogate. The release (detachment) was a continuous process for $P$. aeruginosa during the early periods and for P22 and E. faecalis for the entire duration of experiment. However, detachment became random for P. aeruginosa during the latter stages.

These results show that in shallow depths with ample sunlight, biofilms can function as a secondary source of pathogens long after the initial release. Hence, while designing best practices and monitoring strategies of water quality, especially if waterways are designated for intended direct usage, like recreation, biofilm reservoirs need to be taken into account. We also observed a high autochthonous population of $E$. faecalis in the canal water and that it can grow within the biofilm. Such trends call into question the suitability of enterococci as a 
microbial indicator in the tropics. Interestingly, from the batch study and flume based experiments, we found that phages like P22 can act as a conservative tracer.

\subsubsection{Role of hydrodynamic conditions in fate of surrogates}

Since biofilms were found to be acting as a reservoir of surrogates at low flow rate, we compared the data with those from experiments performed at high flow rate to evaluate the effects of a change in flow rate. At either flow rate, the surrogates settled in the biofilm within the first $24 \mathrm{~h}$. We previously observed that detachment of the bacterial strains, especially $P$. aeruginosa, from the biofilm at low flow was random, suggesting sloughing to be the dominant mechanism. In contrast, at high flow, the detachment was more continuous, pointing towards erosion as the detachment mechanism. The time required to remove $99 \%$ of the surrogates from water $\left(\mathrm{T}_{99}\right)$ was lengthened by $24-57 \%$ at the high flow rate. In contrast, $\mathrm{T}_{99}$ in biofilms was $35-500 \%$ shorter at this flow rate. The detachment rates of $P$. aeruginosa and P22 DNA were increased by approximately $80 \%$ at the high flow rate. Decay in biofilms was also heightened at high flow rate. The corresponding decay rate constants increased between 22 and $83 \%$ compared to those at the low flow rate. These results were in agreement with biofilms models suggesting that in low shear environments, biofilms are more porous and thus more protective, and sloughing is the dominant mechanism of release, whereas at higher shear, biofilms become more compact and less penetrable and erosion becomes the main mechanism (Van Loosdrecht et al. 2002). P. aeruginosa was found to grow at low flow but not at high flow, whereas E. faecalis grew at both flow rates, their growth rate being more than $50 \%$ higher at the high flow rate. A combination of factors like competitive advantage in stressed environments (Barcina et al. 1990), and the presence of crustaceans (Signoretto et al. 2005) and algae (Byappanahalli et al. 2003) which are flow sensitive and known to assist in E. faecalis growth could have resulted in a better growth environment for this bacteria at high flow. 
Our results show that an increased flow rate leads to increased detachment and higher decay of pathogens in the biofilm. Hence, a change in flow regime of a water body resulting in low flow conditions will enhance pathogen survival in benthic biofilms due to lower decay rates; pathogens will subsequently become mobilized if flow rates increase. This would lengthen the $\mathrm{T}_{99}$ to more than what would expected if the flow rate had remained constant.

I further show that length of time a pathogen will survive depends more on the pathogen in question than the hydrodynamics. For example, in general, pathogen detachment would pose a threat for longer periods at high flow compared to lower flow rates. However, for microorganisms like $P$. aeruginosa, low flow conditions will be worse as $P$. aeruginosa can grow at low flow and then be released abruptly long after the initial release. In contrast, it decays faster and does not grow at high flow, thereby leading to quicker depletion in biofilm reservoirs. Results also prove that it is important to consider biofilms as source and sink of pathogens and incorporate kinetic parameters like detachment rates and decay rates as state variables in predictive models. I also showed that decay kinetics can be biphasic, or be a combination of growth and decay, with one process dominating the other at different times. Hence, assuming decay to be an exponential first order reaction in models can be erroneous. Finally, we observed growth patterns of bactrial surrogates to be varying at different flow rates, which means, growth rate should be incorporated in predictive analysis only if there is experimental evidence of growth in the system.

\subsubsection{Impacts of introduction of surrogates on autochthonous biofilm community}

After analyzing the link of hydrodynamics, biofilms and pathogen fate, I finally evaluated the impacts of pathogen release on the autochthonous community. We compared the prokaryotic and eukaryotic biofilm communities from all four experiments and analyzed whether the abundance, composition or functional potential of the community changed in the presence of surrogates. We used two software applications, (i) RiboTagger for abundance (Chao et al., 
2016) and (ii) MEGAN for in silico functional analysis (Huson et al. 2007). Ribotags (OTU equivalents) identified using RiboTagger were taxonomically assigned, whenever required, using the SINA aligner against the SILVA SSU database.

The results showed that prokaryotic communities were not affected by surrogate addition at either high or low flow rates. Eukaryotic communities showed similar resilience, except when Podocopida and Haplotaxida were present. If these eukaryotes were present in the flumes (as in two of the four experiments, one at each flow rate), a significant effect of surrogate addition was observed, even though the surrogates used were not known to be pathogenic for any of them. Resilience of microbial communities have been reported earlier for freshwater systems (Baho et al. 2012), drinking water systems (Buse et al. 2014) as well as host based systems like the gut microbiome (Lozupone et al. 2012). Eukaryotic communities that were not affected by surrogates changed over time. The communities on days 1 and 3 were different from those collected afterwards. Such differences reflected the algal growth in the flumes.

My studies showed that pathogen release in freshwater are a case of co-existence and not invasion. This is important in the context of intentional releases or in the context of persistent pathogens in treated water as large numbers of specific biological agents do not seem to affect the biofilm community.

This work shows that biofilms play a significant role in fate of pathogens. In future studies, predictive modeling should thus incorporate the biofilm potential while determining pathogen fate in natural water bodies. We did not consider sediments in our system. In shallow water bodies that receive ample sunlight, biofilms tends to cover the sediments following which the sediment properties are more controlled by the biofilms. Biofilms are also present on rocks and other non-sediment surfaces. The next step would be to analyze how different types of 
biofilms, such as those in light restricted zones, or in marine and intertidal habitats interact with pathogens.

I further showed that biofilm properties that affect pathogen growth, detachment and decay vary at different flow regimes, within a laminar flow range. Future studies can build on this crucial finding and address scenarios at turbulent or intermittently varying flows, or under various hydrodynamic niches forming due to bed undulations. It was also observed that even though the general trends were the same, the behavior of all the surrogates tended to differ at fine scales under different scenarios. Hence, the relationship between these surrogates and human pathogens should be validated.

Tropical regions often experience high levels of precipitation that cause flow to be increased several folds within a span of few hours. Once the precipitation event is over, the flow goes back to previous levels. These incidents thus can be treated as short term pulses of high velocity. To address this scenario, I would propose to increase the flow in the flume temporarily, for one of two hour and then reduce it back to the starting value. I would then proceed with data collection and analysis as before to see how this pulse of high flow had changed the surrogate dynamics. However, I did not study this scenario in my PhD work due to the design limitation of the flumes. In the current flumes, we were unable to generate flow rates high enough to mimic rain events. Future studies should address this scenario as well.

The final part of my study concluded that the introduction of high numbers of specific microorganisms did not influence nascent autochthonous communities, which should inform metagenomic analysis for monitoring microbial quality of water. I showed that small scale perturbations will not be detected using this approach. It should also be studied if the trends differ if a continuous source of pathogens, for example, discharges emanating from the recreating public, is present. Additionally, in this system, the bacteriophages did not find a 
suitable host in the biofilms. It should be analyzed if the biofilm remains resilient in the presence of a suitable host as well. Finally, future work can include sewage effects with and without greater number of pathogens present, especially in the sediments.

Additionally, due to the short term rain events, it is expected to have sudden high levels of contamination events. It is also likely, that due to the heightened flow the concentrations may be diluted, after the short first flush. Even though we spiked the surrogates in high concentrations, we were limited by number of surrogated being added. To address this limitation, future studies can see the effect of real storm water, collected during rain event and monitor its effect on the biofilm.

Another limitation was in the experimental design, which is that experiment date can't be decoupled from flow rate. It is possible that some differences in the properties of the biofilms (e.g. hydrophobicity, chla content) and interaction with surrogates may be due to the different biofilm communities that assembled during the first set of experiments compared to those that assembled during the second set of experiments. Under ideal conditions, the experiments should have been run with a companion flume at the low-flow setting during the high-flow experiments to examine the hypothesis that the variation in biofilm properties was due to flow regime rather than assembly of a different biofilm community on a different date. Since the number of flumes available was limited, a future modification might be rerunning the experiments with mentioned controls.

I hope that future investigations may build upon the key findings of this research and lead to development of better guidelines for management and monitoring strategies for freshwater systems and ensure public health safety. 


\subsection{References}

Baho DL, Peter H, Tranvik LJ (2012). Resistance and resilience of microbial communities temporal and spatial insurance against perturbations. Environmental Microbiology 14: 22832292.

Barcina I, Gonzalez J, Iriberri J, Egea L (1990). Survival strategy of Escherichia coli and Enterococcus faecalis in illuminated fresh and marine systems. Journal of Applied Bacteriology 68: 189-198.

Battin, T. J., Sloan, W. T., Kjelleberg, S., Daims, H., Head, I. M., Curtis, T. P., \& Eberl, L.. (2007). Microbial landscapes: new paths to biofilm research. Nature Reviews Microbiology 5: 76-81.

Buse HY, Lu J, Lu X, Mou X, Ashbolt NJ (2014). Microbial diversities (16S and 18S rRNA gene pyrosequencing) and environmental pathogens within drinking water biofilms grown on the common premise plumbing materials unplasticized polyvinylchloride and copper. FEMS Microbiology Ecology 88: 280-295.

Byappanahalli MN, Shively DA, Nevers MB, Sadowsky MJ, Whitman RL (2003). Growth and survival of Escherichia coli and enterococci populations in the macro-alga Cladophora (Chlorophyta). FEMS Microbiology Ecology 46: 203-211.

de Brauwere A, Ouattara NK, Servais P (2014). Modeling fecal indicator bacteria concentrations in natural surface waters: a review. Critical Reviews in Environmental Science and Technology 44: 2380-2453.

Huson DH, Auch AF, Qi J, Schuster SC (2007). MEGAN analysis of metagenomic data. Genome Research 17: 377-386.

Lozupone CA, Stombaugh JI, Gordon JI, Jansson JK, Knight R (2012). Diversity, stability and resilience of the human gut microbiota. Nature 489: 220-230.

Rice, S. A., Wuertz, S., Kjelleberg, S. (2016). Next-generation studies of microbial biofilm communities. Microbial biotechnology, 9(5), 677-680.

Stoodley P, K. Sauer, D. G. Davies, Costerton JW (2002). Biofilms as Complex Differentiated Communities. Annual Review of Microbiology 56: 187-209.

Signoretto C, Burlacchini G, Pruzzo C, Canepari P (2005). Persistence of Enterococcus faecalis in aquatic environments via surface interactions with copepods. Applied and Environmental Microbiology 71: 2756-2761. 
van Loosdrecht M, Heijnen J, Eberl H, Kreft J, Picioreanu C (2002). Mathematical modelling of biofilm structures. Antonie van Leeuwenhoek 81: 245-256.

Xie, C., Goi, C. L. W., Huson, D. H., Little, P. F., \& Williams, R. B. (2016). RiboTagger: fast and unbiased $16 \mathrm{~S} / 18 \mathrm{~S}$ profiling using whole community shotgun metagenomic or metatranscriptome surveys. BMC Bioinformatics, 17(19), 277.

Yoder JS, Hlavsa MC, Craun GF, Hill V, Roberts V, Yu PA et al. (2008). Surveillance for waterborne disease and outbreaks associated with recreational water use and other aquatic facility-associated health events — United States, 2005-2006. MMWR Surveill Summ 57: 129. 